\title{
Volume 33
}
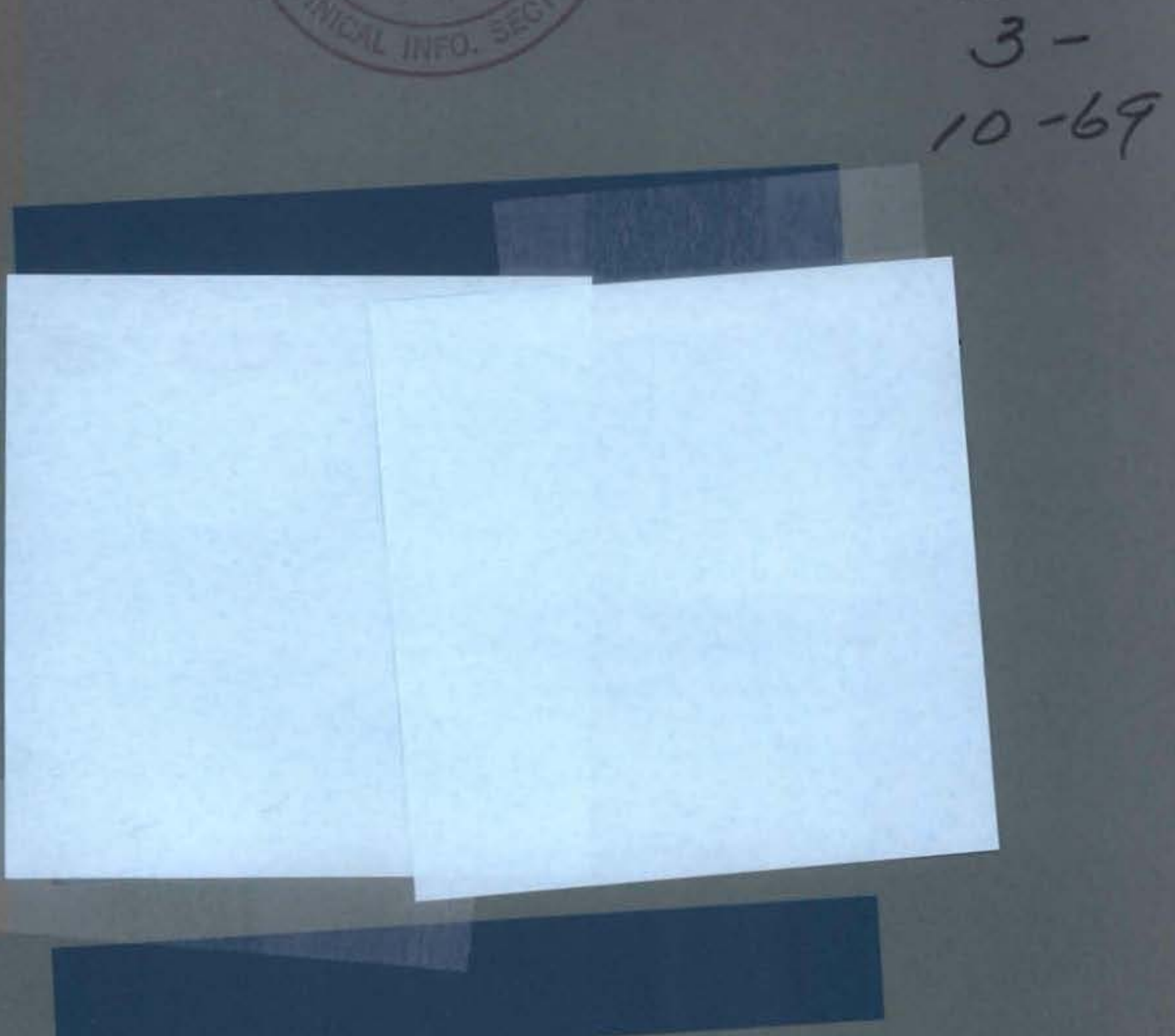

FAST FLUX TEST FACILITY
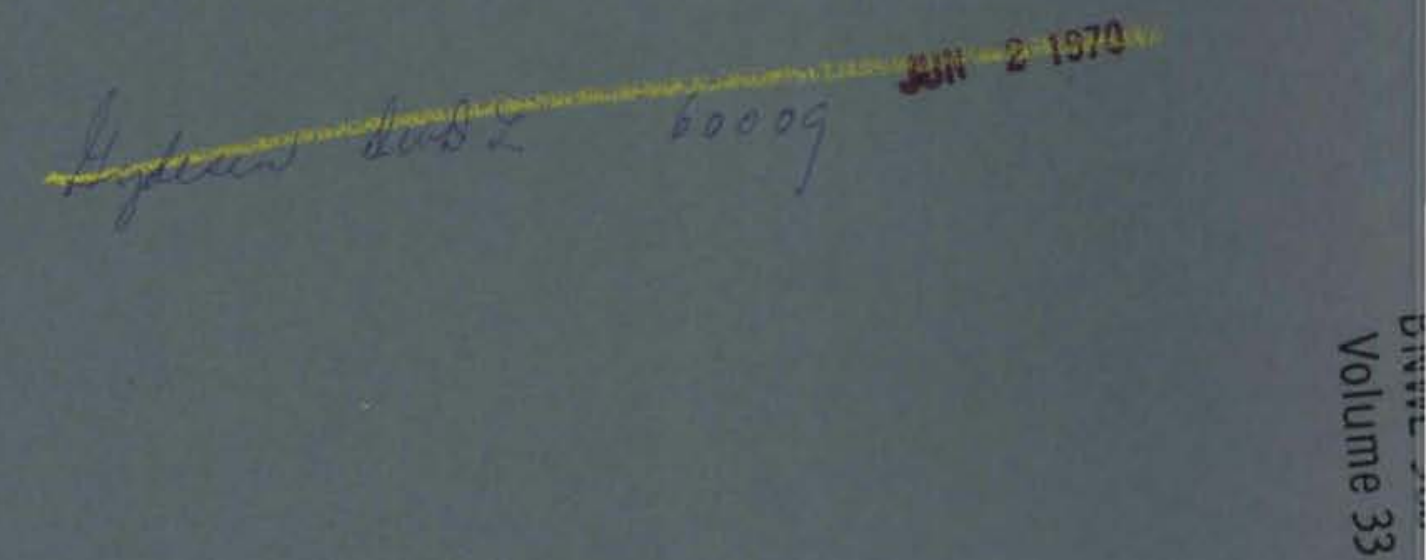

BATTELLE $\beta$ NORTHWEST 

CONCEPTUAL COMPONENT DESIGN DESCRIPTION

FOR THE

REACTOR NUCLEAR CONTROL COMPONENTS

No. 33

October 1, 1969

PACIFIC NORTHWEST LABORATORIES

Richland, Washington 99352

Operated by

Battelle Memorial Institute for the

U.S. Atomic Energy Commission under Contract No. AT $(45-1)-1830$ 


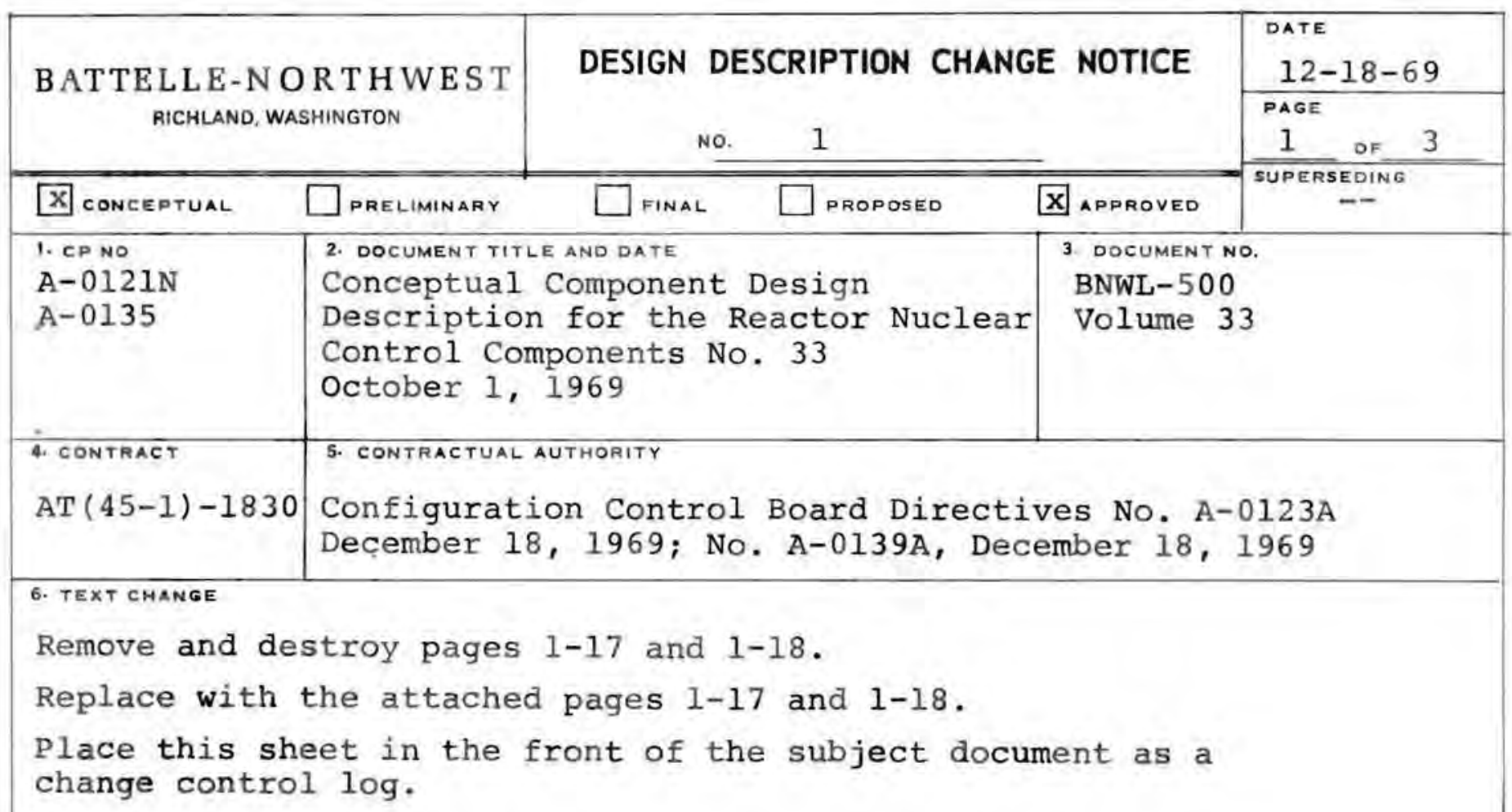

Result of redirection of Conceptual Design and to baseline boron carbide as a poison material. 
BNWL-500

Volume 33

Prepared by $\left.U_{1}\right)$ Mancinos Date 3-31-69

Recommended by
Evaluation Boarta

Approved by
Configuration Control Bodra

Approved by AEC Letter, J. M. Shivley, Project Administrator, FFTF Project office, Richland operations office, to E. R. Astley, FFTF Project Manager; Subject CCDD for the NUCLEAR CONTROL COMPONENT (SYSTEM 33), Dated October 1, $196 \overline{9}$. 
BNWL -500

Volume 33

\section{CONTENTS}

INTRODUCTION • • • • • • • • • • V V

1.0 FUNCTIONS AND DESIGN REQUIREMENTS . . . . 1-1

1.1 FUNCTIONS . . . . . . . . . . 1-1

1.1 .1 Operational Control Function , . . . . 1-1

1.1.2 Primary Safety Function . . . . . . . 1-1

1.1.3 Secondary Safety Function . . . . . 1-2

1.1.4 Oscillator Function . . . . . . . 1-2

1.2 NUCLEAR CONTROL COMPONENT DESIGN REQUIREMENTS . I-2

1.2.1 Basic Design Requirements . . . . . . 1-3

1.2.1.1 General Requirements . . . . . . . 1-3

1.2.1.2 Drive Mechanism Requirements . . . . . 1-11

1.2.1.3 Poison Subassembly Requirements . . . . 1-14

1.2.2 Concept Related Design Requirements . . . 1-16

1.2.3 Firm Design Choices . . . . . . . 1-17

1.3 FTR OSCILLATOR . . . . . . . . . $1-18$

1.3.1 Design Requirements . . . . . . . 1-18

2.0 PHYSICAL DESCRIPTION . . . . . . . . $2-1$

2.1 SUMMARY DESCRIPTION . . . . . . . . $2-1$

2.2 DETAILED DESCRIPTION . . . . . . . $2-5$

2.2.I Drive Mechanism . . . . . . . . 2-5

2.2.1.1 Roller-Nut Drive Mechanism . . . . . 2-8

2.2.1.2 Magnetic Jack Drive . . . . . . . 2-9

2.2 .2 Extension Shafts . . . . . . . . 2-10

2.2 .3 Poison Subassembly . . . . . . . 2-12

2.2.4 Rod Worths. . . . . . . . . . 2-14

2.2 .5 Scram Assist . . . . . . . . . 2-29

2.2 .6 Deceleration . . . . . . . . . 2-40

2.2.7 Axial Positioners . . . . . . . 2-41

2.2 .8 Oscillator. . . . . . . . . 2-42

2.3 INSTRUMENTATION, CONTROL AND ALARMS . . . 2-43

2.3 .1 General Sumary . . . . . . . . 2-43 
BNWL -500

Volume 33

2.3.2 Rod Drive Control System . . . . . . 2-43

2.3.2.1 Manual Control . . . . . . . . 2-43

2.3.2.2 Automatic Control . . . . . . . 2-44

2.3.3 Rod Position Indications . . . . . . 2-45

2.3.4 Rod Limits Indication. . . . . . . 2-46

2.3.5 Protective Instrumentation . . . . . 2-46

2.3 .6 Rod Instrumentation . . . . . . 2-47

3.0 SAFETY CONSIDERATIONS . . . . . . . 3-1

3.1 HAZARDS . . . . . . . . . . . $3-1$

3.1 .1 General . . . . . . . . . 3-2

3.1 .2 Operational-Control . . . . . . . 3-3

3.1.3 Shutdown Safety . . . . . . . . 3-3

3.2 PRECAUTIONS . . . . . . . . . $3-4$

3.2 .1 General . . . . . . . . . . 3-4

3.2.2 Operational-Control . . . . . . . 3-5

3.2 .3 Shutdown Safety . . . . . . . . 3-5

4.0 PRINCIPLES OF OPERATION • • • . • . $4-1$

4.1 PRESTART . . . . . . . . . . . 4-1

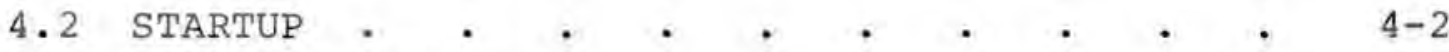

4.3 ASCENT TO POWER . . . . . . . . . 4 4-4

4.4 AT-POWER OPERATION . . . . . . . . . 4-6

4.5 NORMAL SHUTDOWN . . . . . . . . 4-7

4.6 EMERGENCY SHUTDOWN . . . . . . . . . 4-8

4.6.1 Controlled Power Reduction Instrumentation . 4-8

4.6 .2 Scram . . . . . . . . . . . 4-9

4.7 SPECIAI OR INFREQUENT OPERATION * . . . 4-9

5.0 MAINTENANCE PRINCIPLES . . . . . . 5-1

APPENDIX A - REFERENCES . . . . . . . . .

APPENDIX B - SUPPORT INFORMATION REQUIREMENTS . . . B B-I

APPENDIX C - INTERFACES . . . . * . . .

APPENDIX D - GLOSSARY OF TERMS . . . . . . . . . D-1 
BNWL-500

Volume 33

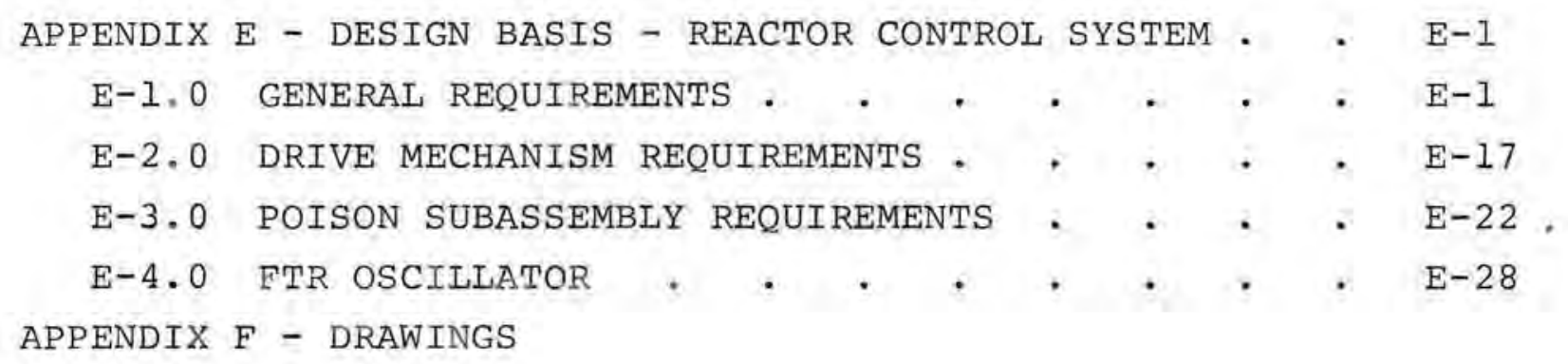




\section{REACTOR NUCLEAR CONTROL COMPONENTS}

\section{INTRODUCTION}

This document describes the nuclear control component of the Fast Test Reactor (FTR). The Fast Test Reactor is the central test bed of the Fast Flux Test Facility (FFTF). The purpose, function, and basic design philosophy and requirements of the FFTF are set forth in the Overall conceptual Systems Design Description $^{1}$ (CSDD) which integrates these requisites on a facility basis.

The Reactor Nuclear Control Components described in this document consist of neutron absorbing elements which are moved axially into and out of the general area of the active portion of the core. The electromechanical drive housings are mounted on the reactor cover and are part of the pressure boundary of the vessel and cover during reactor operation. Drive lines (extension shafts) extend through the cover and are connected to the poison element. The element is guided in the core throughout its travel by a flow duct which resides in the core grid plate receptacle. Sodium coolant from the primary loop is used to cool the neutron absorbing rods.

This Conceptual Component Design Description (CCDD) supports and expands the requirements of the overall conceptual Systems Design Description. Specifically, it establishes the reactor nuclear control design requirements; describes the current reference design of this control; defines safety, operational and maintenance principles; indicates unresolved problems; and identifies the principal interfaces affecting the reactor

1. Refer to References, Appendix A, Item 8. 
control component functional requirements and design configuration. Section 1.0 of this document is baseline and the requirements thereof are mandatory. Section 2.0 is descriptive and presents the reference component conceptual design. Sections $3.0,4.0$, and 5.0 present certain principles and policies which shall govern the methods of operation of the nuclear control component. Capability to adhere to these principles and policies shall be inherent in the nuclear control component design. The appendices provide supplemental information.

Support documents containing design quides and criteria have been developed and provide part of the technical bases for the nuclear control component design. These documents include:

- Survey of Control Rod Drive Mechanisms for Application to the $\mathrm{FFTF}^{1}$

- Selection of Concepts for FFTF Control and Safety Rod Drive ${ }^{2}$

- FTR Fuel and Core Parameter Studies ${ }^{3}$

The use of the terms system, component, drive, extension shaft, guide duct, and element are used to indicate a breakdown of the total control and safety function of the FTR. Beginning with the largest division, the intended definition of each term is as follows:

System: The entire composite nuclear control function including all individual nuclear control components plus the electrical, instrument and other attached services.

1. Refer to References, Appendix A, Item 27.

2. Refer to References, Appendix A, Item 15.

3. Refer to References, Appendix A, Item 32. 
BNWL -500

Volume 33

Component: one reactivity control assembly as a unit, including the drive, extension shafts, guide duct and control element.

Drive: The electromechanical drive assembly. This assembly includes in the reference design, the drive mechanism, position indicator sensors, the accelerator or scram assist mechanism and the decelerator.

Extension

Shaft: The connecting shaft from the element to the drive mechanism. This in turn is broken down in the reference design into the following sub-elements; drive shaft, intermediate shaft and main shaft beginning from the top and ending at the poison element.

Guide

Duct: The hexagonal container for the element in the region of the core, extending from the lower grid plate to the top of the fuel subassembly.

Control

Element or Poison

Sub-

assemly: The moveable poison portion including poison pins, gas plenum, (if used), follower (if used) and structural support up to the lst separation point. 
BNWL -500

Volume 33

\section{SECTION 1.0 FUNCTIONS AND DESIGN REQUIREMENTS}

\subsection{FUNCTIONS}

In conjunction with the Flux Monitoring and Control system, ${ }^{1}$ the Plant Protection System, ${ }^{2}$ and the central Control and Data Handling System, ${ }^{1}$ the Reactor Nuclear Control Components shall satisfy the following functions:

\subsubsection{Operational Control Function}

- Provide means for achieving core criticality by adjusting reactivity of the core.

- Provide stable, accurate and reliable control of the overall power level.

- Provide partial distributional control of local flux by selective adjustment of control rods.

- Adjust reactivity to compensate for transient effects due to temperature and power reactivity coefficients, and to compensate for burnup of fuel and control elements.

- Decrease reactivity for normal shutdown and provide a required shutdown margin.

\subsubsection{Primary Safety Function}

Provide a means in conjunction with the Plant Protection System, ${ }^{2}$ for rapid reactor shutdown to prevent exceeding established safety limits and provide a required shutdown $\operatorname{margin} .^{3}$

1. Refer to References, Appendix A, Item $3 \& 22$.

2. Refer to References, Appendix A, Item 2.

3. Refer to References, Appendix A, Item 6, Section 14. 
BNWI -500

Volume 33

\subsubsection{Secondary Safety Function}

Provide a secondary means in conjunction with the Plant Protection system, for rapid reactor shutdown to prevent exceeding the established secondary Safety system safety limits and to provide a required shutdown margin. 1

1.1.4 Oscillator Function

Provide a means for determining the reactor stability characteristics.

1.2 NUCLEAR CONTROL COMPONENT DESIGN REQUIREMENTS

The Reactor Nuclear Control Components design requirements have been classified" as "Basic", "Concept Related", or "Firm Design Choices". The criteria portion of the Design Safety Criteria is used as requirements in this document. Design bases for these requirements are given in the appendix. ${ }^{3}$ Each design safety criterion is identified by the index number used in the reference document Design Safety Criteria, ${ }^{4}$ i.e., a requirement ending with (DSC 2.4) indicates that that requirement is criterion 2.4 of that Design Safety Criteria.

Specific design requirements for functional control of the reactor nuclear control components are presented in design descriptions for the Plant Protection system, ${ }^{5}$ the Flux Monitoring and Control system, ${ }^{6}$ and in Functional Requirements for Overall FFTE Plant Control. 7

1. Refer to References, Appendix A, Item 6, Section 14, Appendix B.

2. Refer to References, Appendix A, Item 33.

3. Refer to Design Bases - Reactor Control System, Appendix E.

4. Refer to References, Appendix A, Item 6, Section 14.

5. Refer to References, Appendix A, Item 2.

6. Refer to References, Appendix A, Item 3 .

7. Refer to References, Appendix A, 1 tem 1. 
BNWL -500

Volume 33

\subsubsection{Basic Design Requirements}

The requirements of this section of the CCDD are broken into three groups.

- General Requirements

- Drive Mechanism Requirements

- Poison Subassembly Requirements

\subsubsection{General Requirements}

Requirements $A$ through $T$ are safety oriented and are reproduced from the Design Safety Criteria. ${ }^{2}$

A. The design of the operational control system shall be integrated with the design of the Reactor Core system, ${ }^{2}$ the reactor vessel and cover, ${ }^{3}$ and the Flux Monitoring and Control system ${ }^{4}$ to assure that the accuracy and reproducibility of positioning the operational control elements shall be within the following reactivity tolerances for the entire system.

$\begin{array}{ll}\text { Accuracy } & \pm 10 \% \\ \text { Reproducibility } & \pm 5 \%\end{array}$

$(\text { DSC } 2.5)^{1}$

B. The accuracy and reproduclbility of positioning the primary shutdown safety elements with the elements in their most reactive position shall be within the following reactivity tolerances for the entire system: Accuracy $\leq 5.0 \mathrm{c}$ Reproducibility $\pm 2.06$ $(\text { DSC } 3.5)^{1}$

C. The accuracy and reproducibility of positioning the secondary shut-down safety elements with the elements in their most reactive position shall be within the following reactivity tolerances for the entire system:

1. Refer to References, Appendix A. Item 6 section 14,

2. Refer to References, Appendix A, Item 9.

3. Refer to References, Appendix A. Item 24.

4, Refer to References, Appendix A, Item 3. 
BNWL -500

Volume 33

Accuracy

$\pm 5.0 \&$

Reproducibility

$\pm 2.06$

If a common system is designed to perform both the secondary shutdown safety function and the operational control function, the following reactivity tolerances for the entire system apply during operation at or near critical:

Accuracy

$$
\begin{aligned}
& \pm 10.0 \% \\
& \pm 5.06
\end{aligned}
$$

Reproducibility

$(\text { DSC } 4.5)^{1}$

D. The operational-control function and one shutdown safety function may be performed by a single reactivity-control system provided the most critical total control and speed-of-control requirements of both are met.

$(\text { DSC } 2.4)^{1}$

E. A primary shutdown safety system shall terminate reactor operation at or near critical in sufficient time to meet allowable damage level limits upon signal that a protective system trip setting has been reached and shall maintain subcriticality following termination of reactor operation.

$(\text { DSC } 3.1)^{1}$

F. A secondary shutdown safety system shall be provided in the FTR as an independent safety system. In the event of failure of the primary shutdown safety to perform its design function upon signal that a protective system trip setting has been reached, the secondary shutdown safety system shall terminate operations at or near critical and maintain subcriticality following shutdown.

$(\text { DSC } 4.1)^{1}$

1. Refer to References, Appendix A, Item 6, Section 14. 
BNWL -500

Volume 33

G. The response and acceleration of the primary shutdown safety system shall be at a rate capable of terminating the power transient resulting from reactivity insertions consistent with accident severity criteria for the initiating fault. $\quad$ (DSC 3.4) 1

H. The response and acceleration of the secondary shutdown safety system shall be at a rate capable of terminating the power transient resulting from reactivity insertions consistent with damage severity criteria for the initiating fault. $\quad$ (DSC 4.4$)^{1}$

I. The control and safety components shall be designed to maintain their structural integrity and operability for all normal and abnormal reactor conditions up to and including any "Minor Accident" 2 and to maintain their capability of shutting down the reactor and maintaining subcriticality for any "Major Accident." ${ }^{2}$ (DSC 1.1) 1

$\mathrm{J}$. Provisions in the design of the element and guide tube shall be required to prevent element movements, even on scram, below its full-in position for any single "Unlikely Fault." 2 (DSC 1.4)

K. The drive mechanism, extension shaft, and element for each operational-control component will be directly coupled, either hydraulically or mechanically, to assure stable and accurate control of the element position under all conditions (except scram if combined with a shutdown safety system as described in Requirement D). If operational control system elements are released from the extension rods upon scram to facilitate rapid insertion rates, each element will be designed to prevent recoil or expulsion from any position. (DSC 2.6) 1

1. Refer to References, Appendix A, Item 6, Section 14. 2. Refer to References, Appendix A, Item 6, Section 1. 
I. The drive, excension, shaft, and control element for each component shall be capable of exerting a holding force greater than any expulsion force ${ }^{1,2}$ acting upon the element for any fault up to the threshold of a disruptive accident.

(DSC 1.5$)^{1}$

M. The design of the reactivity control systems shall accommodate an integrated program of surveillance and in-service testing to assure continual operability of the systems to perform their defined functions. (DSC 1.9) ${ }^{1}$

These requirements are to be specified during preliminary design.

N. The reactivity status of the control elements shall be monitored through position ccntrol and displayed in the control room when fuel is in the reactor as follows:

1. During all modes of operation, except when the reactor is in a shutdown condition for maintenance and/or refueling, position control of the reactivity-control elements shall include at a minimum the following:

a. Position indications at any location within the normal limits of travel (full-in to fullout).

b. Full-in limit indication

c. Full-out limit indication

1. Refer to References, Appendix A, Item 6, Section 14.

2. Refer to Support Information Requirements, Appendix B, Item 11 . 
Items (b) and (c) shall be actuated by devices inseparable from the control element during all modes of operation except when the reactor is in a shut-down condition. Separations occurring between the actuating devices and the control element shall be immediately detectable.

Accuracy and reproducibility requirements for the rod position indicating system will be determined by a study during preliminary design. ${ }^{2}$

o. The primary and secondary shutdown safety systems shall be designed to prevent simultaneous disability of both systems through systematic, concurrent, undetected failures in both systems resulting from commonality of components or susceptibility to common environmental conditions.

$$
(\text { DSC } 1.7)^{1}
$$

P. The design of the reactor nuclear control components shall include provisions for incorporation and protection of instrumentation required for monitoring and for control of the element positions, and for initiation of protective action for abnormal thermal or mechanical conditions which could result in uncontrolled reactivity changes or component failures. ${ }^{3} \quad$ (DSC 1.8$)^{1}$

Q. Loss of safety circuit continuity to any primary shutdown safety component shall scram the affected safety element. Once initiated, scram action shall go to completion. $\quad(\text { DSC, } 3.8)^{1}$

1. Refer to References, Appendix A, Item 6, Section 14.

2. Refer to Support Information Requirements, Appendix B, Item 22.

3. Refer to References, Appendix A, Items 2,3, and 22. 
BNWL -500

Volume 33

R. The control and safety elements shall be designed such that the net force upon the element under normal operating conditions due to hydraulic and gravitational forces will be in the direction which causes a reduction of reactivity independent of the drive force. All scrammable elements shall scram in the direction aided by gravity. $(\text { DSC } 1.2)^{1}$

S. Signal of a fault affecting the capability of the secondary shutdown safety system to perform as designed shall initiate primary protective action. $\quad$ (DSC 4.8$)^{1}$

T. The operational control system shall be provided in the FTR for reactivity-control of the nuclear reaction under all normal operations at or near critical. (DSC 2.1)

U. The reactor nuclear components provided to perform the primary and secondary shutdown safety functions shall be designed to assure a high overall availability such that the probability of failure of the combined systems to perform the designed safety functions due to random component failures will be less than $10^{-5}$. This probability will be evaluated using the best available failure rate data on the components taken at the 50 \% confidence level or above. 2

(DSC 1.10$)^{1}$

V. Materials used in the reactor nuclear control components shall be selected such that the exposure of these materials to other core materials under normal and abnormal conditions will not initiate or increase the severity of fault conditions beyond the limits corresponding to the condition as defined in the Criteria for Accident severity Levels - FFTF Reactor systems. ${ }^{3}$

1. Refer to References, Appendix A, Item 6, Section 14.

2. Refer to References, Appendix A, Item 10.

3. Refer to References, Appendix A, Item 6, Section 1. 
W. The nuclear control components shall be functionally and physically compatible with the reactor refueling system and all other interfacing systems. ${ }^{1}$

x. The nuclear control components shall be compatible with requirements for power reduction and normal shutdown automatically at a programmed rate or under manual control that minimizes thermal shocks to tests and reactor systems. ${ }^{2}$

Y. Once a protective action (scram) signal is received by the shutdown safety rod components it shall be impossible to delay or cancel the scram action.

Z. Safety and control component drive mechanisms shall be accessible for routine inspection and maintenance during reactor shutdown and shall be replaceable by routine methods.

AA. Control devices that penetrate radiation shields shall be designed to provide radiation attenuation consistent with protective requirements of the equipment and persomel. ${ }^{3}$ Protective requirements for equipment are to be determined in preliminary design.

$A B$. The nuclear control components shall be designed for reliability and maintainability consistent with achieving an FFTF overall plant availability goal of $75 \%$.

\footnotetext{
1. Refer to Interfaces, Appendix C.

2. Refer to Interfaces, Appendix C, Item I8,

3. Refer to References, Appendix A, Item 19.
} 
BNWL -500

Volume 33

AC. All Nuclear Control Components shall satisfy the criteria establishing quality ${ }^{1}$ which will be defined and documented during design. These criteria ${ }^{2}$ shall cover the following areas :

- Design

- Fabrication and construction

- Operation

- Maintainability

AD. The drive train and latches shall be designed to withstand all acceleration and deceleration forces under all conditions up to a disruptive accident.

AE. The drive mechanism primary coolant system boundaries shall be designed to maintain structural integrity equivalent to that of the reactor cover during DBA loading. 3

AF. Design and fabrication of the nuclear control components shall conform to the following codes and standards as applicable:

1. The ASME Boiler and Pressure Vessel Code.

2. AEC Division of Reactor Development and Technology: Material Standards; Plant Standards; and Equipment Standards.

3. General Design Safety Criteria for FFTF PSAR.

4. ASTM Standards for Materials where applicable. 5. Hanford Engineering Standards HWS 10,000.

1. Refer to References, Appendix A, Item 26.

2. Refer to Support Information Requirements, Appendix B, Item 3 .

3. Refer to References, Appendix A, Item 24. 
BNWL -500

Volume 33

\subsubsection{Drive Mechanism Requirements}

Requirements A through $\mathrm{F}$ are safety oriented and are reproduced from the Design Safety Criteria. ${ }^{1}$

A. Reactivity insertion rates by withdrawal of operationalcontrol elements shall be limited by equipment design of the drive train and application of interlocks which limit simultaneous operation of different drives such that any power transient resulting from continuous uninterrupted movement of control elements at the design maximum rate may be terminated by primary protective action with no fuel damage, and by backup protective action (assuming failure of the first) with 1 no more than "Gross Damage" ${ }^{2}$ to the fuel. (DSC 2.7)

-B. Reactivity insertion rates by movement of primary shutdown safety elements shall be limited by design of the drive mechanism such that any power transient resulting from continuous withdrawal of the shutdown safety elements at the maximum rate may be terminated by primary protective action with no more than "Moderate Damage" to fuel if criticality occurs during the withdrawal. $\quad$ (DSC 3.7$)^{1}$

C. The limitations of Requirement B on the reactivity insertion rate by movement of the primary shutdown safety elements also apply to the secondary shutdown safety elements. (DSC 4,7$)^{1}$

D. The drive mechanism for the primary shutdown safety elements shall be designed such that its operation will not interfere with the protective system functions of the element during any movement from any position.

1. Refer to References, Appendix A, Item 6, Section 14 . (DSC 3.9$)^{1}$

2. Refer to References, Appendix A, Item 6, Section 1. 
E. Requirement $D$ also applies to the design of the secondary shutdown safety system if a rod-type system is used. $\quad$ (DSC 4.9$)^{1}$

F. The rod drive mechanisms shall be axially supported relative to the core to limit axial movements under any normal or abnormal condition up to the severity of a "Disruptive Accident" to assure that the consequences of less severe accidents are not aggravated by movements of the reactivity-control structural supports. ${ }^{2}$ (DSC 1.6$)^{1}$

G. The nuclear control system shall be compatible with the interlocks provided to insure that all primary safety rods are fully withdrawn before any shim or regulating rod is withdrawn during reactor startup. ${ }^{3}$

H. The central rod drive mechanisms shall be capable of movement increments small enough to eliminate cyclic power level "hunting" or constant adjustment during steady-state operation.

I. Primary coolant system boundary integrity shall be maintained to prevent loss of sodium or mixtures of sodium vapor and cover gas to the aeneral environment during normal reactor plant operation. ${ }^{4}$.

J. A rod deceleration device shall be provided to absorb all the kinetic energy generated by the control element during its scram cycle.

$\mathrm{K}$. The rod deceleration device shall maintain a deceleration rate which will limit stresses in the components to acceptable levels.

\footnotetext{
1. Refer to References, Appendix A, Item 6, Section 14.

2. Refer to Interfaces, Appendix C, Items 8 and 9.

3. Refer to Interfaces, Appendix C, Item 16.

4. Refer to Support Information Requirements, Appendix B, Item 7 .
} 
I. A scram assist mechanism shall be provided, if found to be necessary to satisfy the speed of response requirements, for the primary and secondary safety elements. The scram assist mechanism design shall consider the hydraulic resistance forces of sodium flow in the duct as well as mechanical and other frictional forces.

M. The drive mechanism and materials used in the drive train shall be compatible with the environment in which they operate.

N. Control rod components shall be designed to limit any potential for reactor or primary sodium contamination by hydrogeneous and organic fluids. It is a design objective that two independent barriers prevent such contamination. However, one barrier is sufficient when the rate and quantity of contamination upon occurrence of a single fault are such that 1. reactivity effects associated with hydrogen contamination of sodium in the core will cause no more than 'Operational Incident' and

2. plugging and metallurgical effects associated with carbon contamination will not shorten the design lives of reactor components.

o. All electrical and mechanical connections on the Nuclear Control Components shall be designed (by either size, thread, or key location) such that incorrect connections cannot be inadvertently made during installation or maintenance. 
BNWL -500

Volume 33

\subsubsection{Poison Subassembly Requirements}

Requirements $\mathrm{A}$ through $\mathrm{H}$ are safety oriented and are reproduced from the Design Safety Criteria. ${ }^{1}$

A. All portions of the primary shutdown safety component that are necessary for the element to fulfill its safety function shall be designed to prevent recoil or expulsion from any position.

$(\text { DSC } 3.6)^{1}$

B. All portions of the secondary shutdown safety component which are necessary for the element to fulfill its safety function shall be designed to prevent recoil or expulsion from any position. (DSC 4.6$)^{1}$

c. The maximum reactivity worths of any single operational control element and single control pin within any element shall be limited. $\quad$ (DSC 2.2) ${ }^{1}$ The limit shall be $4 \$$ per element and $0.65 \$$ per pin. D. The minimum reactivity worth of the operational control system shall be such that the reactor may be maintained subcritical by at least $18 \delta \mathrm{k} / \mathrm{k}$ independent of any shutdown safety systems not combined with operational control and under all fuel loading variations and potential core temperatures. (DSC 2.3$)^{1}$

E. The maximum reactivity worth of any single primary shutdown safety element and any single pin within that element shall be limited. $(\text { DSC } 3.2)^{1}$ The limit shall be 8 \$ per safety element.

F. The minimum reactivity worth of the primary shutdown safety system shall be such that the reactor may be shut down and maintained subcritical by either $1.0 \% \mathrm{z} / \mathrm{k}$ or

1. Refer to References, Appendix A. Item 6, Section 14. 
the accidental reactivity insertion allowance for any single "Unlikely Fault", whichever is greater, with the provision for the most effective primary shutdown safety element stuck in its most reactive position. The minimum reactivity worth presumes that the secondary shutdown safety system and the operational-control system remain in their pre-scram position except as affected by any single "Unlikely Fault" for which the accidental reactivity insertion allowance is provided as defined above. $(\operatorname{DSC} 3.3)^{1}$

G. The maximum reactivity worth of any single secondary shutdown safety element and single pin within any element shall be limited as specified in Requirement $E$ for any primary shutdown safety element, except that (DSC 4.2) 1 the limits for a control system shall apply if the control system is also used as a secondary safety system.

H. The minimum reactivity worth of the secondary shutdown safety system will be such that the reactor may be shut down and maintained subcritical in its hot condition by either (a) $1.0 \% \delta \mathrm{k} / \mathrm{k}$, or (b) the accidental reactivity insertion allowance for any single "Unlikely Fault," whichever is greater. This minimum reactivity worth presumes that the primary shutdown safety system and the operational-control system (if it should exist as a separate system) remain in their pre-scram positions except as affected by any single "Unlikely Fault" for which the accidental reactivity insertion allowance is provided as defined above. $\quad$ (DSC 4.3 ) $^{1}$

I. The design shall consider element movement caused by thermal expansion or radiation damage effects such that the reactivity worth requirements of both the primary and secondary shutdown safecy systems are always met. 
BNWL -500

Volume 33

J. Pressure plenums located above the poison pins shall be provided for poison materials which evolve gas during irradiation.

K. Poison gas plenums shall be designed for a life expectancy consistent with the poison burnup limits.

L. The design of the structural assembly containing the poison element and the duct in which it operates shall provide for wear surfaces which are compatible with the environment in which they operate.

M. The poison materials shall be protected from detrimental effects of the coolant by cladding if necessary.

N. The subassembly containing the poison pins shall provide complete structural support for the entire subassembly, i.e., the poison pins shall not be utilized as a structural member.

o. The rod assembly design shall provide, as necessary, a metal follower of a hydraulic cross section no larger than the pin bunde cross section.

\subsubsection{Concept Related Design Requirements}

A. Control and safety rod subassembly quide ducts shall have mechanical holddown and a hydraulically balanced coolant supply arrangement at the inlet plenum for the reactor core. Hydraulic balance plus guide duct weight shall exceed the hydraulic lifting force developed by the combination of maximum operational pump pressure and maximum hydraulic shock pressure.

B. Provision shall be made to provide separation of the poison rod from its extension during refueling operation. 
c. Auxillary seals shall be provided, if necessary, to permit occupancy over the reactor during and after disassembly of the drive trains.

D. Design shall provide the capability that will allow for removal of any portion of the drive train through the cover penetration for that drive train.

E. Design shall provide the capability that will allow for removal of a rod which is stuck in any position as a non-routine operation. ${ }^{1}$

DDCN-1 F. The control elements shall be designed to be compatible with the length prescribed by a 12 foot long fuel subassembly.

G. The secondary safety function and the operational control function shall be performed by a single secondary safety-operational control system.

\subsubsection{Firm Design Choices}

A. The nuclear reaction of the FTR shall be controlled by axial movement of neutron absorbing (poison) rods. The rods shall be axially moved into or out of the core. Primary safety rods, normally above the core, shall be inserted during the reactor shutdown process (including scram).

B. The control rod drives shall be of electromechanical design and be located in the reactor vessel top head area. The rods will be scrammed in the direction of gravity. ${ }^{2}$

1. Refer to Interfaces, Appendix C, Item 12.

2. Refer to References, Appendix A. Item 11. 
BNWL -500

Volume 33

c. The deceleration device for scramed rods shall not act on the rods above the lower $25 \%$ of the core height. ${ }^{1}$

D. Proven concepts and hardware will be used where possible.

E. Provisions shall be made for checks and adjustments of control and safety rod drive devices (e.g., limit switches, engagement switches, position transmitters). Current and continuity checks can be made remotely during operation, however access for manual adjustment to drive mechanism mounted equipment must be provided for at any time during prestart.

F. Control element lifetime shall be a minimum of one reactor operating cycle. However, the design shall be optimized where possible to provide the maximum lifetime.

DDCN-1 G. ${ }_{4}{ }_{4}$ pellets, enriched if necessary, shall be used as a poison material.

\subsection{FTR OSCILLATOR}

\subsubsection{Design Requirements}

A. The frequency of oscillation shall be continuously variable ${ }^{2}$ within the ranges required.

B. The stability and measurement of anv selected frequency within the operating range shall be within the limits ${ }^{2}$ prescribed by transfer function analysis accuracy requirements.

1. Refer to References, Appendix A. Item 12, 13, and 14. 2. Refer to Support Information Requirements, Appendix B, Item 6 . 
c. The reactivity input shall be periodic with a stable amplitude. I

D. The oscillator mechanical hardware shall be physically compatible with both the reactivity control positions and the contact instrumented test positions.

E. Position indication ${ }^{1}$ of the reactivity element shall be available with reference to the core centerpoint.

F. Capability for determining or cancelling the effects of backlash shall be provided.

G. All components of the oscillator shall be capable of operation at FTR environments from zero to full power.

H. The oscillator system shall be compatible with interfacing systems. ${ }^{2}$

1. Refer to Support Information Requirements, Appendix B, Item 6 .

2. Refer to Interfaces, Appendix C, Items 14 and 16. 
BNWL -500

Volume 33

\section{SECTION 2.0 PHYSICAL DESCRIPTION}

\subsection{SUMMARY DESCRIPTION}

The neutron flux of the FTR is controlled by vertical movement of neutron absorbing (poison) material into and out of the core area. The control components for the reference core consist of (1) primary safety rods for rapid shutdown of the reactor; and (2) control rods to regulate the power level, shut down the reactor in a controlled manner and maintain the reactor subcritical. The control rods are also used as a secondary safety system to back up the primary safety rods. The core map, shown in Figure 1, indicates the location and number of rods in each of the two categories. 1

The rods for each of the two categories are made up of similar components although the components may differ in control strength, type of drive mechanism, etc. Basically, each unit consists of an electromechanical drive, an extension drive line, a poison tip and an in-core guide duct. Position sensor instrumentation is incorporated with the drive mechanism and the ex-vessel portion of the extension shaft. ${ }^{2}$ Provisions exist for coolant temperature sensing, flow verification, drive load indication and detection of loss of holddown. The scram assisted rods provide a means for exerting an external force on the extension drive line to meet the required speed of response for overriding an uncontrolled power surge.

1. Refer to Support Information Requirements, Appendix B, Item 1 .

2. Refer to Support Information Requirements, Appendix B, Item 13. 


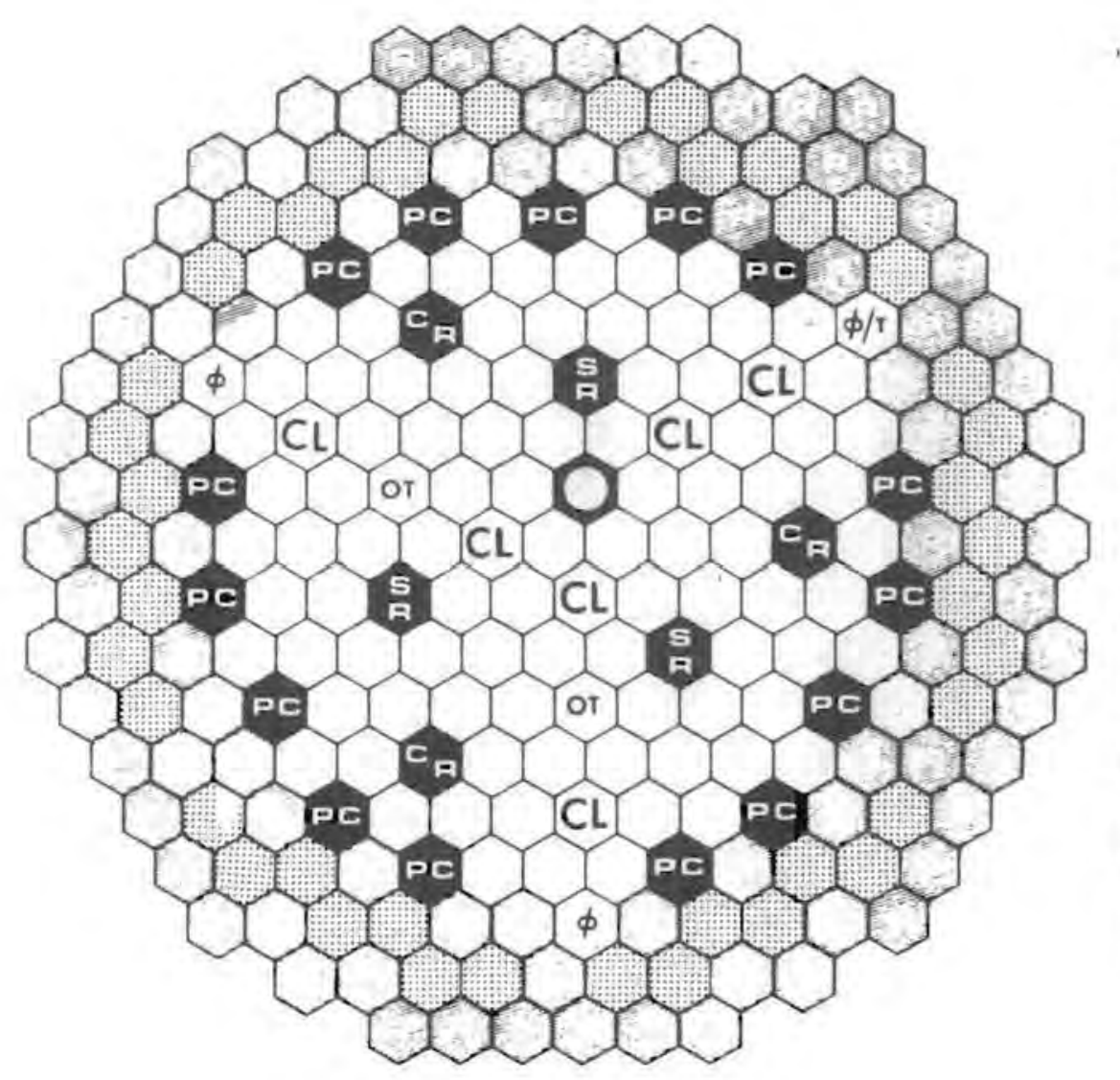

OPEN LOOP WITH PROX. INSTR. - 1

(OT) OPEN TESTS - 2

(CL) CLOSED LOOPS - 6

(5) SAFETY RODS - 3

(1) REFLECTOR/RESTRAINT POSITIONS - 42

PC PERIPHERAL CONTROL RODS - 15

@ REFLECTORS - 88

$\bigcirc$ DRIVERS - 91

CB IN CORE SHIM $\backslash$ CRAM RODS 3

(ф) FLUX MONITOR POSITIONS - 2 क/T COMBINATION FLUX MONITORS
STIF POSITION - 1 
BNWL -500

Volume 33

The drive units ${ }^{1}$ are mounted on the reactor cover. The housing which encloses the drive units is the continuation of the pressure boundary of the vessel. The electrical motive section surrounds the pressure boundary and is cooled with an external gas source.

The drive line ${ }^{2}$ passes through the drive mechanism and cover and extends to the poison tip section. Latch mechanisms are employed to sectionalize the drive line such that air-contact disassembly of the motor and upper drive line can be done in preparation for refueling. The remaining shaft is also shown with a second latch below the cover to allow the in-vessel portion of the extension shaft to be retained by the instrument tree $^{3}$ during the refueling operation. The intermediate shaft remains retracted in the cover to provide the seal function during refueling.

The poison section and duct are handled as a unit by the in-vessel handling machine.

The replacement method is to lift the assembly by picking up the duct. The poison assembly ${ }^{4}$ is composed of a 61 pin bundle of $\mathrm{B}_{4} \mathrm{C}$ rods for the reference core. ${ }^{5}$ The length of the poison section exceeds the length of the core by 2 inches to insure coverage of the core under all thermal conditions. A gas plenum, integral with the poison clad is provided to contain the gas evolved during irradiation.

$\begin{array}{ll}\text { 1. } & \text { Refer to Drawings, Appendix F, SK-3-14558, } \\ \text { 2. } & \text { Refer to Drawings, Appendix F, SK-3-14559. } \\ \text { 3. } & \text { Refer to Drawings, Appendix F, SK-3-14604. } \\ \text { 4. } & \text { Refer to Drawings, Appendix F. SK-3-14550. } \\ \text { 5. } & \text { Refer to References, Appendix A. Items 5, 7, 16,17. }\end{array}$


BNWL -500

Volume 33

Rod worth requirements are based on reactivity values for various effects. The estimated total worth ${ }^{1}$ requirements are $3.2 \% \frac{\delta k}{k}$ plus one stuck rod for the total primary safety rod worth and $8.0 \% \frac{\delta \mathrm{k}}{\mathrm{k}}$ for the combined control and secondary safety rod. Scram assist will be provided for all in core rods with the option of utilizing scram assist on the peripheral rods also. The mechanism for scram assist for the reference concept is a spring Iocated at the top of the drive mechanism. The spring is cocked by a pneumatic cylinder to eliminate this load from the drive mechanism. Spring trip is then activated through a magnetic latch.

The decelerator mechanism is also mounted on the drive unit above tife reactor cover. The FAFET design ${ }^{2}$ has been selected on the basis of its adaptability to the drive mechanism and testing results done at Argonne.

Axial positioners may be used to displace specimens in closed loops during reactor operation. Design will evaluate the adaptability of a control rod drive mechanism as the motive source for test specimen movement. The functional requirements of the positioner as determinea by a test plan will aid in determining this adaptability. Modifications presently visualized include sodium seals for tire drive shaft, flexible instrument leads, and mechanical latch mechanisms.

The oscillator for the FTR is in the preliminary stages of Conceptual design. The requirements are being evaluated for design feasibility in orcier to arrive at an optimum

1. Refer to Support Information Requirements, Appendix B, Item 2 .

2. Refer to References, Appendix A, Item 29. 
trade off position for conceptual design. ${ }^{1}$ A survey ${ }^{2}$ of past oscillator designs has been completed.

\section{$\underline{2.2}$ DETAILED DESCRIPTION}

The reference configuration described in this section consists of a drive mechanisa, extension shafts (drive line), in-core guide duct, poison subassembly and the associated sensors for position instrumentation. Drawings SK-3-14558, SK-3-14559 and SK-3-14560, Appendix F, show the reference concept as a method for complying with the requirements of Section 1.0.

\subsubsection{Drive Mechanism}

The drive mechanism for the reference concept is shown as a "roller nut" type of drive. This drive has been selected based on equipment visibility and envelope requirements of the drive mechanism. Other drive mechanisms to be used must not extend beyond the diameter of the envelope available (approximately $8 \mathrm{in.}$ in diameter).

The AEC Proposed General Design Criteria (Paragraph IV.A. 6) Criterion 27, 28 and 29 requires interpretation in order to finalize the requirements of the drive mechanisms. Criterion 27 states "At least two independent reactivity-control systems, preferably of different principles, shall be provided." Criterion 28 states, "At least two of the

1. Refer to Support Information Requirements, Appendix B, Item 6 .

2. Refer to References, Appendix A. Item 36. 
reactivity-control systems provided shall independently be capable of making and holding the core subcritical from any hot standby or hot operating condition, including those resulting from power changes, sufficiently fast to prevent exceeding acceptable fuel damage limits." Criterion 29 states "At least one of the reactivity-control systems shall be capable of making the core subcritical under any condition (including anticipated operational transients) sufficiently fast to prevent exceeding acceptable fuel damage limits. Shutdown margins greater than the maximum worth of the most effective control rod when fully withdrawn shall be provided." The above criteria are presently recommended for water cooled reactors.

The efforts to satisfy the above oriteria has resulted in differing requirements, depending upon the interpretation of the criteria. In order to arrive at a mutually acceptable interpretation of the criteria, a study ${ }^{1}$ was authorized to 1) make a survey of design bases and past experience, 2) study safety rod drive independence and generic failure, 3) study the effects of two or more types of arives on maintenance, replacement, overall plant design, plant operation availability and costs, and 4) form an independent interpretation of the criteria. Completion of this study will enable a decision of the type or types of drive mechanism(s) to be made for preliminary design.

The reference concept selection of acceptable arive mechanisms to be used in the conceptual design has been made in a way

1. Refer to References, Appendix A, Items 30 \& 31. 
BNWL -500

Volume 33

such that the results of the above study can be used in conjunction with the selected drives to select the optimum drive mechanism(s) for the FTR. The selection procedure consisted of two parts, 1) a survey of state-of-the-art drive mechanisms ${ }^{1}$ and 2) the evaluation of these drives for application in the FIR. 2, 3

The rod drive mechanisms considered for the reference concept are the "roller nut" concept as depicted by the Marvel Schebler drive by Borg Warner and the "magnetic jack" drive by Westinghouse. A third drive to be used in an alternate position may be necessary if the independent study indicates a need for two different types of drive mechanisms. The alternate design has been determined to be a BNW pneumatic arive ${ }^{l}$ if one is required. Selection of the drive mechanism, if a single mechanism is indicated by the independence study, will be heavily dependent upon the step rate required to insure stable operation of the reactor.

A brief description of the two reference drive mechanism concepts is listed below. The descriptions are for existing drives and do not necessarily depict the component that will satisfy all the requirements of the FTR. A more detailed description of each of the drive mechanisms concept can be found in the support documentation. ${ }^{1}$

1. Refer to References, Appendix A, Item 27.

2. Refer to References, Appendix A, Item 15.

3. Refer to Support Information Requirements, Appendix B, Item 18, 19, and 20. 
BNWL -500

Volume 33

\subsubsection{Roller-Nut Drive Mechanism}

The off the shelf drive package ${ }^{1}$ is 9 in. OD $\times 3$ ft long plus an appendix above for the stroke length. The design range for the driving force is 500 to 2000 pounds. The operation is based on an electric motor concept. A magnetic field is generated in six motor winding coils located outside a pressure tube. The split-hinged rotor inside the tube is spread apart by the magnetic force. This action causes the two pairs of connected roller nut followers to engage the lead screw. When the magnetic field is digitally pulsed, the rotor rotates a specific angle for each pulse and is locked there until the next pulse occurs. Thus, continual pulsing of the motor results in withdrawing or inserting the lead screw and attached poison rod at speeds up to 25 inches per minute.

Loss of power to the coils, either intentionally or accidentally, allows the lead screw roller followers to separate because of four push-apart springs, and the lead screw and poison drop into the core. There is a scram spring which operates over the full stroke, and accelerations of $1 / 4$ to $1 / 2 \mathrm{~g}$ are achieved. A dash pot is used to decelerate the rod gently at the end of its travel. The two spring loaded pawls are used to prevent expulsion during the screen stroke. One pawl acts as a ratchet and follows each hill and valley of the lead screw. When the screw is fully inserted, the other pawl is engaged to prevent the rod from bouncing out.

1. Refer to References, Appendix A. Item 20. 
BNWL-500

Volume 33

Position of the poison rod is determined by three methods. The first is by counting pulses applied to the motor. The second is a small magnet attached to one side of the rollernut device. Each time the roller-nut makes one revolution around the lead screw, a magnetic impulse is counted. The third way is by an induction coil around the top of the lead screw which indicates the elevation of the lead screw.

\subsubsection{Magnetic Jack Drive}

This drive ${ }^{1}$ consists of a housing with magnet coils on the outside and corresponding movable poles on the inside. Iift poles lift other poles. Latch poles are linked to latches which engage grooves in an extension rod. The extension rod is connected to the poison rod during all reactor operations including scram. The standard unit has three coils and two sets of latches. By proper sequencing of the coil and latch operations, the poison rod can be moved up or down like a bumper jack for an automobile. When the coils are de-energised, the latches disengage and the poison rod falls into the reactor. The rod position can be continually monitored by an inductive sensor. Position is also indicated by counting the number of pulses to the operating coils and using the full-in position as a reference point.

The commercial three coil drive had a step length of $3 / 8$ in. which was too large for FFTF use. The pitch of the grooves on the extension rod, was decreased to $0.300 \mathrm{in}$. and two coils were added to achieve a 0.150 in. step. Drawing sK-3-12445 in Appendix F describes the operation of the poles and latches during a rod lifting squence.

1. Refer to References, Appendix A, Item 21. 
BNWL -500

Volume 33

The drive envelope is about 8 in. in diameter.

\section{$\underline{2.2 .2}$ Eixtension Shafts}

The drive line extension shafts are divided into three sections: the top, intermediate, and main shafts. ${ }^{1,2}$ The top section is permanently attached to the drive mechanism and extends below the cover a distance of approximately 4 feet when the rod is fully inserted. Disassembly of this portion of the rod is accomplished by unbolting the drive housing from the cover and rotating the entire assembly to disengage the breach locks connecting the drive lines and the housing. This allows the drive mechanism to be lifted from the top of the reactor and placed in its refueling storage rack or taken to the maintenance area.

The remaining two sections are still connected at this point as is the poison section. A disassembly tool is inserted into the extension shaft breach lock and locked in place. The tool manipulated the latch mechanism by holding the center shaft firm while the outer sleeve is raised approximately 1-3/4 inches. This motion separates the collar of the upper collet which connects the intermediate shaft to the main shaft. The tool is lifted with the shaft still attached to a point where the intermediate shaft is totally contained within the cover, At this point the tool is locked in place and the entire tool is below the top of the operating floor level. A secondary seal can be utilized with the tool if necessary although the intermediate shaft maintains a dynamic seal with the cover at all times.

1. Refer to Drawings, Appendix $F_{\text {, }}$ SK-3-14558 and SK-3-14559.

2. Refer to Support Information Requirements, Appendix b, Item 12 . 
The main shaft consists of two hollow shafts with a male collet fitting at the top and a female collet fitting at the bottom. It is guided by a bushing at the upper end which is fixed by the extreme upper plate of the instrument tree. The shaft has a collar above the plate which rests on the plate only during the last 3 inches of upward travel of the instrument tree. Upon lifting of the intermediate shaft with the disassembly tool, the outer sleeve of the main shaft is raised by the enclosed spring action. This action frees the collet connection located on the poison subassembly. The main shaft is now ready to be lifted by the instrument tree when it moves to its refueling position.

Both collets utilize positive action through the use of an internal expander plug attached to the outer sleeve. Withdrawal of the outer sleeve lifts the expander plug which disengages the collet fingers from the male fitting. Development ${ }^{1}$ of this type of latch mechanism is required due to the following: A. Hard surfacing at all contact areas between the sleeve and the collet fingers must withstand galling and self welding at operating temperatures;

B. Spring development to maintain spring constants at outlet temperatures and to operate at shutdown temperatures. Positive disengagement is required to eliminate the possibility of lifting the poison piece from the core during the instrument tree movement. A stripper mechanism on the instrument tree must also be provided to back up this position.

I. Refer to Support Information Requirements, Appendix B, Item 12 . 
The collet type latch mechanism was selected for the reference concept due to the need for a compact mechanism. The OD of the collet mechanism is on the order of 3 inches at the main shaft/ poison subassembly joint. This latch allows some clearance space for possible differential movement of the core and the instrument tree in addition to some space allocated for instrumentation fittings. This space amounts to approximately 0.663 in. annulus in the control rod duct section and a somewhat smaller annulus through the lower plates of the instrument tree.

The extension shafts provide the primary holddown ${ }^{1}$ for the poison subassemblies during normal operation. Failure of the shafts will result in gravity fall of the reactivity element into the core. Detection of loss of holddown in this case may consist of either 1) loss of reactivity, 2) load cell indication in the shaft or 3) continuous current monitoring of the drive mechanism.

\section{$\underline{2.2 .3}$ Poison Subassembly}

The poison tip section consists of a 61 pin bundle of $\mathrm{B}_{4} \mathrm{C}$ pins supported by a structural section attached to the hexagonal carrier. ${ }^{2}$ The carrier is then converged to a 1-1/4 inch diameter shaft fitted with a male collet fitting at the upper end. The fixed poison subassembly duct encloses the poison carrier duct with a clearance of 0.100 inch on the annulus. The overall length of the subassembly is the same length as that of a fuel assembly and fits into the same type

1. Refer to Support Information Requirements, Appendix B, Item 14.

2. Refer to Drawings, Appendix F, SK-3-14560. 
of hydraulic balance receptacle. Orificing for the poison subassembly is maintained through the nosepiece of the fixed duct. A mechanical stop is located in the base of the fixed duct to retain the poison in the core while it is delatched. This stop is located 1.5 inches below the position of the tip of the poison section when it is connected to the drive train in the cold condition. At operating temperature, or immediately after scram the length of the total rod assembly will approach the mechanical stop. After cooldown, the poison tip will lift away from the mechanical stop. Upon disconnection, the tip will fall back to the mechanical stop. For this reason, the poison section must be 2 inches longer than the core and be positioned such that the poison extends beyond the bottom axial core interface by $1 / 2$ inch in the cold condition. This will insure that rod retraction will not occur during thermal cool down. The entire poison section of the rod which is enclosed in the hexagonal carrier must allow enough room at the top for full retraction of the poison from the core without extending the hex section above the fixed duct. This is due to the presence of the secondary holddown plate of the instrument ${ }^{1}$ tree and the ligament restrictions on the plate. This area is also needed for instrument sensor placement. The gas plenum length is an important parameter in the overall length of the assembly. A computer ${ }^{2}$ program has been completed based on stress limits of the clad wall as a result of helium gas generation during the poison burnup. The analysis made for the reference design used the following assumptions:

A. $42 \mathrm{cc}$ of helium is released per $\mathrm{CC}$ of $\mathrm{B}_{4} \mathrm{C}$.

B. Poison swelling is limited to l0\% by burnup limits.

1. Refer to References, Appendix A, Item 9.

2. Refer to References, Appendix A, Item 34. 
BNWL -500

Volume 33

C. Poison element is 38.5 inches long.

D. Burnup is limited to $10 \%$ of the $B_{10}$ atoms assuming natural $\mathrm{B}_{4} \mathrm{C}$.

E. Bulk outlet temperature is $900^{\circ} \mathrm{F}$.

F. Gamma heating - 12 watts/gram.

G. Cladding density - 0.283 lbs. in. ${ }^{3}$

H. Maximum allowable stress on the cladding 14,300 psi.

The program determined the plenum length required as a function of clad thickness and pin diameter. Figure 2 is a curve plotting the gas plenum length required versus clad thickness, in 8 of pin diameter, in the general area of interest to the FFTF. This study, combined with the subassembly length limits mentioned above, indicate that the clad thickness of (0.1) (pin OD) yields a plenum length of 19.6 inches. This value is compatible with 25 inch plenum shown on the conceptual drawings with sufficient contingency to allow for reduced stresses, higher operating temperatures, $\mathrm{B}^{10}$ enrichments and other factors that will be determined during preliminary design.

Preliminary holddown for the duct is incorporated in the hydraulic balance of the nose piece. Secondary holddown is a function of the instrument tree $^{1}$ in the same way the fuel subassembly secondary holddown is maintained. Loss of primary holddown is also detected by the instrument tree.

\subsubsection{Rod Worths}

The reference core consists of 21 rod positions. Three in-core rods are assigned the primary safety function. Three in-core 


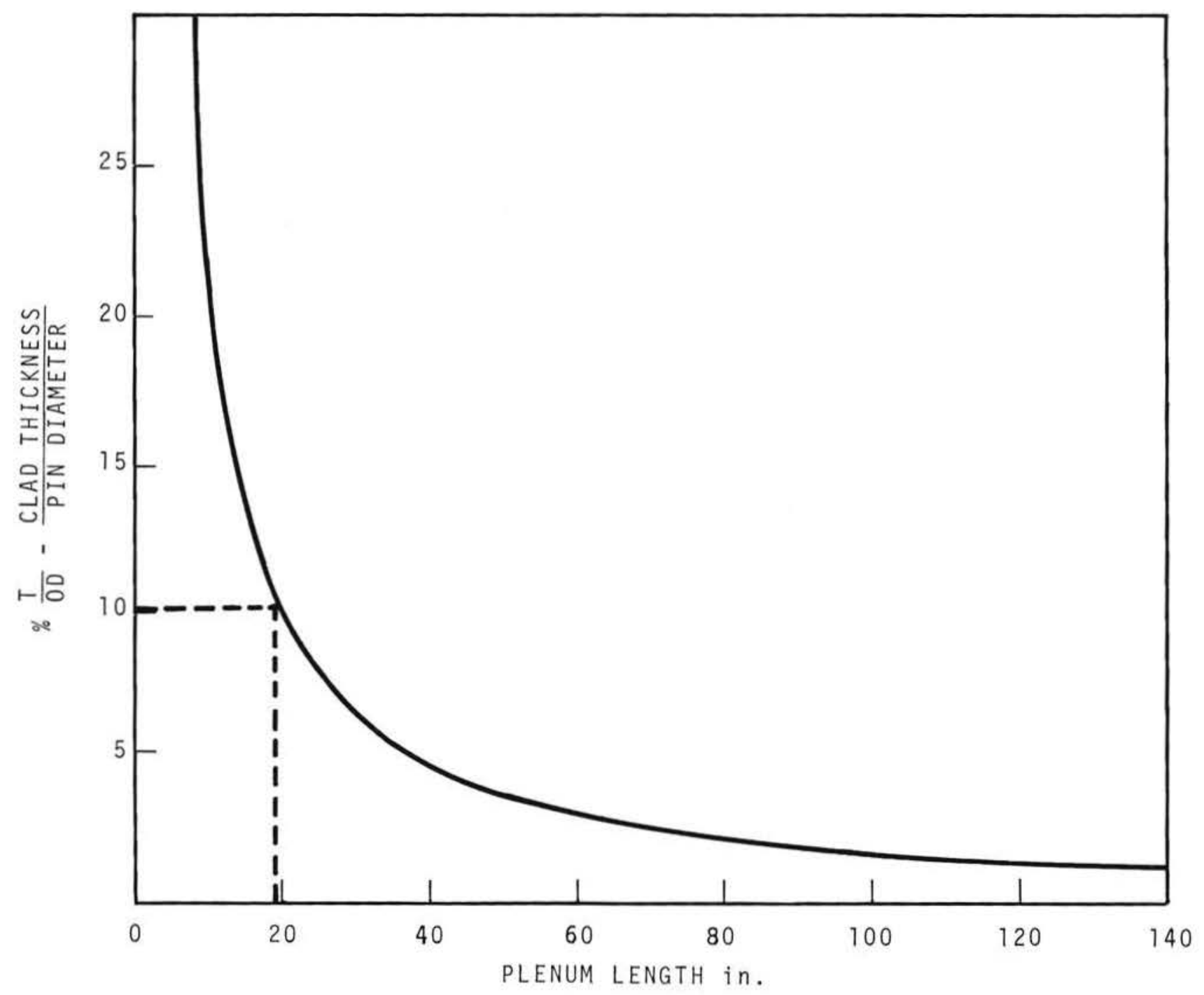


BNWL -500

Volume 33

shim rods are part of the secondary safety/control system as are the 15 peripheral rods. These arrangements are designated to satisfy the safety criteria which specify a minimum of two reactivity-control systems to fulfill the three functions of:

- Operational control

- Primary shutdown safety

- Secondary shutdown safety.

The following tables are presented to clarify the application of the criteria as meeting the total reactivity control requirements for the combined operational-control and secondary shutdown safety system and the primary shutdown safety system.

TABLE I. Reactivity Worth Combined operational-Control and Secondary shutdown safety system

Total minimum safety requirements

6.7

- Temperature reactivity defect

$0.8 \%$

- Fuel burnup allowance

2.6 음

- Test shim and operational flexibility

$2.0 \%$

- Minimum shutdown margin or accidental reactivity insertion allowances 1.0

- Rod Burnup

$0.3 \%$

Margin - 20\% of minimum safety requirements 1.3 Total minimum design requirement

8.0

TABLE II. Reactivity Worth Primary Shutdown Safety System Total minimum safety requirement

2. 65 \%

- Control rod burnup

$0.15 \%$

- Temperature reactivity defect

$1.0 \%$

- Minimum shutdown margin and accidental reactivity insertion allowance

$1.50 \%$

Margin - for minimum safety requirements

$0.55 \%$

Total minimum design requirements (exclusive of a stuck rod)

$3.2 \%$

The system will consider the highest worth rod stuck. 
BNWL -500

Volume 33

The values listed in the tables are minimum requirements for the nuclear worth of the control and safety systems. There are many reasons for worths higher than the minimums shown. However, any increases must be balanced against postulated accident conditions. All negative reactivity effects of any single rod must be considered as a potential positive reactivity insertion upon ejection of the rod.

The individual rod worths ${ }^{l}$ are a function of many variables and are limited by core position, poison packing density, peak poison temperatures, shadow effects of other rods, $B_{10}$ enrichment limits, and thermal hydraulics. In order to arrive at allowable worths, a comprehensive study ${ }^{2}$ shows that the optimum $\mathrm{p} / \mathrm{d}$ ratio for the pins is around 1.1 . This rationale is as follows: For a given acceleration force, the rate of negative reactivity inserted into the core is optimum for $\mathrm{p} / \mathrm{d}$ ratios between 1.06 and 1.12 . This is based on volume of poison inserted as a function of the hydraulic resistance, i.e., as the $\mathrm{p} / \mathrm{d}$ ratio decreases, the hydraulic resistance increases which tends to slow the lineal insertion rate. However, the decreased $\mathrm{p} / \mathrm{d}$ increases the volume of poison inserted per lineal inch of insertion until the ratio falls below 1.06 . The result is a net increase in negative reactivity insertion up to this point. With a thermal conductivity value of 9.0 Btu/hr-ft ${ }^{\circ} \mathrm{F}$ the temperature of the material remains within what is considered a reasonable extension of the state-ofthe-art.

\footnotetext{
1. Refer to Support Information Requirements, Appendix B, Items 15,16 , and 17.

2. Refer to References, Appendix A, Item 32.
} 
BNWL -500

Volume 33

Since rod worths are a function of the amount of poison material within a given subassembly, the OD of the pin is the first determination of the poison available. Figure 3 shows the oD of the pin for a 61 pin geometry in the reference lattice versus the pin $\mathrm{p} / \mathrm{d}$ ratio. The assembly carrier duct remains fixed in all cases as follows:

- Lattice 4.715 in, across the flats.

- Void between subassemblies - 0.050 annulus.

- Guide duct outside size - 4.615 in. across flats.

- Guide duct inside size - 4.335 in. across flats.

- Clearance annulus 0.100 in.

- Carrier duct outside size 4.1335 in. across flats.

- Carrier duct inside size 3.855 in. across flats.

The total weight of boron per subassembly for a 36 inch core can be selected from Figure 4, which relates the weight of boron as a function of the pin p/d. Recall that a clad thickness of $10 \%$ of the pin OD is required to maintain gas plenum stresses within the allowable range for $10 \%$ burnup and a 24 inch gas plenum.

The rod worths for various $\mathrm{p} / \mathrm{d}$ ratios and $90 \%$ TD with the pin clad thickness of $I 0 \%$ of the pin $O D$ is shown on Figure 5. From these curves, using the reference core map and a $1.1 \mathrm{p} / \mathrm{d}$ the worths are as follows: 
BNWL-500

Volume 33

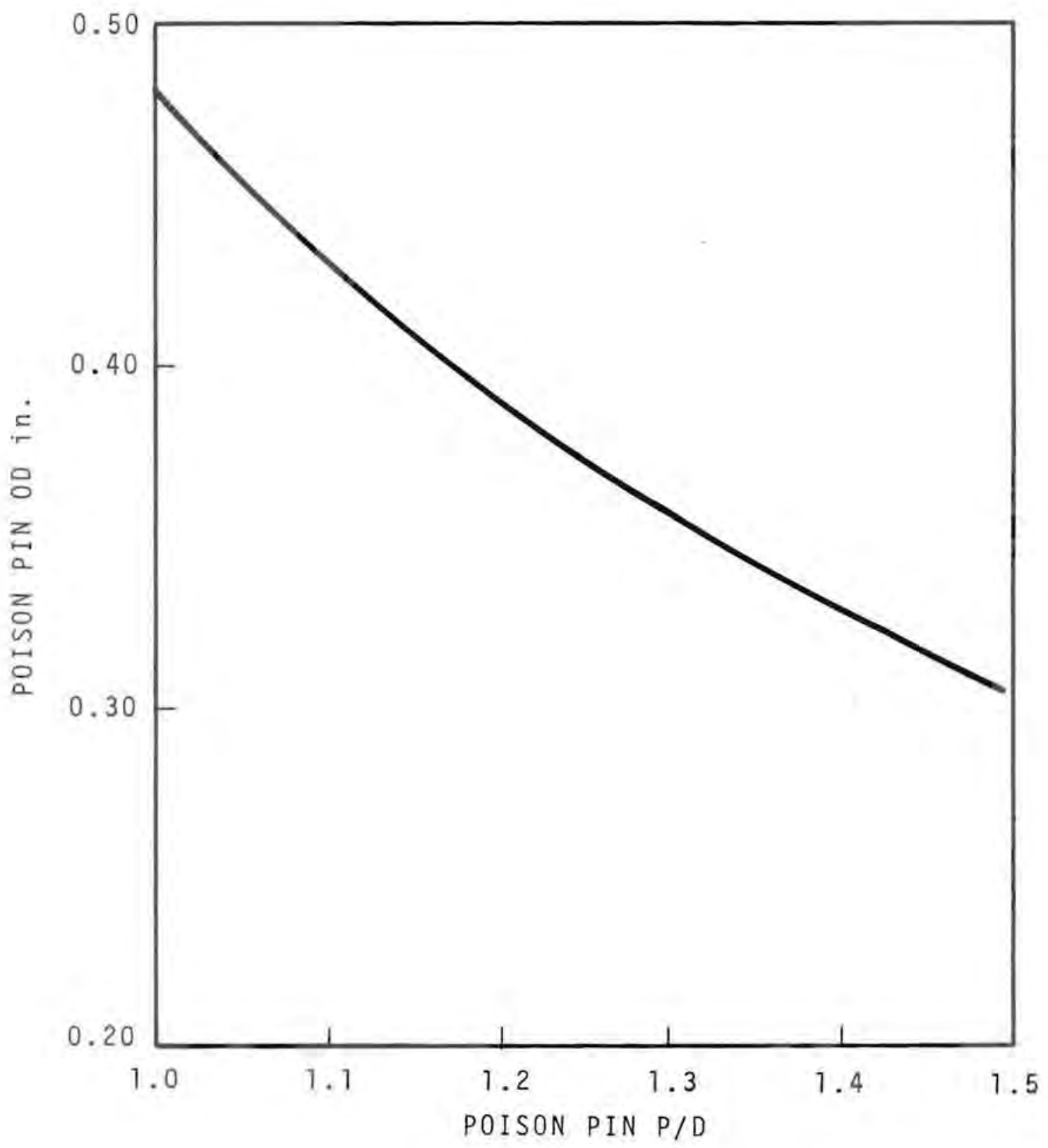

FIGURE 3. Poison Pin OD Versus Pin P/D For a 61 Pin Control Rod Assembly 
BNWL -500

Volume 33

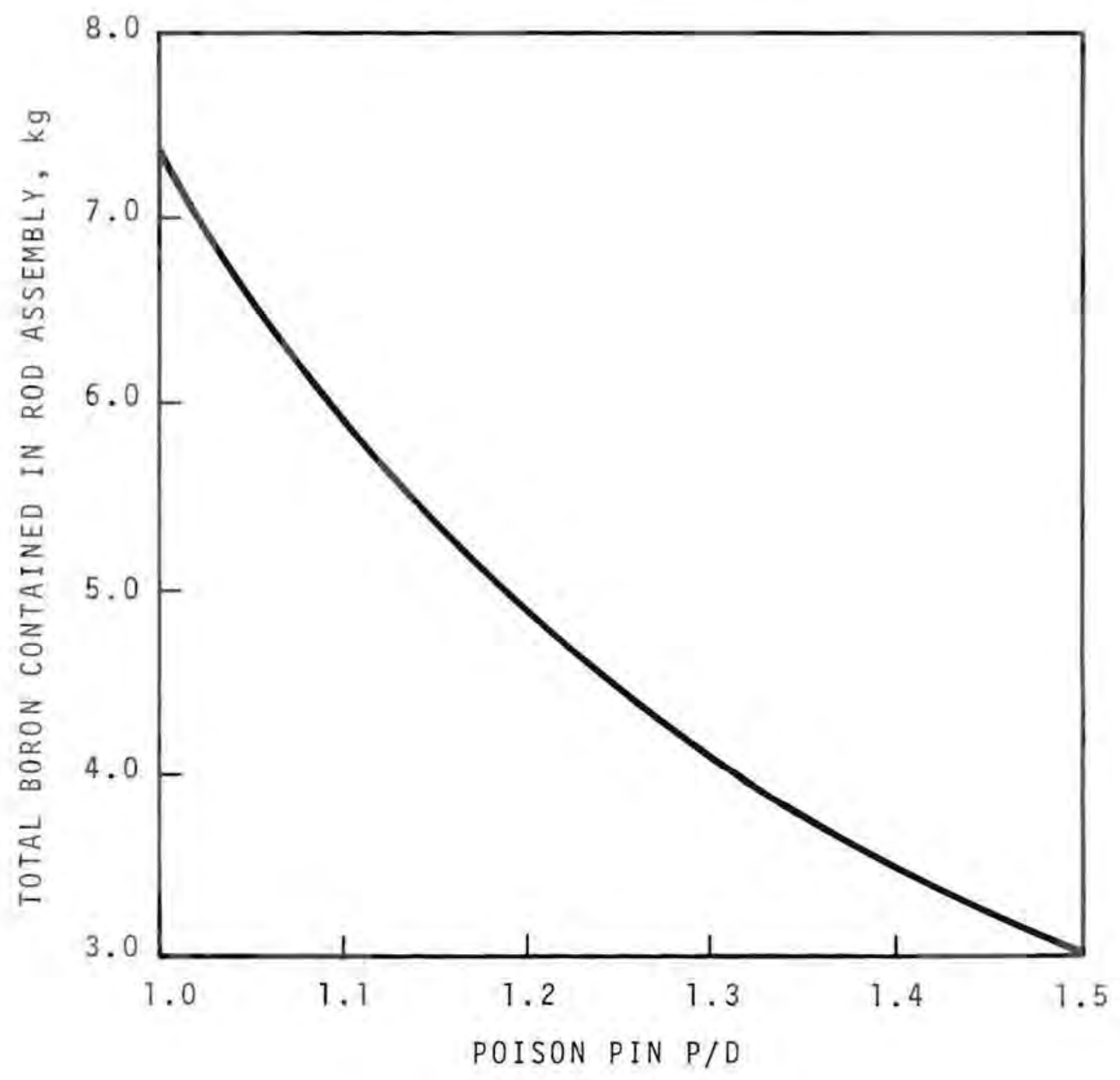

FIGURE 4. Total Boron Contained in Control Rod Assembly Versus Poison Pin OD for 61 Pin Assembly with Cladding Thickness $=10$ \% Pin OD; 36 in. Length 


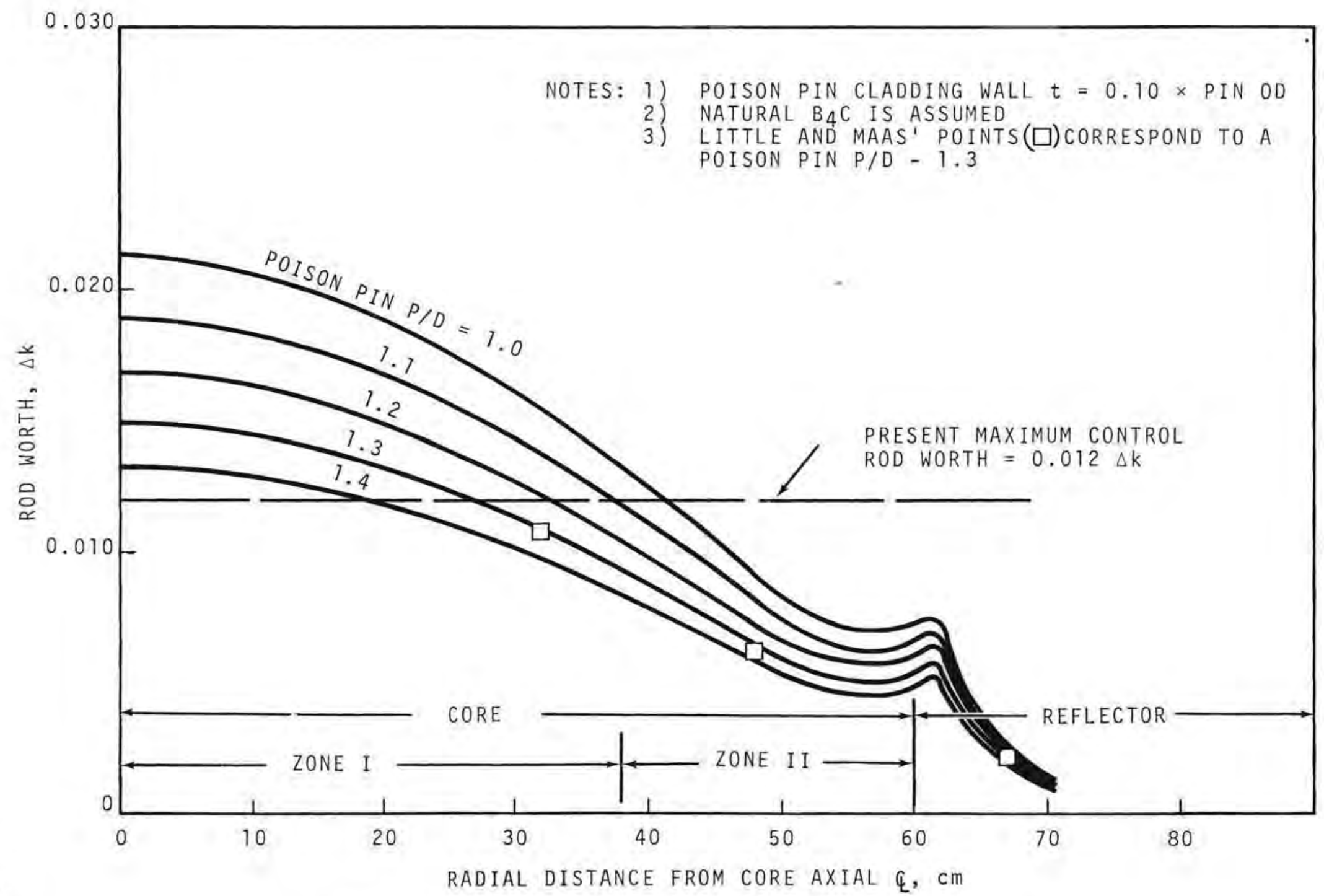

FIGURE 5. Rod Worth Versus Radial Core Location 
BNWL -500

Volume 33

Distance

from Core

$\frac{\text { Rod Type }}{\text { Primary Safety }}$

Centerline

Number Worth/Rod

$\frac{\text { Total Worth }}{4.14 \%}$

In-Core Shim

$47.90 \mathrm{~cm}$

3

$0.85 \%$

$2.47 \%$

Peripheral shim

$66.68 \mathrm{~cm}$

15

$0.26 \%$

$3.90 \%$

Secondary safety/control system total worth

$6.375 \%$

The above worths are for natural $\mathrm{B}_{4} \mathrm{C}$ material containing 18. I5 atom \& $\mathrm{B}_{10}$. Enrichment of both the primary safety rods and any of the shim rods can be accomplished to increase the worth if necessary. The curve on Figure 6 relates relative worth versus $B_{10}$ Content in $\mathrm{kg}$. From Figure 4 and for $\mathrm{a} p / \mathrm{d}$ of 1.1 the weight of boron in $\mathrm{a}$ subassembly is $5.924 \mathrm{~kg}$. Natural boron contains 18.15 atom $\% \mathrm{~B}_{10}$, so each rod will contain $1.075 \mathrm{~kg}$ of $\mathrm{B}_{10}$ in its natural state.

Using these figures and the curve of Figure 6,1 the rod worth of the safety rods can be increased to $2 \%$ per rod by enriching to 35 atom weight $B_{10}$. In this case, the speed of response for the primary safety system is kept to a minimum.

From the above discussions the enrichment of the control rods can be determined to provide the system worth requirements of the reactor. The remaining parameter which is affected by the enrichment of the rod is the maximum temperatures of the poison material. Figure 7 shows the heating rate of the $\mathrm{B}_{4} \mathrm{C}$ as a function of enrichment and radial distance from the core centerline. The maximum poison temperatures are then a function of the heating rates and the individual pin diameters.

1. Refer to References, Appendix A, Item 28. 


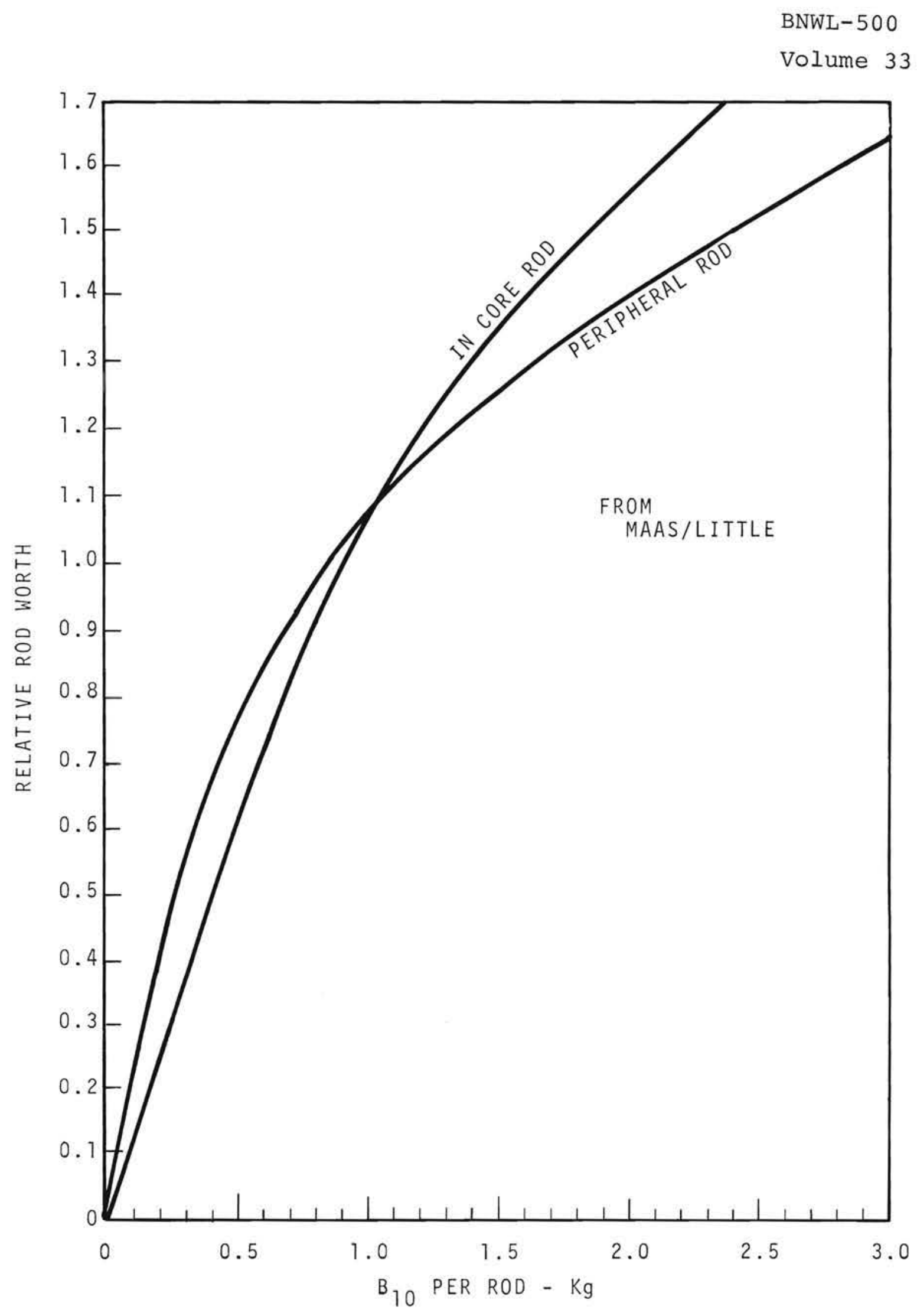

FIGURE 6. Relative Rod Worth Versus $B_{10}$ Content 


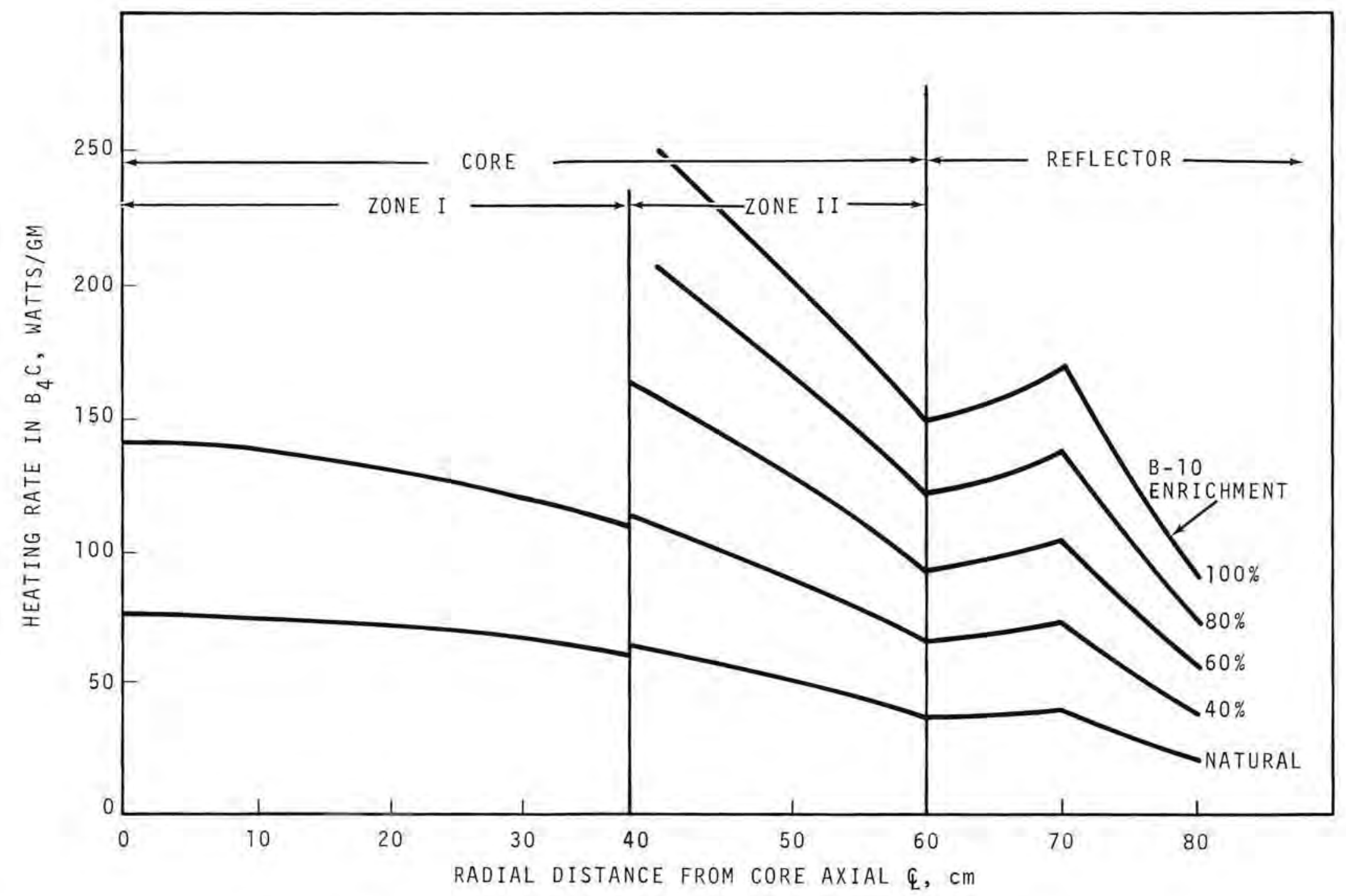


BNWL-500

Volume 33

Figure 8 shows this relationship as a family of curves of varying heating rates with the maximum poison temperature versus the individual pin OD.

Using the reference design for in-core control rods enriched to 40 volo results in heating rates of 100 watts/gram at the position of $47.9 \mathrm{~cm}$ from core centerline. Proceeding to Figure 8, the maximum temperature of the poison would be $1220^{\circ} \mathrm{F}$.

The worth requirements will become more firm as the design progresses from conceptual to preliminary to final design. The many variables involved which have a considerable effect on the worth of the control system makes it mandatory that provisions for increasing the worth be available as long as possible. With the FTR, the ability to vary the worth even after the plant is built is extremely desirable since future cores and/or tests may require additional negative reactivity.

The methods available for increases in negative reactivity include 1) enrichment of the poison, 2) addition of control elements to the core and 3) reduction of the fuel volume of the core. Two avenues of availability for increased poison exist in the F'TR without the penalty of reducing active fuel volume. Since increases in enrichment of the poison with the attendant increases in temperatures may not be available, the second method of poison addition, namely, addition of control elements, is recommended. This is accomplished by retaining three openings through the reactor cover to permit the addition of three additional in-core rods at any time it is found necessary. Alterations to other components of the reactor to permit this addition would be limited to changes in the instrument trees and instrumentation above the cover. 


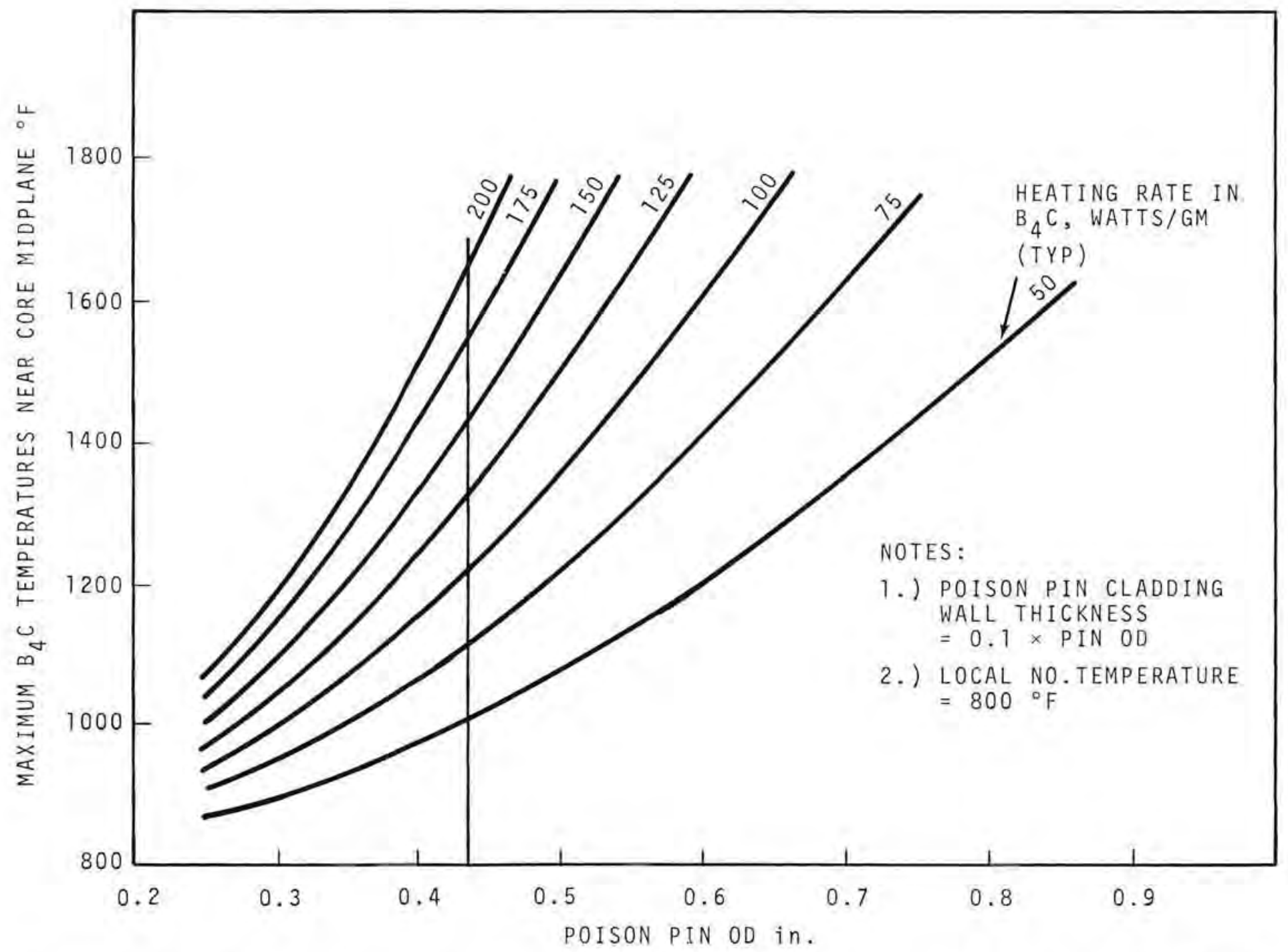

$N$
1
$N$

FIGURE 8. Maximum $\mathrm{B}_{4} \mathrm{C}$ Temperatures Near Core Midplane Versus Poison $\mathrm{Pin} O D$ For Various Heating Rates in $\mathrm{B}_{4} \mathrm{C}$ 
BINWL -500

Volume 33

The worth increases available due to poison enrichments are shown on Figure 9 for the reference concept. As indicated the system worths may be increased to $6.0 \%$ and $8.5 \%$ for the safety and control systems respectively by enriching all rods to $30 \% \mathrm{~B}^{10}$. Recall that the temperatures determined previously ( $\left.1220^{\circ} \mathrm{F}\right)$ are for 40 vol\% enriched material. Alternatively any value between 6.0 and $8.5 \%$ can be achieved by preferentially enriching if temperature becomes limiting for the control rods. Figure 9 does not consider the shadowing effects of the rods with respect to each other and on that basis may be slightly optimistic. However, three of the peripheral rods are located at $62.24 \mathrm{~cm}$ from the core centerline and the remaining 12 rods are $66.68 \mathrm{~cm}$ from the center. In the conceptual reference design all peripheral rods were calculated as if they were located at the furthest position. From Figure 5, it can be seen that this method of calculation is conservative.

The use of tantalum as a poison medium is not recommended for the following reasons:

1. The worth of tantalum is low enough to place the actual requirements in jeopardy if the error band of the calculations to date are not substantiated during preliminary design.

2. Flexibility of the reactor is lost through the inability to increase worth by any means other than increased rod assemblies.

3. The control rod assembly presently weights on the order of 650 pounds using a boron tip. The addition of 150 or more pounds to the assembly will induce excessive requirements on the drive mechanisms and scram functions of the rod. 
BNWL -500

Volume 33

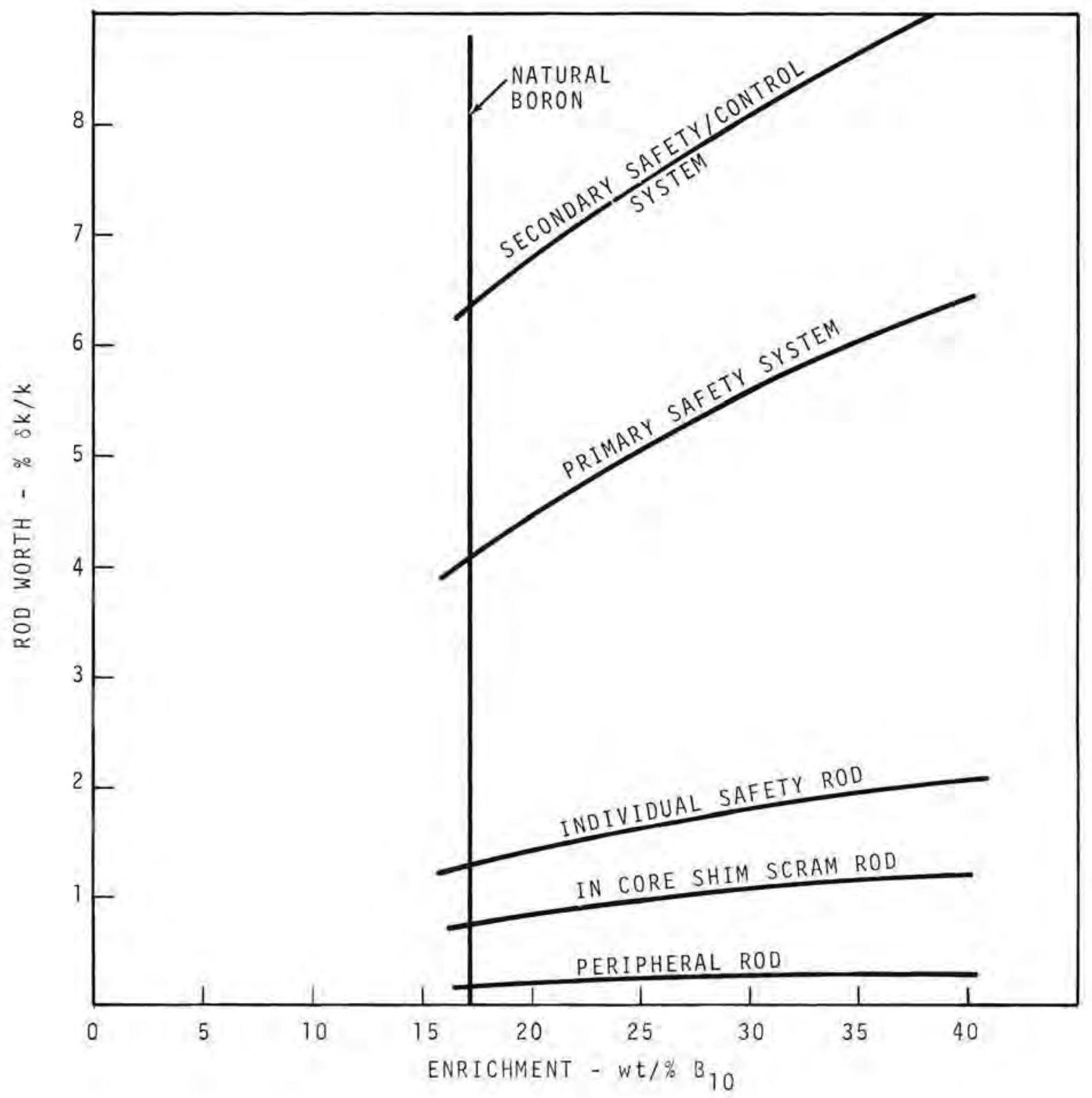

FIGURE 9. Reference Core Rod Worth 


\subsubsection{Scram Assist}

Acceleration of the scram assisted rods is shown in the reference concept as a top mounted device above the drive mechanism. I A spring was selected as the simplest method and therefore a method with the highest probability of dependability. The spring is shown with a cocking cylinder to relieve the drive mechanism of the load of cocking the spring. The drive line including the poison subassembly has been calculated at approximately 640 pounds. This weight is within the limits of the recommended drive mechanisms, however, the additional force required to cock the accelerating device would exceed the capability of all known drive mechanisms that will fit within the space restraints on the reactor cover.

The acceleration rates ${ }^{2}$ required and therefore the force required to achieve these rates are dependent on the following parameters:

(a) Maximum accident ramp rate to protect against.

(b) Trip setting of overpower instrumentation.

(c) Time delay between trip and rod release.

(d) Location of the rod tip relative to the core.

(e) Safety system worth, neglecting stuck rods.

1. Refer to Drawings, Appendix F, SK-3-14559.

2. Refer to Support Information Requirements, Appendix B, Items $8 \& 9$. 
BNWL -500

Volume 33

A preliminary study of scram system response requirements and capabilities $^{1,2}$ has been made to determine a design basis for speed of response satisfaction of the reference system. Postulated accidents resulting in ramp rates of 2 to $4 \$$ per second can be visualized. Uncertainties in calculations and the need to assure the reactor safety requires some conservatism to be added to the estimated ramp rate. The ramp rate selected in the reference design to be protected against, then becomes $5 \$ / \mathrm{sec}$. The studies made to date indicate that reasonable parameters for termination of reactivity ramp rates are as follows using the above designated ramp:

1. Power trip setting $115 \%$.

2. Rod tip to be at the core/reflector interface.

The remaining variables are retained as such to determine the optimum speed of control required. Rod worths can be varied by 1) increasing the number of rods, and 2) enriching the poison. The time delay between signal receipt and rod movement includes a fixed magnet decay period for mechanical release of the rod. The release time for the FARET ${ }^{3}$ design, shows magnet decay times of $0.017 \mathrm{sec}$. This requirement indicates that minimum total time delays that may be achievable are on the order of 0.050 seconds. Maximum time delays for rod release is on the order of 0.100 seconds.

1. Refer to Support Information Requirements, Appendix B, Items 8 \& 9 .

2. Refer to References, Appendix A, Item I8.

3. Refer to References, Appendix A, Item 29. 
A primary safety system of three rods has been selected for the reference concept. From section 2.2.4 the rod worth of the primary system of $6 \%$ has been selected as the reference design. Note that this exceeds the minimum worth required for safety. The excess worth is recommended to reduce the speed of response of the system. This value allows some further enrichment allowance margin for contingency. The curves of Figure 10 show required scrammable worth versus the reactivity insertion rates to incipient melting for 100 and 50 millisecond circuit time delays. The family of curves show the accelerations required with the rods resting at the core interface prior to scram.

Utilizing a one stuck rod criteria the total scrammable worth of the system will be $4.0 \% \frac{\delta k}{k^{-}}$. From the curve, it can be seen that the acceleration required to reverse a $5 \$ / \mathrm{sec}$ ramp rate with a 100 millisecond time delay would be on the order of $1.5 \mathrm{~g}$. (Figure 10)

The forces required to achieve these accelerations are also a function of several parameters, namely the acceleration, the weight of the rod drive line and poison, and the hydraulic resistance of the rod within its guide duct. A computer program ${ }^{1}$ has been developed to compute the forces required to achieve various accelerations as a function of the above variables. The program is based on energy balance and is capable of determining rod velocities as a function of time, accelerations, flows, etc. for various rod configurations. The reference configuration was used to test the program using two types of scram assist and three values of assist for each type. The first run assumed gravity fall for the reference concept, and 14 inch scram assist springs with 


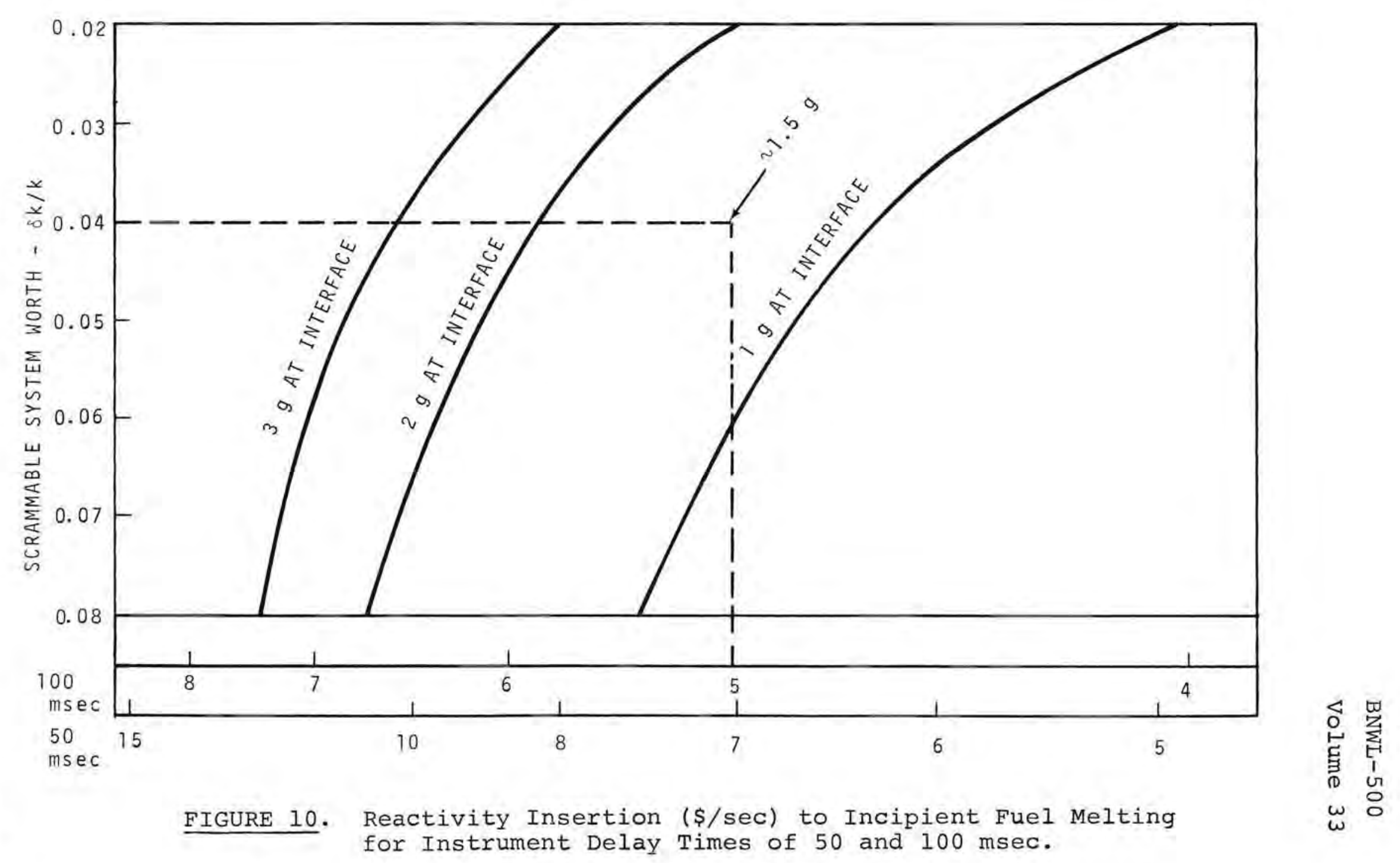


BNWL -500

Volume 33

$1 \mathrm{~g}$ and $2 \mathrm{~g}$ initial forces. The second parametric program assumed a constant force acting on the rod in addition to its weight to simulate a pneumatic cylinder scram assist. Forces of 1000, 1500 and 2000 pounds were assumed.

The results of the program are shown on Figures 11 and 12 . These curves depict the distance versus time traveled by the rod of the reference design with $230 \mathrm{gpm}$ counterflow in the guide tube. The combination of the rod insertion rates for the reference design with calculated negative reactivity insertions versus rod insertions (Fig. 13) results in a set of parametric curves showing total negative reactivity insertion as a function of time for each of the six parameters mentioned above. These curves have been drawn using a $0.04 \frac{\delta \mathrm{k}}{\mathrm{k}}$ scrammable system with $0.100 \mathrm{sec}$ time delay for two cases; I) with the rods at the core/reflector interface, and 2) with the rods $10 \mathrm{~cm}$ above the core/reflector interface.

By adding the $5 \$ / \mathrm{sec}$ ramp rate starting at time zero and determining a 0.75 margin from this ramp as the maximum safe variation of negative reactivity to positive reactivity insertions, it can be seen from Figures 14 and 15 that the rod system is capable of reversing a $5 \$ / \mathrm{sec}$ ramp rate in all cases except the gravity fall when the rods are located at the core/reflector interface. Figure 16 indicates the six scram parameters with the rods located $10 \mathrm{~cm}$ above the core/reflector interface and it can be seen that the case of a $1 \mathrm{~g}$ scram assist spring may also be questionable.

As can be seen by the preceding work, the control and primary safety systems can be designed through various parameters into a workable system for the postulated accident. Trade-offs 
BNWL -500

Volume 33

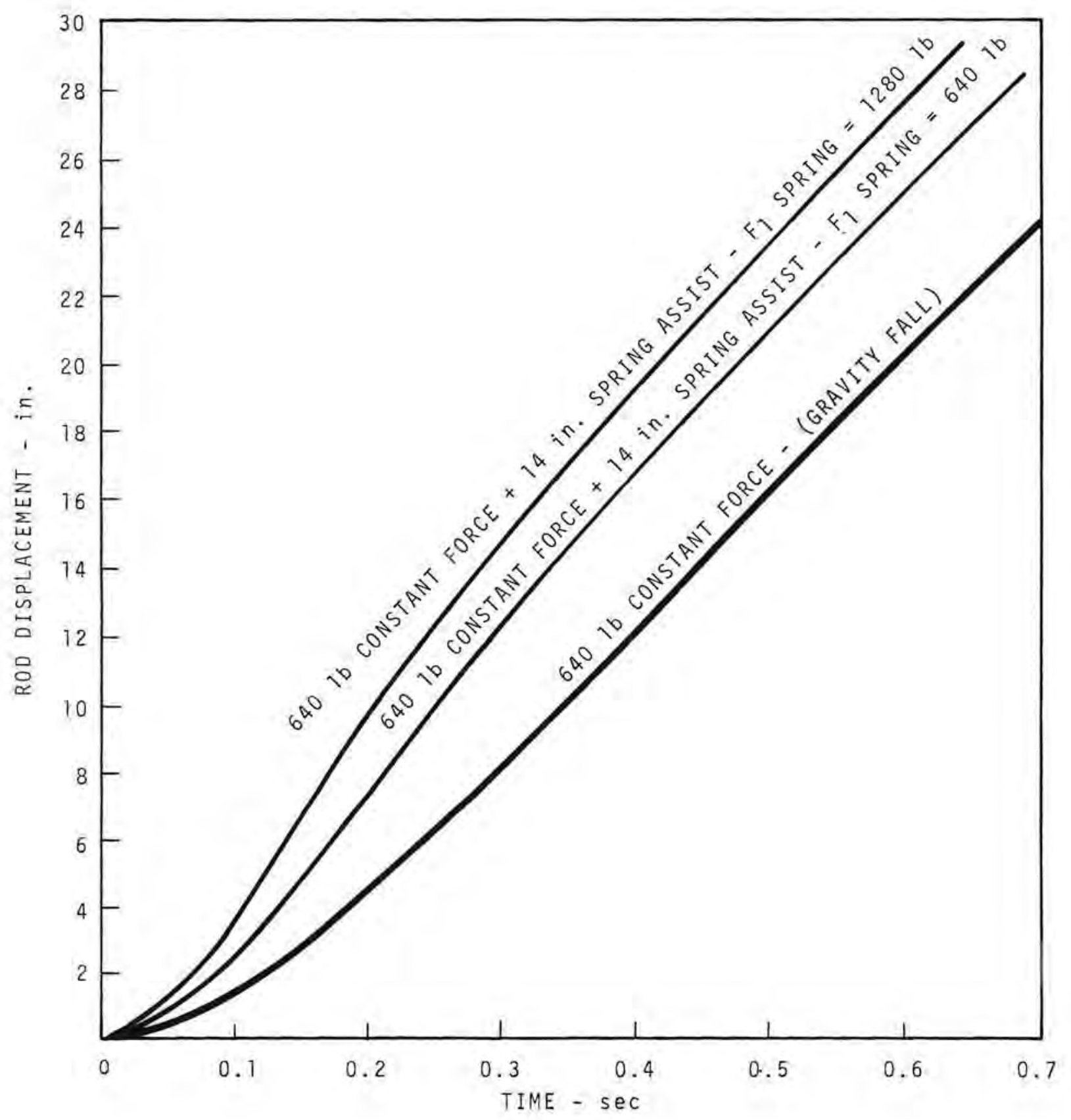

FIGURE 11. Scram Insertion Rates - Spring Assist 


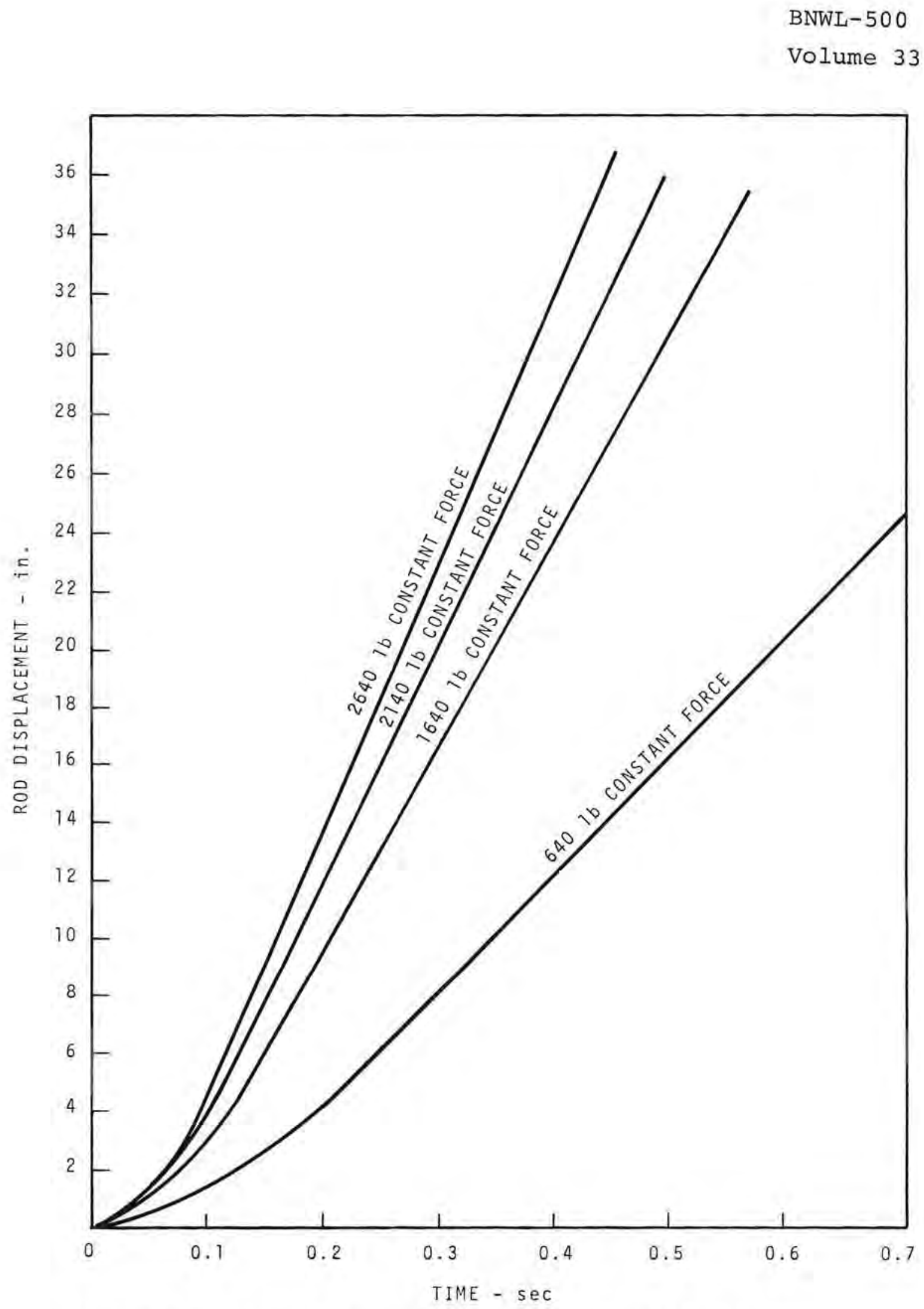

FIGURE 12. Scram Insertion Rates - Constant Force 


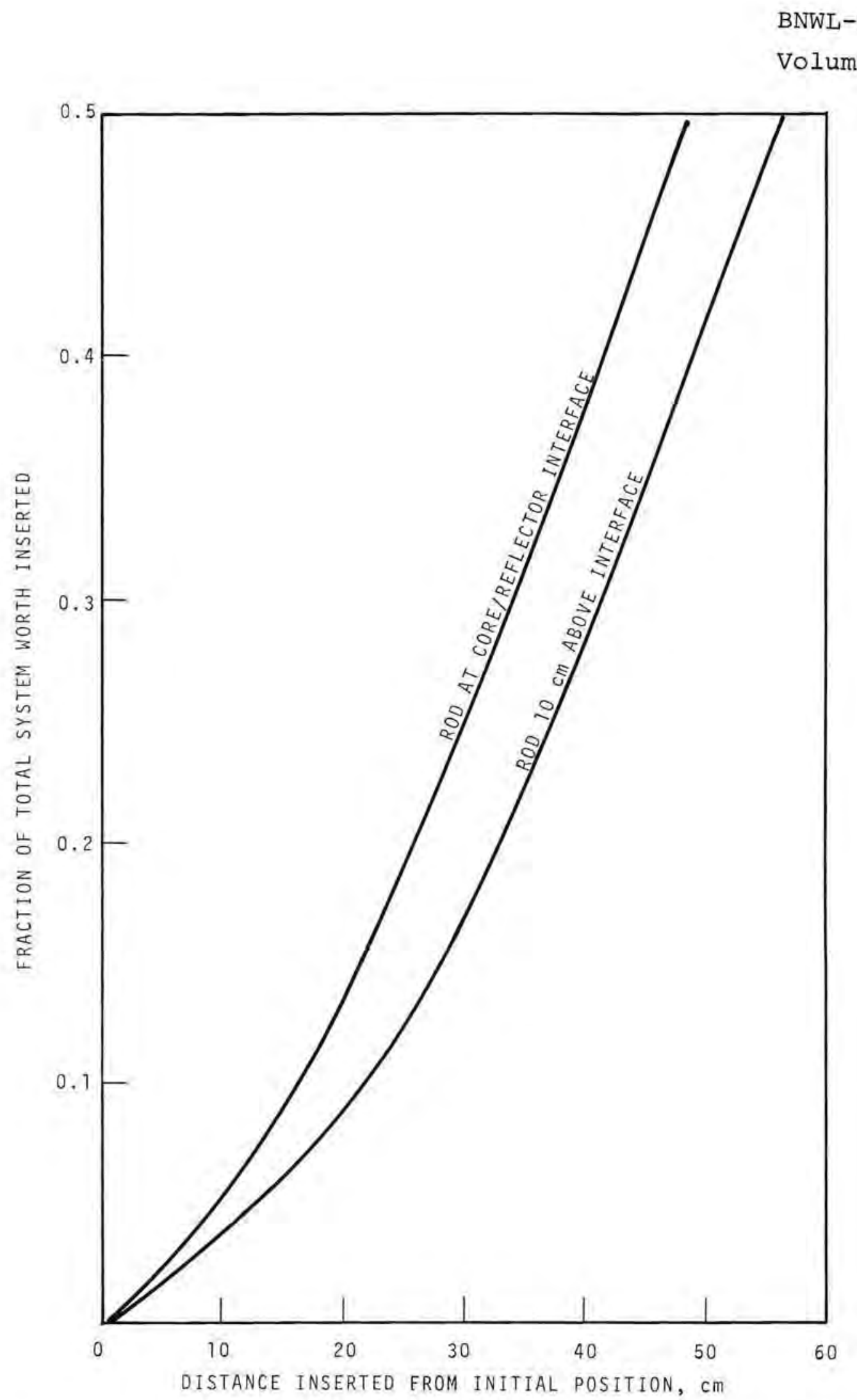

FIGURE 13. Inserted Worth Versus Distance from Full Up. 


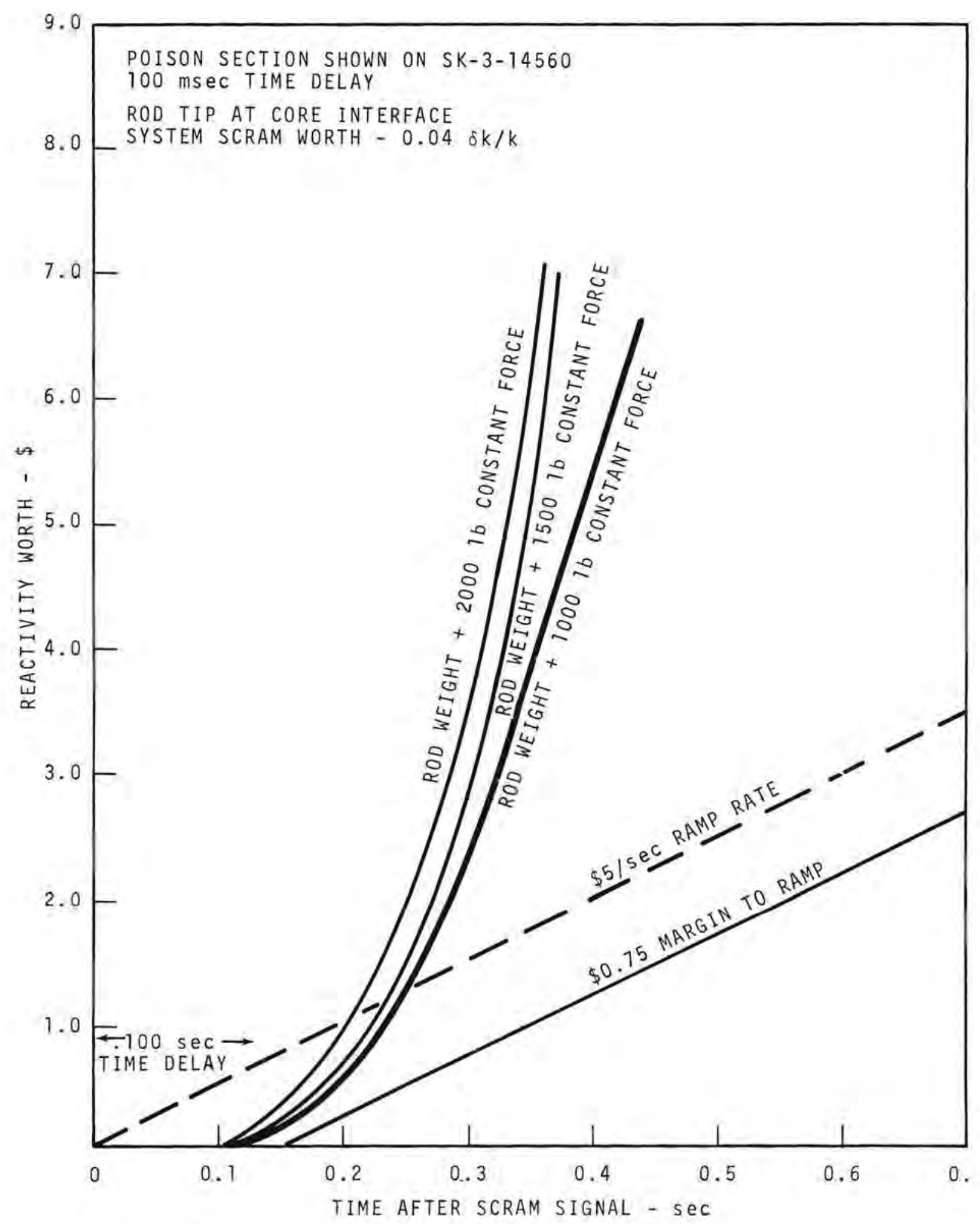

FIGURE 14. Negative Reactivity Insertion Rates 
BNWL-500

Volume 33

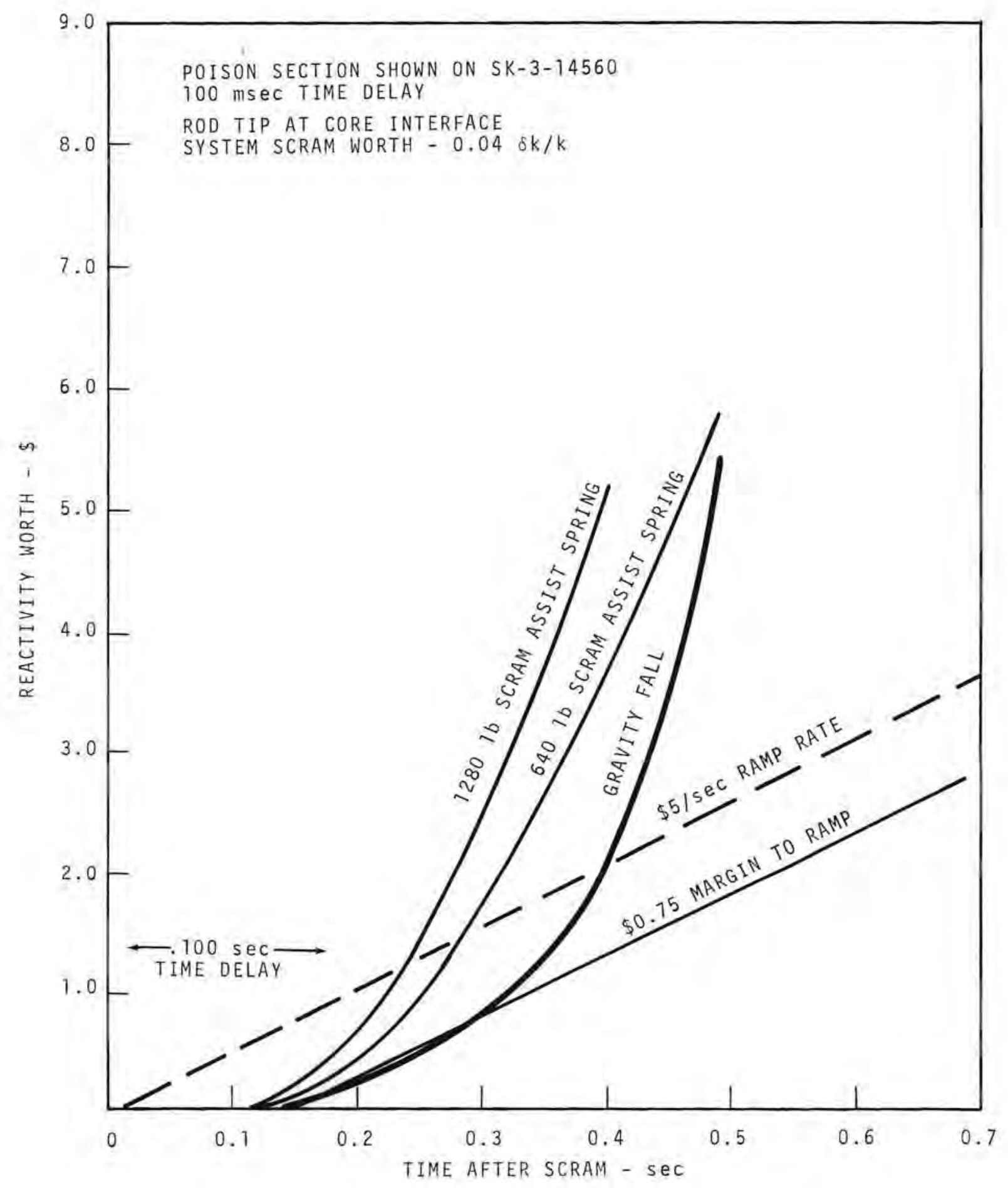

FIGURE 15. Negative Reactivity Insertion Rates 


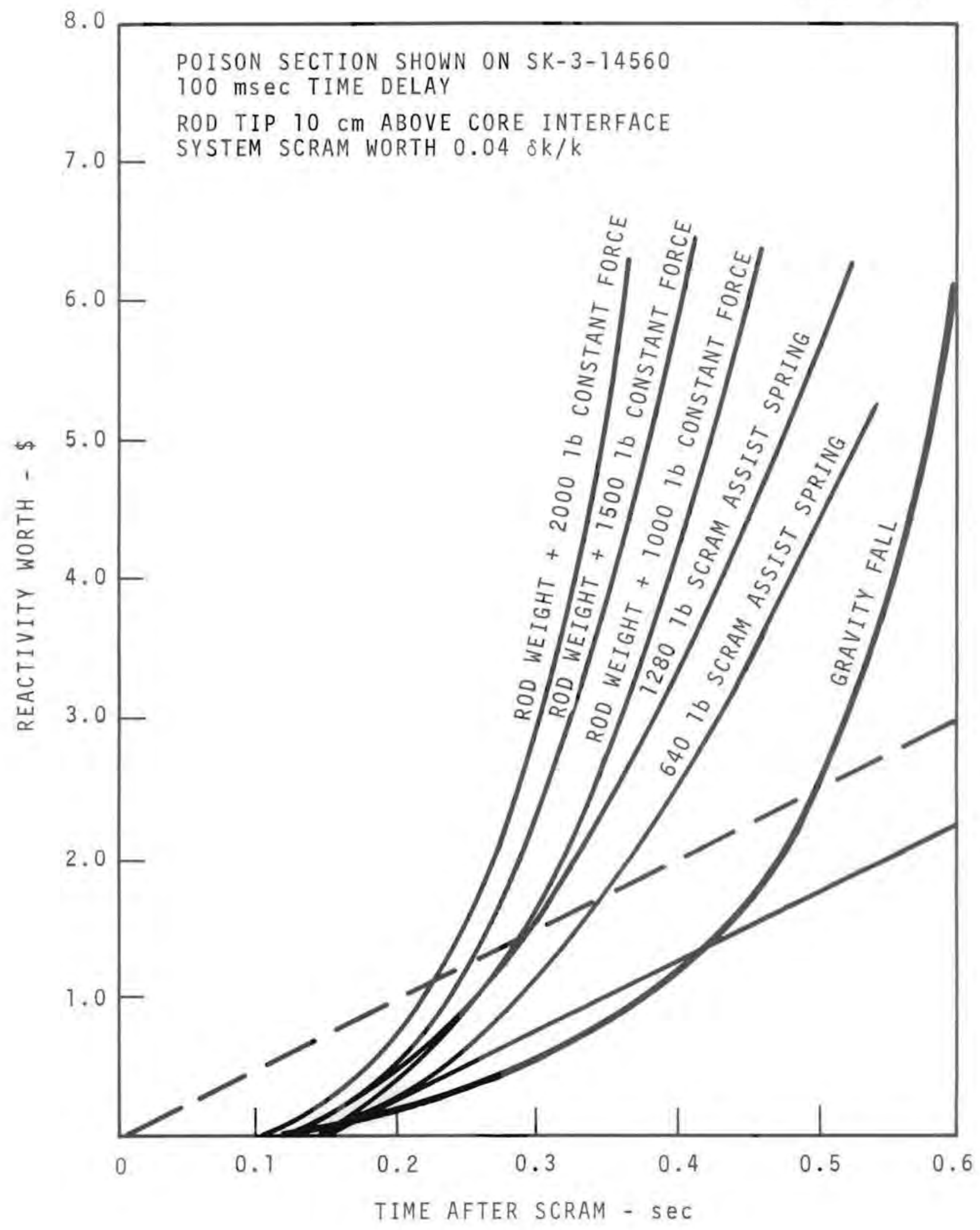

FIGURE 16. Negative Reactivity Insertion Rates 
of worth versus temperatures, enrichments, number of rods and scram response can be determined as preliminary design progresses to arrive at an optimum system for the FTR.

\section{$\underline{2.2 .6}$ Deceleration}

The decelerating mechanism ${ }^{1}$ selected for the reference concept is a hydraulic piston mounted outside the drive mechanism above the drive motor. Deceleration for a segmented arive line is accomplished at the top of the drive line in order to eliminate the buckling forces on the latch mechanisms. Deceleration is designed to take place during the last $8 \mathrm{in.}$. of stroke. Assuming uniform deceleration, the forces resulting in tensile stresses in the extension shaft amount to approximately $7 \mathrm{~g}$ 's if the upper stroke is considered at constant $2 \mathrm{~g}$ acceleration. This results in deceleration on the order of $225 \mathrm{ft} / \mathrm{sec}^{2}$ and forces of about 4420 pounds for a 640 pound assembly. Total forces including the weight of the rod are then 5060 pounds, The weakest sections in the extension shafts are the collet fingers. The minimum area of the collet fingers is about $1.0 \mathrm{in.}{ }^{2}$ which results in stresses on the order of about 5000 psi.

The decelerating mechanism is patterned after the design for the FARET control rod drive mechanism. ${ }^{2}$ The FARET design conditions were $1.5 \mathrm{~g}$ accelerations with about a $4.5 \mathrm{~g}$ deceleration force. Development of a decelerating system for the FTR will be a minor extrapolation of the work done by Argonne Laboratories.

1. Refer to Support Information Requirements, Appendix B, Item 5

2. Refer to References, Appendix A, Item 29. 
BNWL -500

Volume 33

\subsubsection{Axial Positioners}

The use of control rod drive mechanisms as motive power for axial positioners in closed loops has been preliminarily recommended. The major basis for this recommendation is that the CRDM is a logical choice from the space and stroke standpoint. The requirements of such an axial positioner will not be firm until a test plan is developed. ${ }^{1}$ Some basic requirements could be specified at the present time, however, these requirements would be basically design oriented and will not be complete enough to permit conceptual design to proceed.

The basic envelope size of the closed loop indicates the use of a CRDM for the axial positioner. Basic design differences are as follows:

A. The sodium level in the loop is above the structural portion of the reactor cover. As such, the seal for the drive mechanism must be a liquid sodium seal rather than a gas seal as in the control system.

B. Instrumentation leads from the test specimen must be carried through the hanger shaft to a point where a reasonable connection with flexible leads can be attached to allow for the drive stroke.

c. A mechanical disconnect for the drive line from the support rod may not be feasible since it would have to be done remotely and would result in a sodium wetted latch mechanism through which instrument connections must be made.

D. The final design requirements for rate of movement, frequency of movement etc. may indicate a manual positioning device.

1. Refer to Support Information Requirements, Appendix B, Item 4. 
E. The drive train/motor separation prizciple, which is mandatory in the control application for scram action is not allowed for an axial positioner. This change to the existing reference drives is not a serious one.

2.2.8 Oscillator

An oscillator is used in a reactor system to measure tie transfer function of the reactor under various operating conditions. The data from the tests are an indication of the stability of the reactor. The need for an oscillator for the FTR has been designated in two studies. ${ }^{1,2}$ Alditionally, a survey ${ }^{3}$ has been made of prior uses, successes, and planned future uses of oscillator systems in other reactors. The survey encompasses some 19 installations, and developinent programs in order to assess their applicability to the FTR.

The present management plan is to initiate a prototype development program under which an oscillator mechanism, drive line, and poison configuration will be built and tested, ${ }^{4}$

Access to the core of the reactor during the test proqram will be provided through an in-core shim rod position or a test position.

1. Refer to References, Appendix A, Item 35.

2. Refer to References, Appendix A, Item 37.

3. Refer to References, Appendix A, Item 36.

4. Refer to Support Information Requirements, Appendix B, Items $6 \& 21$. 
BNWL -500

Volume 33

The development program will begin with a RFP for prototype design of an oscillator drive and reactivity section. Evaluation of the proposals will enable the selection of a contractor to accomplish the work. Fabrication and testing of the prototype will then provide the FTR with a developed and tested mechanism that can be used in pre-startup and initial power operating conditions of the reactor.

\subsection{INSTRUMENTATION, CONTROL AND ALARMS}

$\underline{2.3 .1 \text { General Summary }}$

The basic instrumentation and control functions supplied to the Reactor Nuclear Control Components by other systems are: - The ability to command the rod drive system to move certain rods at prescribed rates and direction to achieve desired reactor power levels. ${ }^{1}$

- The determination of the position of each rod. ${ }^{1}$

- The full-in, full-out limit indications. ${ }^{1}$

- The scram signal. ${ }^{2}$

- Instrumentation to adequately monitor the status of each rod to assure its continued integrity. ${ }^{3}$

\subsubsection{Rod Drive Control System}

2.3.2.1 Manual Contro.1 ${ }^{1,4}$

Handswitches on the operating console provide the capability to:

1. Refer to References, Appendix A, Item 3.

2. Refer to References, Appendix A, Item 2.

3. Refer to References, Appendix A, Item 23.

4. Refer to Drawings, Appendix F, SK-3-14325. 
BNWL -500

Volume 33

- Select the drive to be operated.

- Start and stop the drive.

- Determine the direction of the drive.

- Determine the speed of the drive

These handswitches are a spring return type which will stop rod motion when released. The interface between the Flux Monitoring and Control System CSDD and this $\operatorname{CCDD}^{1}$ is the signal to the drive motor. The present concept incorporates a magnetic jack drive for the safety rods and a roller nut drive for the shim/scram and regulator rods. The Flux Monitoring and Control system CSDD provides the pulse generator, direction switching and other circuits required for these types of drives.

In any case the control system and the drive system are compatible. The rod control logic system ${ }^{2}$ of interlocks controls the operational access to the rod drives and prevents improper sequence of events.

\section{$\underline{2.3 .2 .2}$ Automatic Control ${ }^{3}$}

The Flux Monitoring and Control System CSDD provides the capability to switch to an automatic control mode. In this mode one or more regulator rods will be driven to maintain the reactor power level. The feedback loop may be closed on a reactor neutron flux signal, a thermal power signal or a temperature signal. A $\Delta \mathrm{k}$ limiter circuit ${ }^{2}$ prevents excessive rod movement due to a malfunction in the automatic control

1. Refer to Drawings, Appendix F, SK-3-14196.

2. Refer to References, Appendix A, Item 3.

3. Refer to Drawings, Appendix F, SK-3-14325. 
system by switching control mode to manual if the limit is exceeded. The actuation of any manual control switch also transfers control from automatic to manual mode.

$\underline{2.3 .3}$ Rod Position Indications ${ }^{1}$

The position of all rods is monitored and displayed as follows:

- A digital display which shows the rod position in discrete units.

- A qraphic display which shows the relative position of the rods.

Iights also indicate the following:

- Rod-in.

- Rod-out,

- Rod selected for movement.

- Rod in motion.

The accuracy and reproducibility requirements for the rod drive system are included in section 1.0. A study ${ }^{2}$ will determine the accuracy and reproducibility requirements of the rod position indicating system necessary to ensure compliance with these section 1.0 requirements. The rod position sensing and indicating system depends upon the final rod drive systems selected. The sensors will probably be packaged with the rod drive system and could be one or more of the following types:

- Pulse counters monitoring the drive system in the case of stepping motors or magnetic jacks.

1. Refer to References, Appendix A, Item 3.

2. Refer to Support Information Requirements, Appendix B, Item 22 . 
BNWL -500

Volume 33

- A spur gear in the drive train to operate a linear, precision multiturn potentiometer.

- A magnet or actuation finger attached to the side of a gear or other rotating body in the drive train to generate a pulse by means of a magnetic pickup. A pulse counting system monitor position.

- A coil around the top of the extension rod. An inductive follower will indicate position.

- A small radioactive source with a follower system. The calibration of any of these systems can be checked. against the rod limits indication.

\subsubsection{Rod Iimits Indication ${ }^{1}$}

A completely separate system indicates when each rod reaches its full-in or full-out position. These indications will be actuated by devices inseparable from the control element during all modes except prestart. Any couplings in the extension between the rod and the drive system will be monitored to assure immediate detection of any separation during criticality operations.

2.3.5 Protective Instrumentation ${ }^{2,3}$

A manual scram switch is prominently mounted on the operator's board. Its operation causes the irrevocable release of all rods in the safety, shim/scram and regulator systems. The same action is initiated automatically when protective

1. Refer to References, Appendix A, Item 3 .

2. Refer to References, Appendix A, Item 2.

3. Refer to Drawings, Appendix F, SK-3-14189. 
system trip settings are reached. Scram actuator also causes an alarm and is annunciated in the control room. 1

\subsubsection{Rod Instrumentation}

Instrumentation is required to adequately monitor the status of each rod to assure its continued integrity.

Unexpected reactivity increase in the reactor could result from conditions initiated by:

- Poison rod withdrawal or ejection from the core.

- Poison compaction.

- Poison washout or expulsion.

- Rod meltdown.

During shutdown the subcritical reactivity monitor will indicate these increases. ${ }^{2,3}$ The Central Control and Data Handling system CSDD will provide a continuous reactivity balance anomoly detection system whenever the reactor is critical.

The temperature and flow in each poison rod system will be monitored ${ }^{4}$ by thermocouples and flowmeters attached to the instrument tree and projected into the rod instrument probe tube.

\footnotetext{
1. Refer to References, Appendix A, Item 22.

2. Refer to References, Appendix A, Item 3 ,

3. Refer to Support Information Requirements, Appendix B, Item 10 .

4. Refer to References, Appendix A, Item 23.
} 


\section{SECTION 3.0 SAFETY CONSIDERATIONS}

Safety considerations applicable to the design of the Reactor Nuclear dontrol domponents are related to: (a) Capability for adequate and timely control of the neutron chain reaction during all modes of operation with emphasis on detection and prevention of potential fault conditions, (b) Capability for adequate and timely termination of criticality operations upon initiation of some fault condition to mitigate the consequences of that fault within an acceptable level of severity, and (c) Capability for adequately maintaining subcriticality during all shutdown operations with consideration for the tolerances of subcriticality detection and possible fault conditions.

The design of the reactor nuclear control components which are part of the plant protective system must be integrated with the designs of the interfacing subsystems, e.g. instrumentation and logic networks, to fulfill the overall system performance and reliability requirement. Minimum performance is established by the maximum acceptable severity levels corresponding to given accident conditions. Preliminary definitions of the maximum allowable severity levels for various accident conditions have been established for the FFTF. 1

\subsection{HAZARDS}

The potential hazards associated with the reactor nuclear control components are those which potentially may initiate an accident conditions and those which prevent the system 
BNWL -500

Volume 33

from performing its designed function in mitigating the consequences of some accident condition. I specific hazards are outlined as follows (but not to be construed as all inclusive):

\subsubsection{General}

A. Premature structural failure of control or safety elements under accident conditions could prevent mitigation of those conditions to limit core damage within acceptable severity levels.

$B$, Inaccurate indications or failure of position monitoring for each control and safety element could lead to erroneous evaluation of the reactivity status of the reactor and thus contribute to failure of recognition of potentially hazardous conditions.

c. Failure of the decelerator devices on scram could lead to 'pass-through' of the elements and thus an ineffectual scram.

D. Failure of holddown of the elements could result in their uncontrolled movement to more reactive positions.

E. Excessive forces generated under accident conditions and impinging upon the control element support plane could effectively withdraw elements from the core and grossly aggravate the accident.

F. Susceptibility of components in the various reactivitycontrol systems to common environmental conditions could potentially result in simultaneous failure of all such common components.

G. Insufficient monitoring, surveillance, or in-service testing could allow potential failures or faults to be undetected until a more severe condition arises. 


\subsubsection{Operational-Control}

A. Excessive reactivity worth within a single operational control element or pin could lead to accidental reactivity insertions beyond the design values.

B, Insufficient total reactivity worth of the operational control system could result in insufficient shutdown or holddown capability.

C. Expulsion or excessive rate of movement of the operational control elements could initiate a severe accident condition by excessive reactivity insertion.

\subsubsection{Shutdown Safety}

A. Insufficient total reactivity worth of the shutdown safety systems could result in ineffectual protective action under accident conditions or insufficient shutdown or holddown capability.

B. Insufficient response of the shutdown safety systems upon signal of a fault condition could result in excessive damage to the core corresponding to that fault.

C. Recoll or expulsion of any shutdown safety element could aggravate the initial fault condition and result in additional damage.

D. Excessive rates of withdrawal of shutdownn safety elements could result in core damage if criticality occurs during the movement.

E. Failure to detect faults within the shutdown safety systems could result in their failure to function when called upon to do so. 
BNWL -500

Volume 33

\subsection{PRECAUTIONS}

Precautions which are taken to protect against the various hazards described in the foregoing section are described below and correspond to the hazards in 3.1 .

\subsubsection{General}

A. The control and safety elements will be designed to withstand the forces and temperatures generated during accident conditions to assure adequate operation of the control systems up to the point at which core disassembly makes control inconsequential.

B. Accurate and redundant position monitoring will be provided to assure continuous knowledge of the core reactivity status.

c. The design of deceleration depices and structural rigidity of the control and safety elements will assure that adequate protection is provided against 'pass-through'.

D. Redundant features will be designed to assure against uncontrolled movements of elements to more reactive locations. These features will be provided by mechanical rigidity through the drive train and by assurance that the element weight is greater than the potential hydraulic lifting force.

E. The forces generated for accidents ranging in severity up to core disruption will be evaluated and the structural rigidity of the support plane will be designed to limit movement of control elements under the influence of these forces to acceptable values. 
F. Redundancy of shutdown safety reactivity-control will be provided with emphasis upon application of different principles of operation and different components to assure against systematic failure of both systems under common accident conditions.

G. Instrumentation will be provided to monitor the critical parameters for assurance of continuous as-designed system operability. In addition, a surveillance program will be developed to detect potential failures before their occurrence with interruption of operating continuity.

\section{$\underline{3.2 .2}$ Operational-Control}

A. The reactivity-control worth for any control element or pin will be limited to a value which does not result in excessive reactivity insertions with consideration for the various postulated fallure modes.

B. The total reactivity-worth of the operational control system will be established to provide the minimum specified shutdown and holddown capability during all modes of operation.

C. Features will be provided to prevent recoil or expulsion of any operational control element. The drive rates will be limited to assure that the corresponding reactivity insertion rates are within the design values established for the protective system.

\subsubsection{Shutdown Safety}

A. The minimum reactivity worth of each of the shutdown safety systems will be sufficient to shut down the 
reactor with consideration for stuck elements and accidental reactivity insertions. At least one of these systems will be capable of maintaining subcriticality with the above considerations in addition to cool-down of the core to refueling conditions.

B. The design speed of response of the shutdown safety systems will be integrated with the design of the plant protective system to assure mitigation of the accidental conditions within the allowable severity limits.

C. Features will be provided to prevent recoil or expulsion of any shutdown safety element even during the shutdown mode.

D. Design features will be provided which limit the rate of withdrawal, (reactivity addition) of the shutdown safety elements such that damage is limited even if criticality occurs during withdrawal.

E. Design features will be provided to assure immediate detection of fault conditions which would affect the performance of any shutdown safety element. In addition, loss of signal will result in scram in one of the systems. 
BNWL -500

Volume 33

\section{SECTION 4.0 PRINCIPLES OF OPERATION}

\subsection{PRESTART}

During shutdown operation, the prime efforts will be refueling, maintenance, and plant modifications. Fuel handing will require most of the shutdown cycle to complete the required changeout and rotation of driver fuel, as well as removing and installing test assemblies. The refueling sequence will proceed at its own pace and other activities will generally defer to the fuel handling needs. During this period, the following conditions will be maintained:

- The primary flux instrument at this time will be a subcritical neutron monitor (fission chamber) that will have an on scale reading at all times.

- The period circuit will provide an alarm if the period exceeds the shutdown period set point.

- The flux monitoring circuit will provide an alarm if the flux level exceeds the shutdown flux set point.

- The subcritical reactivity will be calculated from the subcritical neutron monitoring signal, and will be displayed for continuous observation by the operator.

- The safety circuit will be tripped (the state which occurs after a reactor scram).

- All nuclear control rods (safety, shim, shim-safety, and regulatory) will be fully inserted.

- The main heat transport systems will be adjusted to maintain the primary and secondary coolant temperatures constant between 350 and $400{ }^{\circ} \mathrm{F}$. 
Since it can be expected that a number of control elements may be withdrawn occasionally during some refueling cycles to calibrate the subcritical reactivity monitor, to assure that the monitor is operational, or to provide a subcritical reactivity check point, the design should emphasize simplicity in the design of the reactor head, machinery dome, and control rod drive mounts so that these actions are not time consuming. This will require the capability and circuitry to withdraw individual poison rods during this interval of time.

The reactor will be preheated by electrical heating on piping and pumping power in the primary loops, in addition to vessel heating by circulating hot gas exterior of the vessel. Electrical immersion heaters may also be employed. Heatup rates for the core will be limited lestimated to be 50 to $100 \mathrm{~F} / \mathrm{hr}$ ) to minimize thermal stresses on fuel and core components. Preheating will continue to the desired startup temperature. This temperature will be the reactor inlet temperature for the next test run (as high as $900{ }^{\circ} \mathrm{F}$ ) in order that a maximum amount of thermal expansion of reactor and systems may take place before control rods are withdrawn.

\subsection{STARTUP}

Before the approach to criticality is made, the values of the important process variables are checked to assure that equipment and instruments are in good operating condition. During this period the plant protection systems are reset to satisfy all interlocks for withdrawing control rods. 
Most of the status checks for interlocks and process variables will be accomplished using computer-programmed sequences to determine that all equipment is in proper condition for operation. Means for performing these checks manually will also be provided.

As the checks proceed, discrepancies will be alarmed and require either operator acknowledgement or correction before the checkout procedure continues. When the entire check has been completed, the check procedure may be rerun, possibly on a limited basis, to assure that no changes have occurred on critical parameters or devices. With all systems information being available in the control room, the digital data handling equipment will provide this service.

The approach to critical will follow the sequence below:

A. The safety rods will be withdrawn singly at a predetermined rate of motion.

B. The rod which will be used during normal operation as the regulating rod will be withdrawn at a predetermined speed to its predetermined initial operating position.

c. The shim-safety rods will be individually withdrawn to their predetermined initial operating positions.

D. The proper number of peripheral shim rods will be individually withdrawn in a predetermined sequence designed to result in a balanced core flux.

E. During the above rod withdrawals, the rod positions and subcritical reactivity (derived from the neutron flux level) will be correlated by a computer program. A significant lack of correlation will be annunciated and the sequence will be halted. 
BNWL -500

Volume 33

F. The withdrawal of the peripheral shims will continue until the desired true period is obtained. This period will be on the order of 30 to 100 sec and will be maintained until the reactor power level is approximately I/2\% of full power (approximately 2 MW).

G. At this point, a peripheral shim rod will be inserted and the power will be stabilized at about $1 \%$ of full power (approximately $4 \mathrm{MW}$ ). A full systems checkout will then be made to determine the readiness for power increase.

During startup, the controlling variables to be observed will be the low level (subcritical) flux and the apparent reactor period until the reactor goes critical. After the reactor goes critical, the intermediate range flux period and level will become the controlling parameters. At the time of transfer from the low level instrumentation to the intermediate range instruments, both instrument sets must have on-scale readings and must agree with each other. At 18 of full power, the linear power range instruments must also be on-scale and in agreement.

\subsection{ASCENT TO POWER}

Following the full systems checkout, the regulating rod is withdrawn to establish a reactor period between 50 and 200 sec. As reactor power increases, the heat transport systems for main and closed test loops will respond to the increased heat by changes in DHX air flow rate in order to dissipate the heat and maintain proper temperatures. As reactor power approaches full power, the period will be increased 
BNWL -500

Volume 33

to limit the magnitude of the power change with time. All reactivity adjustments will be made with the selected regulating rod.

The ascent to power from roughly 1 to $100 \%$ of operating power requires a reactor power increase that does not exceed the limit of either the minimum acceptable period (estimated operational limit at $30 \mathrm{sec}$ ) or the maximum acceptable operational thermal transient (estimated at $100{ }^{\circ} \mathrm{F} / \mathrm{hr}$ for bulk sodium temperature). Within the overall bulk thermal transient, a maximum rate of change will also be specified (estimated at $\pm 30^{\circ} \mathrm{F} / \mathrm{min}$ for the fuel coolant outlet temperature of the initial core), based on the large number of startup-shutdown transients expected over the plant life (estimated at 2000). Period and thermal transient limits will be eevaluated-as-reactor design progresses.

In order to limit the rate of temperature increase, it may be necessary to have holding points (e.g., at 25\% increments of full power). For example, with three heat transport circuits in operation at full flow, the full power conditions for the initial FTR core are $400 \mathrm{MW}_{\mathrm{t}}$ and $300{ }^{\circ} \mathrm{F} \Delta \mathrm{T}$. If full flow is maintained during the rise to power, $3 \mathrm{hr}$ are needed to spread the $\Delta T$ to meet a thermal transient limit of $100 \mathrm{~d} / \mathrm{hr}$ at the core outlet. Since the power would be increased from $4 \mathrm{MW}_{\mathrm{t}}$ to $400 \mathrm{MW}_{\mathrm{t}}$ in $15 \mathrm{~min}$ while on a $200-\mathrm{sec}$ period, holding points appear to be needed unless thermal transient limits are relaxed.

Initially, the approach to power will be performed manually. However, provision should be made for automatic rise to power based on preprogrammed power and flow control. 


\subsection{AT-POWER OPERATION}

While at power, a single regulating rod will continually be positioned to maintain the reactor at the desired power level. Neutron flux will be controlled to within a specified deadband (estimated at $\pm 2 \%$ maximum) about the mean level, to achieve testing flux goals, and to provide ease of control for the entire heat transport system. Larger variations will not be desirable because of the resulting temperature variations and their effects on coolant flow control. Linear power range flux instrumentation, entirely apart from the protective instrumentation, will provide the feedback for this control loop. Automatic flux control will be provided as well as manual control, with manual control having priority (i.e., the operator may switch to manual at any time).

Neutron flux for any test loop is not expected to vary more than $\pm 15 \%$ from the testing goal during the operating cycle. These are long-term local variations, due to burnup and the resulting control repositioning, as contrasted to oscillatory behavior of the average reactor flux about a mean value. Neutron flux may be changed at a test location by multiple control rod position adjustments. Although such rod positionings have a limited effect on the flux at adjacent lattice positions (estimated at 5 to 10 s change for a rod full-in to full-out for the FTR), the effect is sufficiently strong to be considered in the design stage. Since the regulating rod should not be fully withdrawn, the resultant need is for regulating ability on each shim control rod, as opposed to choosing a single rod for exclusive regulating duty. 
As fuel burns up, the regulating rod must be further withdrawn to maintain criticality. When the regulating rod approaches its upper operating elevation limit, a shim rod will be raised in order to allow the regulating rod to be returned to the lower elevation part of its operating range. The desired operating range for the regulating rod is estimated to be between 20 to $80 \%$ withdrawn, based on limits at one-half the peak differential rod worth. Any of the incore or peripheral shim rods may be used as the regulating rod.

As an additional operator aid, reactivity changes with respect to a reference core condition will be continuously computed from the appropriate temperatures, flows, and power, and compared to that computed from control rod positions with respect to reference rod positions. Deviations between the two values will be alarmed so that the operator may be made aware of reactivity anomalies (e.g., shifting of fuel).

4.5 NORMAL SHUTDOWN

The reactor is shut down to replace fuel, to reposition fuel, to replace or check experiments, to replace poison rods, or to perform schedules or emergency maintenance. Normally, the power level is reduced to about $1 \%$ of full neutron power. The reactor may then be scrammed as a check on the safety system, with minimal thermal transients.

The shutdown sequence will be roughly the reverse of the rise-to-power procedure. Holding points in the power descent 
BNWL -500

Volume 33

may again be prescribed to ease thermal stresses. The shutdown sequence will normally proceed according to a programmed plan and any variations from expected limits will be alarmed and displayed. Flux instrumentation will be phased from the power range to the intermediate range monitors.

\subsection{EMERGENCY SHUTDOWN}

When the reactor and process systems are performing normally at power, a wide class of system perturbations (e.g., air inlet temperature, pump voltages) will be handled adequately by the normal reactor and plant control systems. Those incidents involving malfunctions or loss of components, however, will require more drastic action to prevent possible escalation of damage. Two types of power reductions will be available: (1) Controlled Power Reduction, which will reduce reactor power in response to selected abnormal conditions when the normal control systems are unable to react, and (2) Plant protection, which will scram the reactor in response to any serious abnormal condition or in the event that the normal control or Controlled Power Reduction Instrumentation fails to act.

\subsubsection{Controlled Power Reduction Instrumentation}

Instrumentation will be provided to detect any abnomal situations which might arise during operation of the facility. The philosophy governing the use of $\mathrm{CPR}$ instrumentation is outlined in the Plant Operation and Control Document. 1

1. Refer to References, Appendix A, Item 1. 


\section{$\underline{4.6 .2 \text { Scram }}$}

A safety circuit trip signal or loss of safety circuit continuity causes all scramable rods to be released into the core simultaneously, the six in-core rods by spring assist insertion and the fifteen peripheral rods by gravity insertion.

\subsection{SPECIAL OR INFREQUENT OPERATION}

The Reactor Nuclear Control System may be operated under special procedures duxing the following circumstances:

- calibration

- rod drop tests

- flux mapping

- physics tests

- initial loading to criticality.

Whenever unusual operating conditions are planned, deviatıons from normal parameters will be specified in detail and examined for safety implications. All departures from normal operating procedures must be within the Technical Specifications as defined in the Final Safety Analysis Report. 
BNWL -500

Volume 33

\section{SECTION 5.0 MAINTENANCE PRINCIPLES}

The reactor control components will be periodically checked to determine their condition, behavior and life expectancy. The poison rods and guide tubes will be replaced periodically as they are exposed to a high neutron flux. These poison rods and guide tubes will be changed out during refueling operations by the In-Vessel Fuel Handling Machine. They will be transported to Radioactive Maintenance or Examination by the Irradiated Fuel Handling System. ${ }^{1}$ A threebarrel radioactive maintenance machine ${ }^{2}$ will remove the extension rods, ${ }^{3}$ transport them to an examination, ${ }^{4}$ repair or disposal facility ${ }^{2}$ and place replacement extension rods back into the reactor. ${ }^{5}$ Control components above the reactor cover will be removed, repaired and stored by contact maintenance modes to facilitate refueling and repair procedures to allow convenient reuse of the units.

A seal plug 5-3/4 in. in diameter is provided in the reactor cover plug to be used in the removal of the intermediate and main shaft assemblies for replacement or maintenance. The plug also forms the seal for the rod unit and the cover. Seal replacement is accomplished by removal of the plug with the attached seal to the radioactive repair shop. The intermediate shaft can also be removed and repaired in a like manner. A sealed transport cask is required for removal of either of the components.

1. Refer to Interfaces, Appendix C, Item 11.

2. Refer to Interfaces, Appendix C, Item 12.

3. Refer to Drawings, Appendix F, SK-3-14558, SK-3-14559.

4. Refer to Interfaces, Appendix C, Item 13.

5. Refer to Support Information Requirements, Appendix B, Item 12 . 
Removal of the main shaft can be accomplished without removal of the large rotating refueling plug by rotating the instrument tree into its operating position and the shaft removed through the red plug opening. A second cover plug located beneath the seal plug will be removed along with the main shaft by contact with the lifting collar when the shaft is removed. The lower plug is stepped for shielding purposes.

All control components received from off site will be handled and stored prior to use by the Non-Irradiated Fuel Handing system.

As presently conceived each of the control rod drives and the attendant power, control, and purge jumpers must be periodically removed, and reinstalled. The time in which the removal and reinstallation can be done will have a material effect on FFTF availability and, therefore, the testing capabilities of the entire facility.

Conceptual design does not permit a detailed review of potential maintenance problems, but these problems can be alleviated regardless of final design by focusing attention in areas which will increase individual accessibility, maintainability, replaceability and in place and test stand testing and calibration capability.

Maintenance time and outage time can be reduced by providing proper storage facilities as close to the top face as practical.

Special design attention must therefore be focused in these areas: 
A. Ease and rapidity of component removal - Breech lock fittings and high quality quick disconnects should be used wherever possible.

1. Jumpers

2. Control Rod Drive Mechanisms

3. Hanger Rods

4. Plug

B. Adequate top face sealing capability and ease of seal replacement by either contact or remote means as design considerations dictate.

C. Safe storage and shielded storage (where required) for all control rod components and plugs, including required spares.

1. Control Rod Drive Mechanisms

2. Power, Control and purge jumpers

3. Seal Plugs

4. Hanger Rods

The storage facility must be such that components will not be damaged during storage and that the units can be reached for required maintenance either contact or remote.

D. Control and limit switches must be accessible for each rod when it is in place so that individual rods (21 are proposed), may be calibrated without removal of adjacent installed top face equipment.

E. Each set of jumpers must be capable of being removed without interference from other top face equipment.

F. Special tooling in the form of yokes, impact wrenches. etc., will be required if rapid removal and maintenance of the drivers and associated components is to be accomplished. Special attention to their design and storage must be made. 
BNWL -500

Volume 33

G. The nuclear control system may have a different drive mechanism for control rod than that for the safety rods. The difference must be readily recognized to prevent inadvertent interchange.

H. Special design attention must be given to areas requiring remote handling. Transfer casks, hoists, etc., must either have adequate redundancy or extremely high reliability and ease of maintenance, and must interface with all required component exit or entry points.

I. As a goal, the poison element and associated equipment must be designed for total replacement (Removal and reinstallation in one hour per unit.)

J. All components must be stout enough to withstand the normal rigors of rapid remote or semi-remote removal and replacement without loss of preset calibration.

K. Design must include required portable special scaffolding for access to the jumper and Iimit switch areas of the control rod mechanisms. Storage areas for the scaffolding must be denoted on the preliminary sketches.

L. Protection must be afforded for the ends of electric jumpers and fixed electrical connectors.

M. A test stand near the storage rack for calibration and limit switch check must be provided.

N. When pneumatic systems are used, special coal must be made to assure that the gas supply carries no oil or water.

o. The poison section and fuel element should require the same grapples with interlocks to distinguish between driver and poison elements.

P. Hanger rod removal must interface with casks, ports and floor valves required for general radioactive maintenance, 
Q. Storage for irradiated hanger rods must be provided in the Radioactive Maintenance area or some other suitable area for periods of reactor outage.

R. Control rod services, power, control, or purge must not penetrate the Machinery Dome or any above floor level extension of the dome.

S. Control rod components including power, control, and purge jumpers should have a high degree of interchangeability to reduce the spare parts inventory to a minimum. 
BNWL -500

Volume 33

APPENDIX A

REFERENCES 


\section{REFERENCES}

I. A. I. Gunby, C. I. Fies, G. G. Thieme, Plant Operation and Control, BNWL-1023, Battelle-Northwest, Richland, Washington, January 9, 1969.

2. J. P. Thomas, Plant Protection System, No. 99, A-0101-R, Battelle-Northwest, Richland, Washington.

3. I. W. McClellan and R. R. Cone, Flux Monitoring and Control System, No. 95, A-0056-R, Battelle-Northwest, Richland, Washington.

4. F. W. Fox, Computer Program "Scram", Battelle-Northwest, Richland, washington. (Unpublished)

5. A. Padilla, Jr., W. W. Little, Jr., D. W. Mahagin and W. L. Bunch, Selection of Control Rod Poison for the FTR, BNWL-899, Battelle-Northwest, Richland, Washington, October 1968 .

6. Design Safety Criteria for the Fast Flux Test Facility, BNWL-823, Battelle-Northwest, Richland, Washington, June 17, 1968.

7. Letter, A. Padilla to D. E. Mahagin, "Selection of Control Rod Poison for Concept 5A," December 23, 1968.

8. C. C. Steele, Overall Conceptual Systems Design Description, BNWL-500, vol. 1, Battelle-Northwest, Richland, Washington, July 7, 1967.

9. G. R. Waymire, Conceptual System Design Description for the Reactor Core, No. 31, BNWL-500 vol. 31 BattelleNorthwest, Richland, Washington. August 27, 1969.

10. S. H. Hanaver and C. S. Walker, Design Principles of Reactor Protection Instrumentation Systems, ORNL-NS16-51, September 1968.

11. Letter, M. Shaw to D. G. Williams, FFTF Program Direction, Attachment B, Item 2.a. (1), January 23, 1966. (Unpublished)

12. Memorandum, W. W. Little, Jr., to J. D. Herb, Scram Deceleration Distance, December 6, 1967. (Unpublished)

13. Memorandum, C. A. Munro to J. D. Herb, Scram Deceleration Distance, December 6, 1967. (Unpublished) 
BNWL -500

Volume 33

14. Memorandum, J. C. Noakes to J. D. Herb, Deceleration Device for Scrammable Rods, December 29, 1967. (Unpublished)

15. J. C. Noakes, Selection of Concepts for FFTF Control and Safety Rod Drive, BNWL-1126, Battelle-Northwest, Richland, Washington. June 27, 1969.

16. Memorandum, J. W. Helm to I. M, Finch, System 33, Nuclear Controls Design Requirement Decision 33-15 Determine Candidate Neutron Poison Materials, Battelle-Northwest, Richland, Washington, August 28, 1967. (Unpublished)

17. R. W. Campbe11, S. G. Carpenter, Reactivity Worths of Several Fast Reactor Control Materials, NAA-SR-11368, Atomics International, July 25, 1965.

18. C. L. Fies, "FFTF Scram System Response Requirements, and Parametric Analysis," BNWL-1226 FF, Battelle-Northwest, Richland, Washington.

19. H. J. Paas, Radiological Design Criteria, BNWL-MA-3, Battelle-Northwest, Richland, Washington, March 1965.

20. P. W. Secrist and A. J. Fiorelli, Component Examination Program on PWR Core 1 Control Drive Mechanisms, WAPD-3I1, Bettis Atomic Power Laboratory, January 1967.

21. D. L. Dill et al., FFTF Control Rod Drive Mechanism Continuation Study (Task 13), AEC Contract AT(30-1)3977, Westinghouse Electric Corporation, December 1968.

22. G. I. Waldkoetter, G. G. Thieme, Central Control and Data Handling System, No. 91, A-0059-R, BattelleNorthwest, Richland, Washington. (To be issued)

23. W. Dalos, Reactor and Vessel Instrumentation System No. 92, A-0052-R, Battelle-Northwest, Richland, Washington. (To be issued)

24. D. P. Schively, Conceptual Component Design Description for the Reactor Vessel and Shield Component No. 32, BNWL-500 vol. 32, Battelle-Northwest, Richland, Washington, April 24, 1969.

25. D. E. Simpson et al., Preliminary Analysis of Postulated Maximum Accidents for the FFTF, BNWL-760, BattelleNorthwest, Richland, Washington, November 1968. 
BNWL -500

Volume 33

26. W. F. Albert, Design and Development Quality Assurance Requirements for the FFTF, BNWL-510, Battelle-Northwest, Richland, Washington, October 1968.

27. J. C. Noakes, Survey of Control Rod Drive Mechanisms for Application to the FFTF, BNWL-973, Battelle-Northwest, Richland, Washington, February 1969.

28. W. W. Little, Nuclear Parameters and Parametric Studies, BNWL-1067, Battelle-Northwest, Richland, Washington. May 8, 1969.

29. E. Hutter, Sulilivan and Giorgis, FARET Control Rod Drive Mechanism, ANL-7158, Argonne National Laboratory, June 1968 .

30. Letter, A. Selz (Westinghouse) to W. B. McDonald (BattelleNorthwest), Outline of Reactor Safety System Independence Study, W-69123, February 26, 1969. (Unpublished)

31. Letter, W. B. McDonald (Battelle-Northwest) to D. C. Spencer (Westinghouse), Continuation of Westinghouse Conceptual Design Work, Attachment II, BNW/FFTF-69129, January $17,1969$.

32. A. F. Lillie, FTR Fuel and core Parameter studies, Battelle-Northwest, Richland, Washington, April 1969.

33. R. V. Dulin, Instructions for Design Description Preparation, BNWL-592, Battelle-Northwest, Richland, Washington, October 1967.

34. F. W. Fox, Computer Program "Plenum", Battelle-Northwest, Richland, washington. (Unpublished)

35. J. R. Sheff, Justification and Specification of an FTR Oscillator. Battelle+Northwest, Richland, Washington. (To be issued)

36. P. K. Telford, Design Survey and Conceptual Definition of a Reactivity Oscillator for the Fast Test Reactor, BNWL-1036, Battelle-Northwest, Richland, Washington. 
BNWL -500

Volume 33

37. G. Edison, Evaluation of Need for an FTR Oscillator System, WARD-FRP-40, November 27, 1968, Westinghouse Electric Corp., Pittsburgh, Pennsylvania.

38. J. W. Hagan et al., Parametric Scram Transient Analyses for the FFTF FTR, BNWL-657, Battelle-Northwest, Richland, Washington, November 1967.

39. J. R. Samuel et al., Seismic Design Criteria, A-0078, Battelle-Northwest, Richland, Washington. (To be issued) 
BNWL -500

Volume 33

APPENDIX B

SUPPORT INFORMATION REQUIREMENTS 
APPENDIX B

SUPPORT INFORMATION REQUIREMENTS

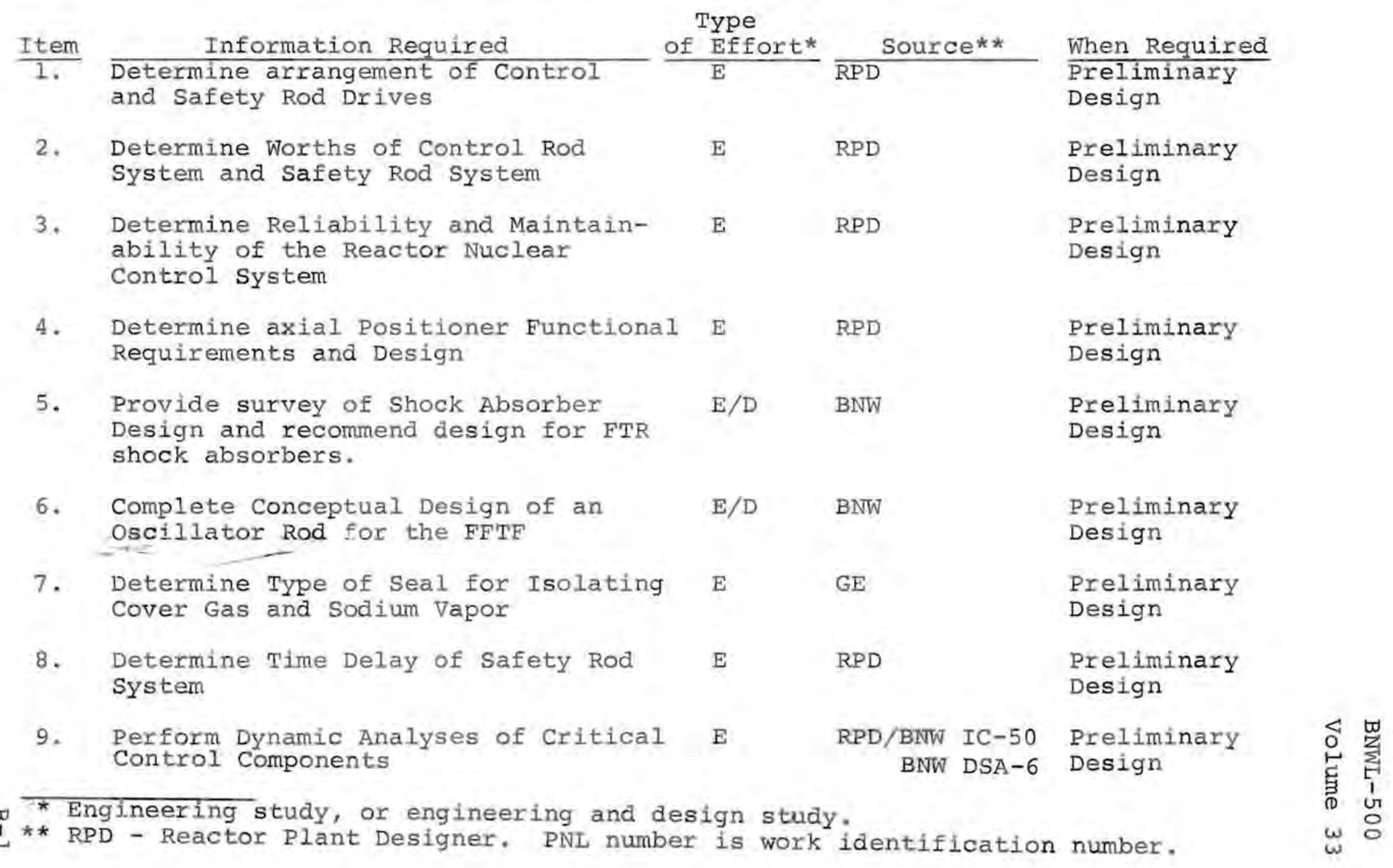




\section{APPENDIX B \\ SUPPORT INFORMATION REQUIREMENTS}

\begin{tabular}{|c|c|c|c|c|}
\hline Item & Information Required & $\begin{array}{l}\text { Type } \\
\text { Effort* }\end{array}$ & Source** & When Required \\
\hline$\overline{10 .}$ & $\begin{array}{l}\text { Determine Method of Assuring } \\
\text { ghutdown During Refueling }\end{array}$ & $\mathrm{E}$ & $\overline{\mathrm{RPD}} / \overline{\mathrm{BNW}}$ & $\begin{array}{l}\text { Preliminary } \\
\text { Design }\end{array}$ \\
\hline 11. & $\begin{array}{l}\text { Determine Design Expulsion Force } \\
\text { on Poison Rods }\end{array}$ & $\mathrm{E}$ & $\mathrm{RPD} / \mathrm{BNW}-\mathrm{RS}-3$ & $\begin{array}{l}\text { Preliminary } \\
\text { Design }\end{array}$ \\
\hline 12. & $\begin{array}{l}\text { Determine the Types of Extension } \\
\text { Rods for Control Rods \& Safety Rods }\end{array}$ & $\mathrm{E}$ & RPD & $\begin{array}{l}\text { Preliminary } \\
\text { Design }\end{array}$ \\
\hline 3. & $\begin{array}{l}\text { Determine Types of Rod Position } \\
\text { Sensing Devices }\end{array}$ & $\mathrm{E}$ & RPD & $\begin{array}{l}\text { Preliminary } \\
\text { Design }\end{array}$ \\
\hline 4. & $\begin{array}{l}\text { Develop a Device to Prevent the } \\
\text { Accidental Expulsion of Scram Rods }\end{array}$ & $\mathrm{E}$ & $\mathrm{BNW}-\mathrm{RS}-3$ & $\begin{array}{l}\text { Preliminary } \\
\text { Design }\end{array}$ \\
\hline 5. & $\begin{array}{l}\text { Provide Burnup Data for } \mathrm{B}_{4} \mathrm{C} \\
\text { Irradiated in Thermal Reactor }\end{array}$ & & $\mathrm{BNW}$ & $\begin{array}{l}\text { Preliminary } \\
\text { Design }\end{array}$ \\
\hline 16. & $\begin{array}{l}\text { Provide Burnup Data for } \mathrm{B}_{4} \mathrm{C} \\
\text { Irradiated in Fast Reactor }\end{array}$ & & $\mathrm{BNW}$ & $\begin{array}{l}\text { Preliminary } \\
\text { Design }\end{array}$ \\
\hline 17. & $\begin{array}{l}\text { Provide Burnup Data for Prototypic } \\
\text { Poison Segment }\end{array}$ & & $\mathrm{BNW}$ & $\begin{array}{l}\text { Preliminary } \\
\text { Design }\end{array}$ \\
\hline 8. & $\begin{array}{l}\text { Provide Data for Operation of } \\
\text { Commercial Roller Nut Drive } \\
\text { Mechanism in Sodium Environment }\end{array}$ & & BNW & $\begin{array}{l}\text { Preliminary } \\
\text { Design }\end{array}$ \\
\hline
\end{tabular}

* Engineering study, or engineering and design study.

** RPD - Reactor Plant Designer. PNL number is work identification number. 


ORMATION REQUIREMENTS \\ SUPPORT INEORMATION REQUIREMENTS}

\begin{tabular}{|c|c|c|c|c|}
\hline Item & Information Required & of Effort* & Source** & When Required \\
\hline 19. & $\begin{array}{l}\text { Provide Prototype Design of } \\
\text { Drive Mechanisms }\end{array}$ & & TBD & $\begin{array}{l}\text { Preliminary } \\
\text { Design }\end{array}$ \\
\hline 20. & $\begin{array}{l}\text { Provide Prototypic Drive } \\
\text { Mechanism Test Information }\end{array}$ & & BNW & $\begin{array}{l}\text { Preliminary } \\
\text { Design }\end{array}$ \\
\hline 21. & $\begin{array}{l}\text { Determine Oscillator Reactivity } \\
\text { Section Iife Requirements Based } \\
\text { on FFTF Test Requirements }\end{array}$ & & TBD & $\begin{array}{l}\text { Preliminary } \\
\text { Design }\end{array}$ \\
\hline 22. & $\begin{array}{l}\text { Determine Accuracy and Repro- } \\
\text { ducibility Requirements of } \\
\text { Control Component Sensors }\end{array}$ & E & RPD & $\begin{array}{l}\text { Preliminary } \\
\text { Design }\end{array}$ \\
\hline
\end{tabular}

\footnotetext{
*Engineering study, or engineering and design study.

**RPD - Reactor Plant Designer. PNL number is work identification number.
} 
BNWL -500

Volume 33

APPENDIX C

INTERFACES 
APPENDIX C

INTERFACES

\begin{tabular}{|c|c|c|c|}
\hline & Service & No. & System Title \\
\hline 1. & Electrical Power & 12 & Building Electrical Powe \\
\hline 2. & Alarms & 15 & Communications \\
\hline 3. & Building Layout & 21 & Structures \\
\hline 4. & Cool Drives & 23 & Service Piping \\
\hline 5. & Cooling & 25 & Heating and Ventilating \\
\hline 6. & Fire Control & 26 & $\begin{array}{l}\text { Plant Fire Protection } \\
\text { System }\end{array}$ \\
\hline 7. & $\begin{array}{l}\text { Reactor Cover } \\
\text { Closures }\end{array}$ & 27 & $\begin{array}{l}\text { Reactor Containment } \\
\text { System }\end{array}$ \\
\hline 8. & Core Design & 31 & Reactor Core \\
\hline 9. & Component Support & 32 & $\begin{array}{l}\text { Reactor Vessel and } \\
\text { Shielding }\end{array}$ \\
\hline
\end{tabular}

Interface
Normal and emergency
electrical supply
Sensors and wiring
Space requirements for
replacement of components
Cooling lines and coolant
Heating load of drive
mechanisms in machinery
dome
Electrical fire suppres-
sion equipment
Top plug design
Component configuration,
core restraint, control
requirements
Component configuration,
vessel plug design, slp-
port grid plates




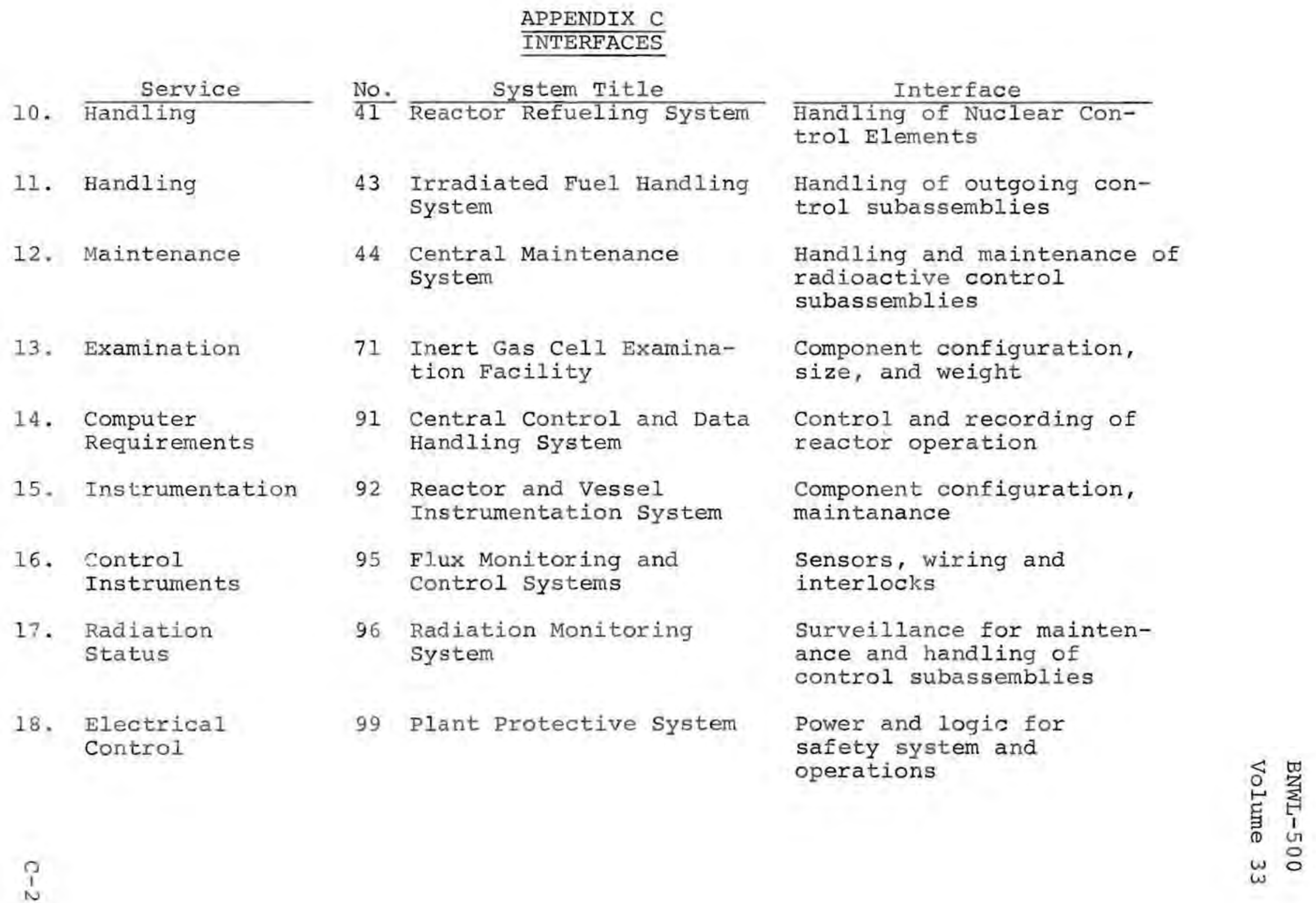


BNWL -500

Volume 33

APPENDIX D

GLOSSARY OF TERMS 
APPENDIX D

GLOSSARY OF TERMS

1. Accuracy

2. Control Functions

3. Control Rod

4. Criticality

5. In-service Rod

6. Precision
Conformity to a true value.

Those corrective actions which are performed only by Nuclear Control System equipment and consist of:

- Startup

- Steady-state operation

- Power level changes for tests

- Flux skewing

- Power setback (not resulting in shutdown)

- Normal shutdown (may be interrupted by operator)

- Fast shutdown (noninterruptable, except for scram, programmed shutdown)

A shim rod with a scram feature, and a shim rod without a scram feature, and a regulating rod without a scram feature.

Condition of a sustained (steady state) nuclear chain reaction. $k_{\text {eff }}=1$ (exactly)

A rod that meets all functional requirements during a given operating period and is used to perform those functions during that period.

Degree of refinement. The value, 9.28 , is more precise than 9.2 but is not necessarily more accurate. 
7. Reactivity

8. Regulation

9. Reproducibility

10. Safety Functions

11. Primary Safety Rods

12. Scram

13. Shall

14. Shimming

15. Will

16. Worth

17. Anticipated Fault
A measure of departure from criticality. plus values are super-critical, zero is just critical, and minus values are subcritical. The conversion factor for one dollar of reactivity (1\$) is approximately $0.31 \%$ SK of the FFTF first core.

Fine and Frequent adjustment of reactivity. The word "operating" is similar but "regulating" is preferred.

The degree of ability to return a part to a previous position.

Those corrective actions which are performed only by nuclear safety system equipment and consist of actuation (trip) of the safety system and the scram of the related poison rods.

A reactivity control device with a scram feature. It does not have shim or regulating functions.

Reactor shutdown performed by decreasing reactivity at a maximum rate.

Mandatory

Coarse and infrequent adjustment of reactivity.

Not mandatory

The amount of reactivity change due to placing a specific part or amount of material in a certain place in the reactor core.

An off-normal condition which may be expected to occur once or more during the plant lifetime. 
18. Operational Incident An occurrence for which no damage occurs to any component unless failure of the component constitutes the "Anticipated Fault".

19. Unlikely Fault

20. Minor accident

21. Major Faults

22. Disruptive Accident

23. Instrument Tree

24. Deceleration
An off-normal condition which is not expected to occur during the plant lifetime.

An occurrence for which damage to designed replaceable components will be no greater than loss of effective lifetime and damage to permanent or semipermanent components will be such that the effective lifetime is not reduced below its design value with consideration for the expected frequency of such occurrences.

An occurrence for which damage will require replacement of replaceable and semi-permanent components or systems and may require replacement, or at minimum extensive inspection, of permanent components prior to resumption of operation of the facility.

An occurrence which will not require recovery and resumption of operations, with the Design Basis Accident representing upper boundary for safety.

An instrument supporting and positioning device within the reactor vessel serving as a secondary holddown mechanism and control rod extension support mechanism.

A device positioned in the control rod drive mechanism which exerts a constant braking effect on the control rod and poison at the end of the scram stroke. 
25. Prestart

26. Routine.

27. Secondary Safety Rod

28. Protection Function

29. Protection System

30. Protection Action

31. At or Near Critical
The non-operating period of the reactor from the time of complete rod insertion to the time the safety circuit is made up for startup.

A repeatable occurrence that is part of a cyclic pattern as opposed to an occurrence for which special preparation, tooling, etc., must be initiated with the intention that it will not be required again.

Commonplace. of, or relating to, or in accordance with, established procedure (Webster). Applies to those operations or functions that do not require special actions or procedures and are regularly accomplished in the course of normal operations or maintenance.

A reactivity control device with scram features. It may have shim or regulating capabilities.

The monitoring of one or more variables and/or conditions and the initiation of protective action(s) in accordance with the Design Basis.

All sensors, instruments, power supplies, bistables, logic elements, and final control device actuators required to fully implement the protective Functions required by the Design Basis.

An action initiated by the Protection System (e.g., reactor scram, containment isolation, etc.).

The approach to reactor criticality while withdrawing operational control elements or, at power. 
APPENDIX E

DESIGN BASIS - REACTOR CONTROL SYSTEM

E-1.0 GENERAL REQUIREMENTS

E-2.0 DRIVE MECHANISM REQUIREMENTS

E-3.0 POISON SUBASSEMBLY REQUIREMENTS

E-4.0 OSCILLATOR ROD 
BNWL -500

Volume 33

\section{DESIGN BASIS FOR REACTOR CONTROL}

The design rationale listed in this document provides the design basis for support of the design requirements listed in Sections 1.2.1.1, General Requirements; 1.2.1.2, Drive Mechanism Requirements; 1.2.1.3, Poison Subassembly Requirements and 1.3.1 Design Requirements-FTR Oscillator, of the Conceptual Component Design Description for the Reactor Nuclear Control Components.

The design bases are directly correlated with the Design Requirements of the CCDD. They carry the same alphabetical letter designation listed in the CCDD although the numerical heading designation is different.

E-1.0 GENERAL REQUIREMENTS (Section 1.2.1.1)

A. Accurate evaluation of the reactivity status of the operational control system is required to (a) verify that the response and operation of the reactor are continuing normally and anomalies which affect reactivity have not occurred, and (b) verify that the minimum required shutdown capability is maintained per paragraph 1.2.1.3D.

Position accuracy of the reactivity-control elements is with respect to the core axial midplane. Since the core is located from the lower tubesheet, which in turn is located by the support structure and vessel, whereas the reactivity-control elements are located from the support structure attached to the upper head, accuracy is dependent upon relative thermal movements of the respective support planes. Reproducibility refers to the capability of repeating positioning of the element at some 
BNWL -500

Volume 33

given position and includes tolerance associated with approaching from either direction. Assuming an element worth of $28 \mathrm{~s} \delta / \mathrm{k}(\sim 6 \$)$ and four elements at different positions in the core, the accuracy and reproducibility are, in terms of inches per element:

$\begin{array}{ll}\text { Accuracy } & \pm 0.15 \mathrm{in} . \\ \text { Reproducibility } & \pm 0.07 \mathrm{in.}\end{array}$

B. This requirement is similar to Requirement $A$ but more relaxed since the elements will remain stationary (except for effective thermally and mechanically induced deflections) during all criticality operations in a relatively low reactivity worth region. The requirement for reproducibility is to reduce the total integrated effect of variations upon the reactivity evaluation defined in the basis of $\mathrm{A}$. These requirements do not apply during withdrawal of the elements upon approach to criticality.

C. Again the accuracy and reproducibility tolerances assume that the safety elements are in their most reactive positions and stationary during criticality operations. If a common system is incorporated for both the secondary shutdown safety function and the operational control function then the more stringent requirements of Requirement $A$ apply.

D. Either shutdown safety system, primary or secondary, may be combined with the operational-control system provided the reserve worth available for scram action meets the total control and speed-of-control requirements specified for the shutdown safety function alone. The two shutdown safety systems cannot be combined since the requirement for independence of the systems would be violated. 
The minimum reactivity worth of a single system which will perform the functional requirements of both operational-control and shutdown safety will be such that under all anticipated operating conditions, the minimum reactivity-control worth potentially available for performing the shutdown safety action will equal the required minimum worth for the shutdown safety system alone as defined in the requirements for that shutdown system. Application of the criteria in defining the minimum worths for a single system which performs both control and shutdown safety functions is further clarified by the examples in Section 2.2.4 of the description.

E. Protection of the public, plant personnel, and equipment requires that the protective system mitigate the consequences of possible fault conditions within acceptable damage regions consistent with the severity of the initiating fault. The primary shutdown safety system as part of the FTR protective system provides for rapid termination of criticality operations under signal that out-of-limits conditions exist, The speed-of-control (time response) and total control requirements for this system must be integrated with the failure mode analyses and plant safety philosophy ${ }^{1}$ for determination of the potential reactivity insertion rates and maximum allowable severities.

F. The secondary shutdown safety system may be designed to operate simultaneously with the primary shutdown safety system upon any scram signal or it may operate only upon

1. Refer to References, Appendix A, Item I8。 
BNWL -500

Volume 33

signal of failure of the primary system. This would depend upon the type of secondary system proposed; for example, a rod-type system could be scrammed each time with the primary to assure its rapid insertion. Speedof-control is required for the secondary shutdown safety system, although not necessarily with identical requirements to that of the primary system.

Independence of this system relative to the primary system is fulfilled if any single fault cannot result in simultaneous disability of both to perform as designed.

G. The accident severity criteria specify that damage will be limited as follows:

1. Power transients initiated by an "Anticipated Fault" will be terminated such that:

- No fuel damage results when the trip is actuated by primary protective action.

- No more than "Gross Damage" to fuel results when the trip is actuated by backup protective action.

2. Power transients Initiated by a single "Unlikely Fault" will be terminated such that:

- No more than "Moderate Damage" to fuel results when the trip is actuated by primary protective action.

- No more than "Gross Damage" to fuel results when the trip is actuated by backup protective action. Preliminary investigation of the relationships between the relevant design parameters of the protective system; e.g., trip time, release time, 
BNWL -500

Volume 33

acceleration rate, total worth, have been evaluated ${ }^{1}$ to determine critical protective system characteristics and the design ramp reactivity rate for terminations with no fuel damage.

Primary and backup protective actions are defined in the Criteria for Accident Severity Levels - FTR Reactor Systems. ${ }^{2}$

H. The speed-of-response requirement for the secondary shutdown safety system is not as stringent as that for the primary system since failure of the primary must occur simultaneously with the fault before the secondary system is required for shutdown. Under these conditions, the corrective action would be considered backup protective action. The accident severity criteria specify that damage for either an "Anticipated Fault" or "Unlikely Fault" will be limited under these conditions to no more than "Gross Damage" to fuel.

I. To maintain operability during abnormal conditions, the design must consider:

1. Loss of cooling flow to any element.

2. Maximum guide tube distortion due to abnormal core movement caused by thermal gradients, pressure forces, and external acceleration such as seismic activity of the design basis earthquake, ${ }^{3}$

3. Pressure and shock effects caused by anomalous sodium conditions.

1. Refer to References, Appendix A, Item 38.

2. Refer to References, Appendix A, Item 19,

3. Refer to References, Appendix A, Item 39 
BNWL -500

Volume 33

Loss of structural integrity of any operational control elements partially or fully inserted in the reactor could initiate a power transient by reactivity insertion through loss of control material from the core. This could occur by movement of the entire element and its structure or by ejection of the control material from within its structural assembly.

Structural fallure of the safety elements would not initiate a power transient under similar operating conditions since these elements are in a low worth region above the core. However, failure of the elements could result in the safety system not functioning properly when required. The control and safety elements must be designed to fulfill their total control and speedof-control functions independently for any accidental occurrence up to the threshold of a core "Disruptive Accident."

Although the elements may be damaged or be inoperable from their full-in position after the accident, sufficient structural integrity is required to assure that the functional requirements of the scram are fulfilled.

J. Under normal scram conditions, the elements will be decelerated over not more than the bottom $25 \%$ of the core height to minimize the impact at the bottom of its travel and prevent damage to either the element or guide tube. It is required that this be backed up mechanically by some feature to prevent pass-through of the elements out the bottom of the core, even in the 
BNWL -500

Volume 33

unlikely case of mechanical failure of the decelerator device. Because of the greater impact forces upon failure of the decelerator, future operation of that element may be hindered, but it is required that the control element remain in its most effective position until appropriate repairs can be made.

K. Direct control of the element position and its movement must be provided to the operator in the control room. Since the control signal operates only on the drive, it is required that the element and drive be rigidy coupled to prevent oscillation or inaccurate movement of the element relative to the drive to enhance overall system stability as defined in Criterion I.1 of the Design Safety Criteria for the Reactor Component.

For elements which scram, this coupling may be interrupted temporarily upon receipt of a scram signal to allow rapid insertion of the element by minimizing its inertial resistance. However, means must be provided to prevent recoil or expulsion during scram.

L. Failure of flow orifices, sodium vaporization due to coolant flow blockages, or penetration of the guide tube from pressure anomalies in adjacent assemblies could possibly provide expulsive forces upon the operational-control or shutdown safety elements. The severity of power transients associated with expulsion of operational-control elements during operation or shutdown 
safety elements following scram emphasizes the design requirement to prevent expulsion by positive means.

M. Reliable operation of the reactivity-control systems is highly important for safety of the plant and protection of the public health and safety. However, testing of the components under truly prototypic conditions will not be possible until operation within the FTR. Therefore, a detalled program of surveillance is required to assure continual performance above the minimum acceptable standards. In addition, a program of in-service testing is required to assure against deactivation of a system elements within that system or loss of signal without alarm so that immediate corrective action may be taken.

N. Accurate and timely knowledge of the reactivity status of the reactivity-control systems is required for detection of reactivity anomalies which could lead to potential sources of reactivity at or near criticality and for assurance that sufficient control is always available to overcome accidental sources of reactivity. After initial calibration of the elements, evaluation of the reactivity status of the reactivity-control systems is dependent upon the element positions relative to the core.

During operations, except when the reactor is in shutdown condition, the full-in and full-out limit sensing devices provide redundancy of position indication at these locations. In addition, if the drives are separated 
BNWL -500

Volume 33

from the extension rods upon scram to enhance rapid insertion rates, the limit sensing devices will provide immediate indications of any malfunctions which delay full insertion of the elements since these devices will not be separable from the control element during these modes.

o. The primary and secondary shutdown safety systems are required to demonstrate independence to assure that any unlikely failure which may occur in either system will be completely random in nature and not common to both systems through some systematic design deficiency. Demonstration of independence will require detailed and complete failure mode analyses to assure that no single "Unlikely Fault" can cause systematic failure of both systems ,

P. It is expected that instrumentation will include:

1. Outlet coolant temperature for each reactivity control channel.

2. Verification of flow to each reactivity control channel.

3. Drive load indications:

4. Detection of loss of the mechanical holddown.

5. Position indication as defined in requirement $N$.

Instrumentation is required to assure that conditions do not exist which might possibly lead to initiation of an accident by effective loss of reactivity-control elements and to assure that the reactivity-control elements, as part of the protective system, respond as designed to mitigate the consequences of any fault condition. 
$B N W L-500$

Volume 33

Outlet coolant temperatures will indicate possible flow restrictions within the reactivity-control channel. overheating of the control elements could subsequently lead to structural failure of the elements or its cladding. Structural failures, in turn, could result in loss of control material from the core region and thus effectively increase the core reactivity status. cladding failure on elements which incorporate boron as the control material could result in the sudden release of helium in the core region and thus increase the core reactivity status through the spatiallydependent positive coolant void effect. Both these effects on the core reactivity status would require protective action to mitigate the consequences of the overpower transient. If the condition existed within a shutdown safety element channel, structural failure could prevent its proper operation when protective action is required.

The purpose of flow verification within each reactivitycontrol channel is to detect complete flow blockage before fallure of the element can lead to potential reactivity additions to the reactor. This function may be provided through the channel outlet temperature sensor if it can be shown that the sensor can detect complete blockage prior to the element failure. Without flow, the thermal lag of the sensor would be increased since flow is not available to transport heat from the core to the sensor. 
BNWL -500

Volume 33

Drive load indications are required to detect possible interferences within the core or drive lines prior to any sticking of elements when called upon for protective action.

The potential severity of element expulsion has required redundancy of element holddown features (Requirements 1.2.1.1- $\mathrm{L} \& 1.2 .1 .3-\mathrm{A}$ ), However, for the holddown features provided through the mechanical drive and by the hydraulically balanced cooling system to be considered independent and redundant, failure of either must be detectable so that corrective action may be taken before the random occurrence of the other feature.

The basis for position indication on each element has been presented under Requirement $\mathrm{N}$.

Q. The primary shutdown safety system will be designed as fail-safe such that loss of a continuous signal results in scram.

7

R. Preferably all forces, gravitation and hydraulic, which act upon the element will act in a direction of reducing reactivity of the reactor. However, in the FTR the net hydraulic force is upward to enhance forced convection in the same direction as natural convection. Therefore, the net hydraulic force must be such that the gravitational force acting upon a released element more than compensates for the upward force. Thus, the failure of the extension rod or the drive would result in the element falling into a less reactive condition under the action of both these forces, hydraulic and gravitational. 
BNWL -500

Volume 33

S. The secondary shutdown safety system may or may not scram upon signal that some fault has occurred which might prevent its performance if called upon. However, at minimum, sufficient self-checking circuits will be required to attain the overall reliability required for protective systems and signal of a failure in the system will trip the preliminary shutdown safety system.

T. Reactivity-control of the FTR nuclear reaction is required to compensate for all reactivity changes and adjustments associated with normal operations. The safety requirements related to the operational control system differ from those for the shutdown safety systems since movements are made during operations at or near critical. Operational control for the final approach to critical, power ascension, and at-power adjustments.

U. The above criterion is meant to provide quantitative guidance for establishing the reliability and safety for the protective system. The meaning of the criterion can be illustrated by an example. If an accident, which the protective system is designed to contend with, is expected to occur once per reactor year, and if the probability of unsafe failure of the system is $10^{-5}$, and if these two probabilities are independent, there is a probability of $2 \times 10^{-4}$ that in the 20-year life of the FTR the reactor will be damaged to this severity as a result of this particular accident. This result can also be stated as predicting this reactor damage severity once in 5000 reactor lifetimes. This, it would appear is an acceptable risk. 
BNWL -500

Volume 33

To implement the criterion the following steps are visualized:

1. A mathematical model of the protective system, including all instrument components and the primary and secondary shutdown safety systems will be established.

2. Using test data, if available, or assumed failure data if none are available along with an assumed test interval, the probability of unsafe failure of each portion of the system will be calculated. Since each set of components (sensors, logic, safety circuit, rod release mechanism, and the primary and secondary rods) must perform in series, the probability of unsafe failure for the sum of all the parts must be less than $10^{-5}$. It appears reasonable that the information on components be taken at the $50 \%$ confidence level or above.

3. The assumed failure data used in (2) will be used to establish test specifications for component procurement. If, for example, the analysis shows that a particular amplifier must have a failure rate of less than one failure in $10^{5}$ hours this must be established by testing prior to instaliation. If this cannot be met then the test interval must be decreased or the system must be redesigned.

V. Evaluation of the interactions between the materials used on the reactor nuclear components and other materials in the core and environs will be required to assure that any interaction under normal conditions are within acceptable limits with consideration for 
BNWL -500

Volume 33

minimum end-of-life-properties. Evaluation of the possible interaction under abnormal conditions, e.g., failure of control pins, must assure that those interactions do not increase the severity of the faulted condition beyond the acceptable level based upon the likelihood of the initial fallure.

W. All components of the core and top works of the reactor must be carefully controlled due to severe space limitations. Interfaces of the drive mechanisms with all adjacent equipment must take into consideration all operating and transient conditions. Ligament lengths between control rod opening and adjacent openings must be controlled to preserve the DBA requirements of the vessel and cover. Thermal considerations and/or seismic transients must not result in rod binding at any time. Disassembly of the rod train and replacement of poison interface operations with other systems. These interfaces must consider all movements required to prevent damage or other unsafe conditions.

X. The neutron control components provide safe and reliable shutdown devices and the means to control neutron multiplication in the reactor core, thereby minimizing any potential damage to the reactor systems from abrupt changes in power level.

Y. BNWL-500, Vol. 1, Page 3-37, "Reactor safety functions shall be independent of automatio control system functions."

Page 4-7, Emergency Operations. 
BNWL -500

Volume 33

"In any case, the scram safety circuit will override the controlled shutdown circuit and would shut the reactor down rapidly if some parameter exceeded safe conditions during a controlled shutdown." This requirement indicates that all scram assisted devices must be operable for all conditions of rod movement.

z. Design for accessibility and maintenance increases the plant availability factor by reducing repair and down time requirements. Further, increase in plant availability can be accomplished by standardizing replacement techniques and equipment. BNWL-500, Vol. 1, Page 5-2. "The FFTF maintenance philosophy will be to emphasize contact maintenance and direct operation to the extent possible. Replacement of failed components rather than repair in place will be stressed; however, where required, facilities will be provided for remote repair.

AA. Reductiton of the radiation potential in the operating areas above the reactor is necessary to protect equipment and personnel during repair and operating modes. Shielding must particularly be provided for any electrical components that might reside within the cover plug where the shielding is reduced. BNWL-500, Vol. 1, Page 2-3, Section 2.2.3C "Provide shielding to reduce personnel radiation exposures to levels consistent with AECM-0524," 
$A B$. The plant availability target of $75 \%$ is listed in BNWL-500, Vol. 1, Requirement $K$. This requirement concerns both reliability as well as maintainability of components, of the two, reliability would be listed as the more important in that frequent shutdowns due to unreliability may not be able to be overcome by rapid maintainability. This is due to the time required for items other than maintenance for each shut down. Control and safety element faults will lead to reactor shutdown or curtailed power operation a majority of the time and as such, reliability must take precedence over maintainability.

AC. The required quality assurance program is necessary to meet the high reliability (as measured by a $75 \%$ availability criterion) and safety objectives established by the Program Directive, ${ }^{1}$

$\mathrm{AD}$. The most severe service for the latching mechanisms will occur during a scram from full power. The mechanisms must, therefore be designed to withstand the maximum stresses at outlet operating conditions.

AE. The envelope containing the drive train for the rods becomes an integral part of the cover assembiy and is a continuation of the pressure boundary. These envelopes are potential missiles and must be designed to withstand DBA pressures.

AF. Safety and reliability are principal requirements for the FTR plant design. Accordingly, the requirement of design in accordance with applicable portions of 
BNWL -500

Volume 33

the ASME Boiler and Pressure Vessel Code was incorporated in the overall Conceptual Systems Design Description ${ }^{1}$ as baseline. Inasmuch as the code covers minimum construction requirements, other standards and criteria are incorporated in the Design Requirements.

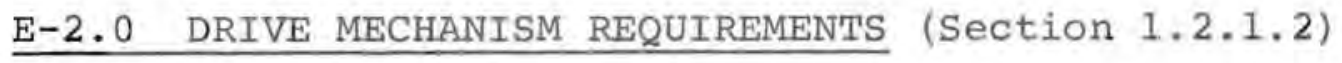

A. The potential for accidental reactivity insertions by element withdrawal without proper control requires that the design limit the reactivity insertion rate and thus limit any significant damage for such an occurrence. In addition, a conservative criterion is proposed for backup to the primary protective action to limit the damage even in the event of protective system malfunctions.

Simultaneous operation of drives will be limited by design to prevent the change of an error involving withdrawal of control at an excessive rate. The highworth per inch of movement of the elements in the FTR requires that interlocks be designed into the system. It is expected that unbalanced control element patterns can affect element worths. Some provision for distorted patterns is required in establishing the actual nominal worths to meet the intent of the worth criteria. However, administrative procedures may be depended upon to prevent distorted patterns beyond the design limit since provisions for limiting the distortion by system interlocks may be excessively complex.

I. Refer to Referenges, Appendix A, Item 8. 
BNWL -500

Volume 33

B. The allowable reactivity insertion rate by withdrawal of the primary shutdown safety system will be greater than that for the operational control system as defined in Requirement A since criticality can only occur during withdrawal of the safety systems after a gross loading error. Therefore, a greater severity of damage is allowed due to the low probability of both a gross loading error and continuous withdrawal through criticality without operator action.

C. (Refer to 1.2.1.2B above)

D. Operation of the drive must not interfere with the protective system functions when those functions are signaled. It is noted that some methods of driving cannot actuate the safety element until the element has been withdrawn some nominal distance, With this limitation, the scrammable worth may be adjusted an amount equivalent to the worth over the travel in which scram is precluded to fulfill its protective system functions.

However, the analyses may show that a free gravity scram of the elements so affected in the specific position may be sufficient. The effect of lower acceleration rates has not been evaluated and particular accident mechanisms which might occur with an element in such a position must be analyzed to evaluate the required acceleration rate.

E. (Refer to 1.2.1.2D above). 
BNWL -500

Volume 33

F. Conceptual designs of the rod support systems show the drive mechanisms supported by the reactor vessel top cover and the core supported by structure from the vessel flange. It is possible, due to the length of support members (30 feet) to get considerable movements between the core and control system unless precautions are specifically taken to assure equivalent expansions of all structural members involved. In addition, accidents may cause pressure impulses on the top cover tending to lift all elements simultaneously. The severity of these effects requires that the movement be limited so that core damage is not aggravated further by any relative movement resulting from the initial fault.

G. The assignment of the primary safety system as a single purpose system or in combination with the control system must take into account the effect of large reactivity changes caused by movement of the primary safety rods. The principal rationale for the primary safety system is to provide rapid shutdown capability at all times of critical operation of the reactor. This criterion does not allow the achievement of criticality through the use of the primary safety system. As a single purpose system, the positioning of the primary system in its least reactive position before criticality is achieved would provide the shutdown margin necessary to bring the reactor back to a safe condition in the event normal operating conditions are exceeded during startup operations. If combined with the control system, specific high-worth rods must be assigned as 
BNWL -500

Volume 33

safety rods in this or the secondary safety system. Interlocks to prevent witharawal of control or secondary safety system rods unless the primary safety system is in lts least reactive position and armed can be utilized in the design. These interlocks, if inviolate, may permit reactivity withdrawal rates for the primary safety system that are different from those of the other systems.

H. The step function or smallest increment of movement of the highest worth control rod will determine the reactivity change resulting from movement of this rod. This reactivity change must be small enough to permit stable operation of the reactor at any power level. It is estimated that reactivity changes should be limited to If per step maximum,

I. Seals at the pressure boundaries of the rod enclosures and the reactor cover must be leak tight to prevent formation of oxides in areas that are subjected to air atmosphere during refueling operation. Cleanup of such formations will have an adverse effect on plant availability.

J. Deceleration of the control drive train is required to minimize stresses of all components.

K. Stress resulting from accelerations and decelerations are a function of the distance traveled during the process. Sudden or erratic stops can lead to the generation of excessive stresses and/or fatigue fallures. 
BNWL -500

Volume 33

I. The hydraulic resistance of the poison section traversing through counterflowing sodium while under high speed scram functions will be a significant force. These forces in addition to normal seal and guide tube friction forces must be accounted for to satisfy speed of response requirements.

M. The drive mechanism for control and/or safety rods will reside in an environment which is dependent on the seal design and cover gas purge gas if used; each mechanism must be compatible with the possibility of sodium vapor gas leakage into the mechanism during operation. Maximum protection from sodium vapor is necessary to minimize the formation of oxides when the drives are removed for refueling.

N. In addition to out-leakage of sodium or sodium vapor in the event of pressure incldents, the in-leakage of contaminants into the reactor vessel through the nuclear control passages must be limited. The working level of the reactor will be in a standard air atmosphere during refueling. Air in-leakage during these periods can result in increased hydrogen and oxygen into the gas-vapor area above the sodium level. Sodium oxide formation as well as other contaminants which may result in plugging or seizing of mechanical components must be limited.

O. The chances of making incorrect electrical or mechanical hookups of the various appurtances to the control component must be remote through either administrative 
measures or mechanical means. Mechanical methods of attaining this goal include color coding, thread or fitting size, or key location. This philosophy is consistant with the-non-interchangeablorety of modules requirement in the Plant Protection System CSDD.

$\underline{\text { E-3.0 POISON SUBASSEMBLY REQUIREMENTS, (SECTION 1.2.1.3) }}$

A. Release of the control elements from the extension rods to reduce the total mass inertia and application of stored energy sources may be required to act upon scram to provide the required initial accelerations for effective speed-of-control. Since various types of accidents are capable of generating pressure fronts which may act as momentary expulsive forces on the elements, positive means (for example a ratchet mechanism) will be provided to prevent expulsion after any prior amount of insertion.

B. This requirement is similar to Requirement $A$ except the additional requirement for some positive force for driving the elements into a distorted core is not included. Whether or not such a force is required will depend upon a failure mode analysis considering the probability of a distorted core and failure of the primary system and evaluation of independence for the two shutdown safety systems.

c. The maximum allowable reactivity worths of any single operational control element and any single control pin depend upon the potential damage which could result from 
BNWL -500

Volume 33

failures involving effective movement or loss of the control material within the core region. The pertinent considerations which influence the establishment of maximum allowable worths for the elements and pins are discussed in Appendix A of the Design Safety Criteria, Section 14, fReactivity Worth Considerations for the FFTF Control and Safety Elements. ${ }^{1}$ The limit values established in the preliminary evaluations to be used as guidelines are 3-4 \$/operational control element and $0.65 \mathrm{~s} / \mathrm{pin}$.

The maximum allowable single operational control element worth defined above is based upon the postulated reactivity ramp rate which would develop upon the ejection of an element from the core during operation at or near critical. Preliminary analyses indicate that expulsive forces are not expected to accelerate any single element at a rate greater than $3-4 \mathrm{~g}^{\prime} \mathrm{s}^{2}$ and this could occur only after two simultaneous failures: (a) loss of mechanical holddown on the element, and (b) generation of the expulsive force, e.g., loss of coolant flow to the channel with sudden vaporization after considerable superheating of the coolant. These highly improbable occurrences would result in core disruption if they did occur in sequence as described and the maximum allowable element worth assures that, even under these extreme conditions, the resulting power transient would

1. Refer to References, Appendix.A, Item 6, Section 14. Appendix A.

2. Refer to References, Appendix A, Item 6, Section 1. 
BNWL -500

Volume 33

be less severe than the containment design basis accident. Although control element ejection appears to be limiting, other considerations are described in the Design Safety Criteria ${ }^{1}$ including the effects of compaction, poison washout, meltdown, poison expulsion, withdrawal, removal, fall-through, and random failure of individual control pins within an operational control.

D. This requirement assures that sufficient control is designed into the system to provide a minimum subcriticality of 1 percent $\delta \mathrm{k} / \mathrm{k}$ during any withdrawal of the shutdown safety system during approach to criticality operations. This provision for the minimum reactivity worth of the operational control system assures that all criticality operations are controlled by this system and not by movement of the shutdown safety systems.

Further clarification of the intent of this oriterion is provided by the various examples in Appendix Bt, of Section 14 of the Design Safety Criteria for the Reactor Nuclear Control Components. ${ }^{2}$

E. The same consideration which limits the allowable reactivity worths of operational control elements as described in the basis of Requirement $A$ are not directIy applicable to the shutdown safety elements since these elements are normally out whenever the reactor is at or

1. Refer to References, Appendix A 4 Item 6, Section 14. 2. Refer to References, Appendix A, Item 6, Section 14, Appendix B. 
near critical. Therefore, larger worths per element are reasonable for the shutdown safety elements as described in Appendix A - Reactivity Worth Considerations for the FFTF Control and Safety Elements. ${ }^{1}$ The limit values defined in Appendix A to be used as guidelines in the FTR are 6-8 \$/shutdown safety element. However, the basis for the guidelines are not as explicit as those described for the operational control elements.

Again, if the shutdown safety elements are designed with rod followers, the effect of the followers upon individual element reactivity worths must be considered in the evaluation.

F. In order to fulfill this requirement, the total reactivity worth of the primary shutdown safety system must be at least equivalent to the summation of the following:

(a) Temperature reactivity defect - Hot operating to minimum cold shutdown condition or hot operating to hot subcritical standby - whichever is greater.

(b) Primary shutdown safety system burmup allowance.

(c) Minimum shutdown margin or accidental reactivity insertion allowance - Requirement equals the maximum reactivity addition resulting from occurrence of any single 'Unlikely Fault' but not less than 1 percent $\Delta \mathrm{k} / \mathrm{k}$ (minimum shutdown margin with the operational and secondary shutdown safety systems at their prescram positions.

(d) Stuck rod provision - Requirement equals the maximum worth of the most effective primary shutdown safety element in its post-reactive position.

1. Refer to References, Appendix A, Item 6, Section 14, Appendix B. 
These requirements do not make provision for holddown with simultaneous removal of all operational control from the reactor. It is assumed that prior to initiation of the fault condition which required primary protective action, the core reactivity is compensated by operational control elements in the reactor. For this reason, the primary shutdown safety system is not completely independent of the operational control system which is required to compensate the long-term operational transients; e.g., fuel burnup and experimental test variations. Thid is further clarified by the examples of the minimum worth requirements in Appendix B, Design Safety Criteria for the Reactor Nuclear Control Components. ${ }^{1}$

The maximum accidental reactivity allowance is to provide additional control to override reactivity insertions which may result from various unlikely fault conditions. Accident conditions which may increase the potential core reactivity and must be considered include:

(a) Meltdown and collapse of any single subassembly.

(b) The maximum positive coolant void effect of a single subassembly.

(c) Maximum expected worth from distortions of the core structural support members.

(d) Loss of poison from any single pin in an operationalcontrol element $(0.65 \$)$.

(e) Uncontrolled withdrawal of any operation-control element. 
BNWL -500

Volume 33

G. (Refer to 1.2.1.3E above)

H. In order to fulfill this requirement the total reactivity worth of the secondary shutdown safety system must be at least equivalent to the summation of the following:

1. Temperature reactivity defect - hot operating to hot subcritical standby.

2. Secondary shutdown safety system burnup allowance.

3. Minimum shutdown margin or accidental reactivity insertion allowance - requirement equals the maximum reactivity addition resulting from occurrence of any single "Unlikely Fault" with failure of the primary protective action, but not less than $1 \%$ $\hat{\mathrm{k}} \mathrm{k} / \mathrm{k}$ (minimum shutdown margin with the operational control and primary shutdown safety sytems at their prescram positions).

Further clarification of these worth requirements is provided by the examples in Appendix B, ${ }^{1}$ Design Safety Criteria for the Reactor Nuclear Control Components.

I. The design of the length of the poison subassembiy must consider that the reactor and its components will be at operating temperature at the time of scram and that these same components will be at shutdown temperatures during pre-startup. The poison length

1. Refer to References, Appendix A, Item 6, Section 14. 
BNWL -500

Volume 33

must be such that thermal effects do not result in reactivity changes while the reactor is shut down. If the poison subassembly is supported by the drive mechanism mounted on the reactor head, relative movement will occur between the poison and the reactor core due to length changes caused by thermal and radiation damage effects.

J. The use of boron carbide as a poison material results in gas evolution during irradiation. Venting of this gas into the coolant is not permitted as a normal operating function. A gas plenum for each pin must be provided to contain this gas.

K. Pressure capabilities of the gas plenums will be designed to contain all of the released gas which is evolved during the lifetime of the highest burnup poison element.

L. Sliding contact between the poison duct and the poison subassembly is a normal mode of operation. Frictional forces between the two must be minimized. Galling potential must be eliminated. This requirement will also apply to all bearing and guide points in the drive train.

M. The use of poison materials other than those evolving gas may still require protective cladding to isolate the poison from the coolant. Cladding materials must be compatible with the thermal and chemical properties of the poison and environment. 
N. The poison pin containing the boron pellets and gas plenum will operate at higher temperatures than the surrounding carrier duct. Additionally, the pellets are restrained from movement by retainer devices while still allowing thermal expansion space. The plenum above will be subjected to higher stresses as burnup continues. For these reasons, the pin envelope must be anchored at the bottom of the assembly with expansion provisions at the upper end. All structural stresses due to acceleration and deceleration forces must be accommodated by each pin only from the standpoint of its own mass. The structural integrity of the carrier duct and the pin support mechanism must not transmit any additional stresses to the individual pins.

o. A metal follower is required to displace the poison material as it is withdrawn from the core. The pressure drop per unit length of follower should be $\leqq$ the pressure drop per unit length of the poison pin bundle.

\section{E-4.0 FTR OSCILLATOR (Section 1.3.1)}

A. A minimum high frequency limit, on the order of $10 \mathrm{cps,}$ is required in order that both the full extent of significant feedback effects upon the transfer function and a small portion of the asymptotic convergence back to zero power transfer function can be measured. The latter provides an independent check upon the absolute equipment calibration. A maximum low frequency limit requirement is set on the basis of state-of-the-art 
since there will be the feedback effects at, and below these frequencies. They are less significant with regard to reactor stability in that very low frequency instabilities can be controlled via the control system. The actual frequency range achieved shall be a compromise between the development required and that which is considered necessary to obtain meaningful transfer function analysis data.

B. The stability and measurement of the frequency is necessarily important because relevant results arise from the differences between measurements of the same magnitude, thereby amplifying the measurement errors. The net effect is an error which may range from 5\% at low frequencies to greater than $100 \%$ at the upper limit of useable feedback information. An error band of about $20 \%$ is desirable. Again, trade-offs in development versus desirable data will be the determining factors.

C. The effect of amplitude errors is exactly the same as stated in basts $B$.

D. The actual location of the oscillator within the core will depend on the availability of positions. The FTR configuration allows the installation of through the head components at the reactivity control positions and test positions. In order to insure the availability of space for the oscillator, it must be compatible with either of these positions. 
BNWL -500

Volume 33

E. The position of the reactivity element when the oscillator is static is required to calibrate the worth values of the oscillator. Traces of the position of the reactivity element with respect to time is also required during operation of the oscillator in order to confirm the transfer function of the FTR.

F. Backlash characteristics, if they exist, must be measurable in order to properly calibrate the oscillator.

G. To adequately assess the power feedback characteristics, the oscillator must operate and the transfer function must be determined at several power levels up to and including fuli power of the FTR.

H. The complete analysis of the transfer function depends on the interfacing of Flux Monitoring system for reactivity measurements and the Control and Data Handing for collecting the data from the above system as well as from the oscillator. 
BNWL -500

Volume 33

$$
\begin{gathered}
\text { APPENDIX F } \\
\frac{\text { DRAWINGS }}{\text { SK-3-12445 }} \\
\text { SK-3-14196 } \\
\text { SK-3-14198 } \\
\text { SK-3-14325 } \\
\text { SK-3-14550 } \\
\text { SK-3-14558 } \\
\text { SK-3-14559 } \\
\text { SK-3-14560 } \\
\text { SK-3-14604 } \\
\text { SK-3-14606 }
\end{gathered}
$$




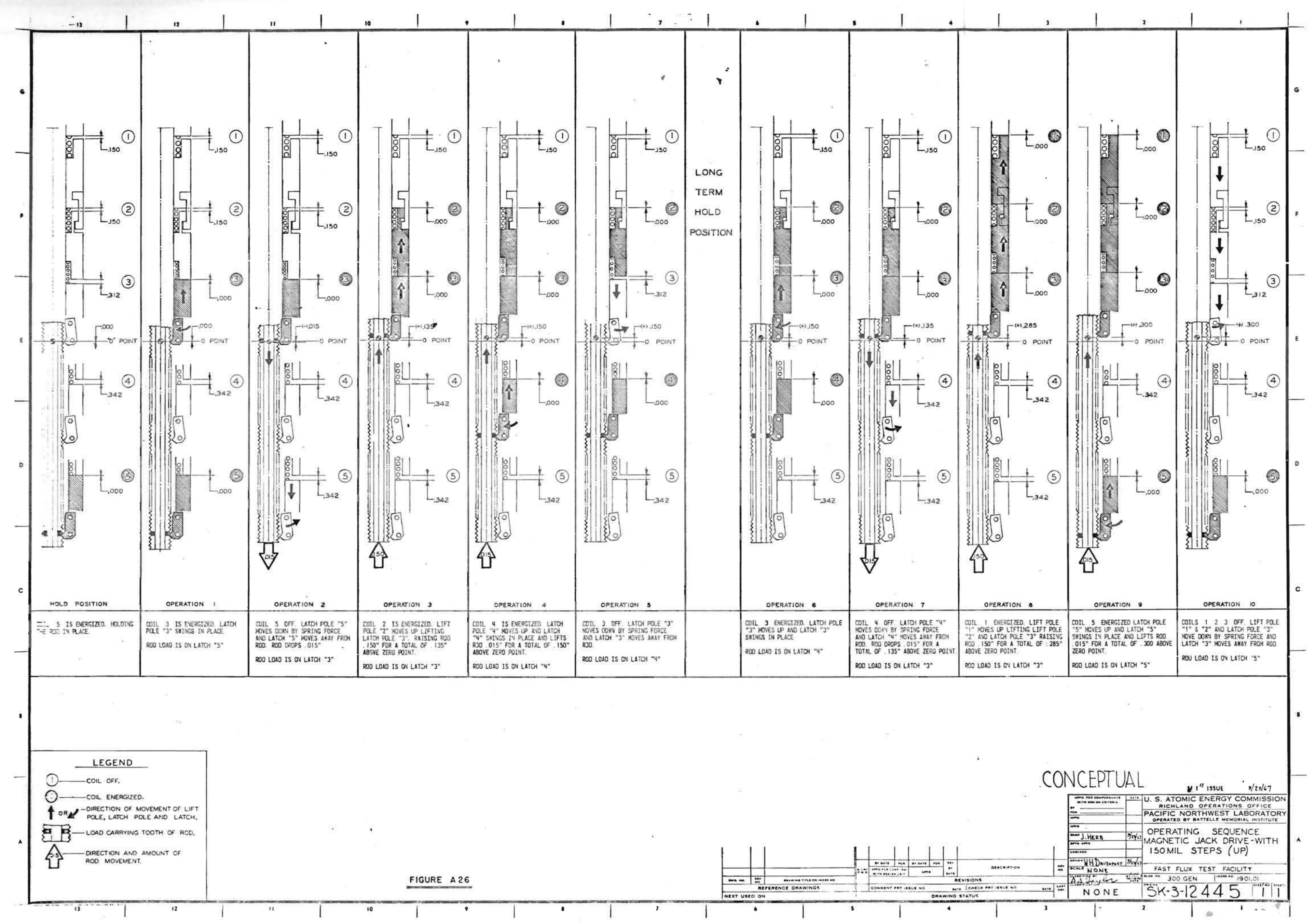




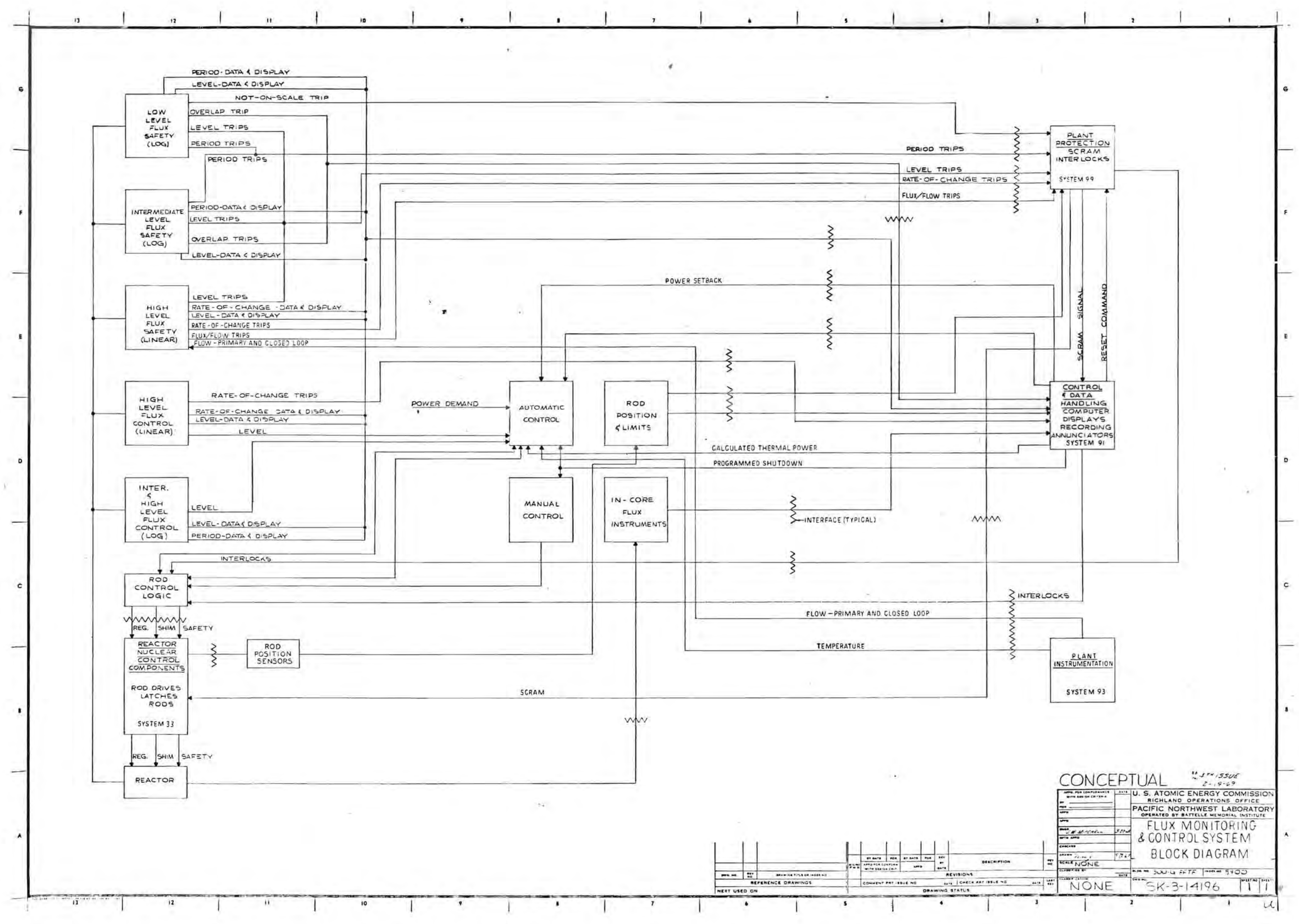




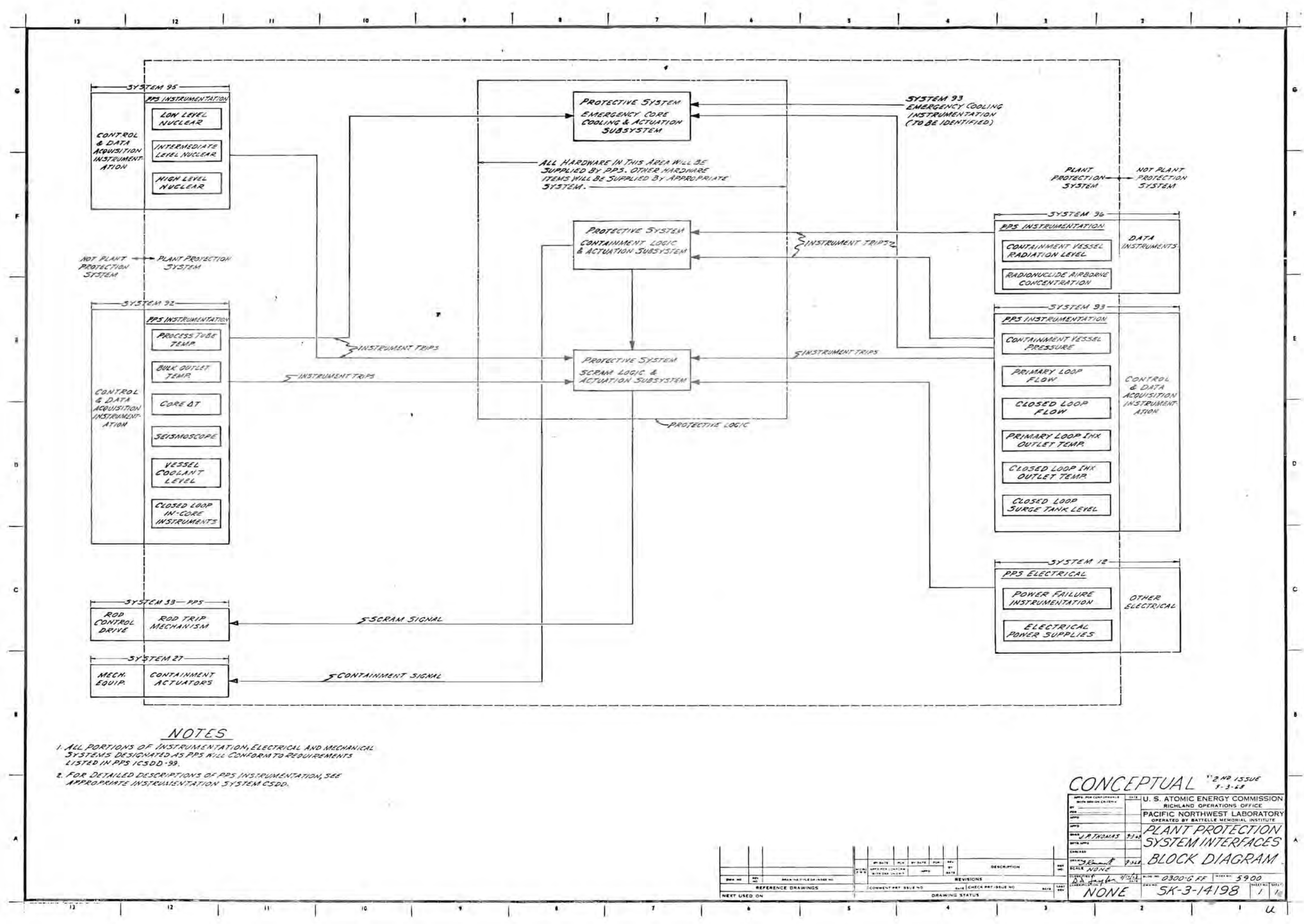




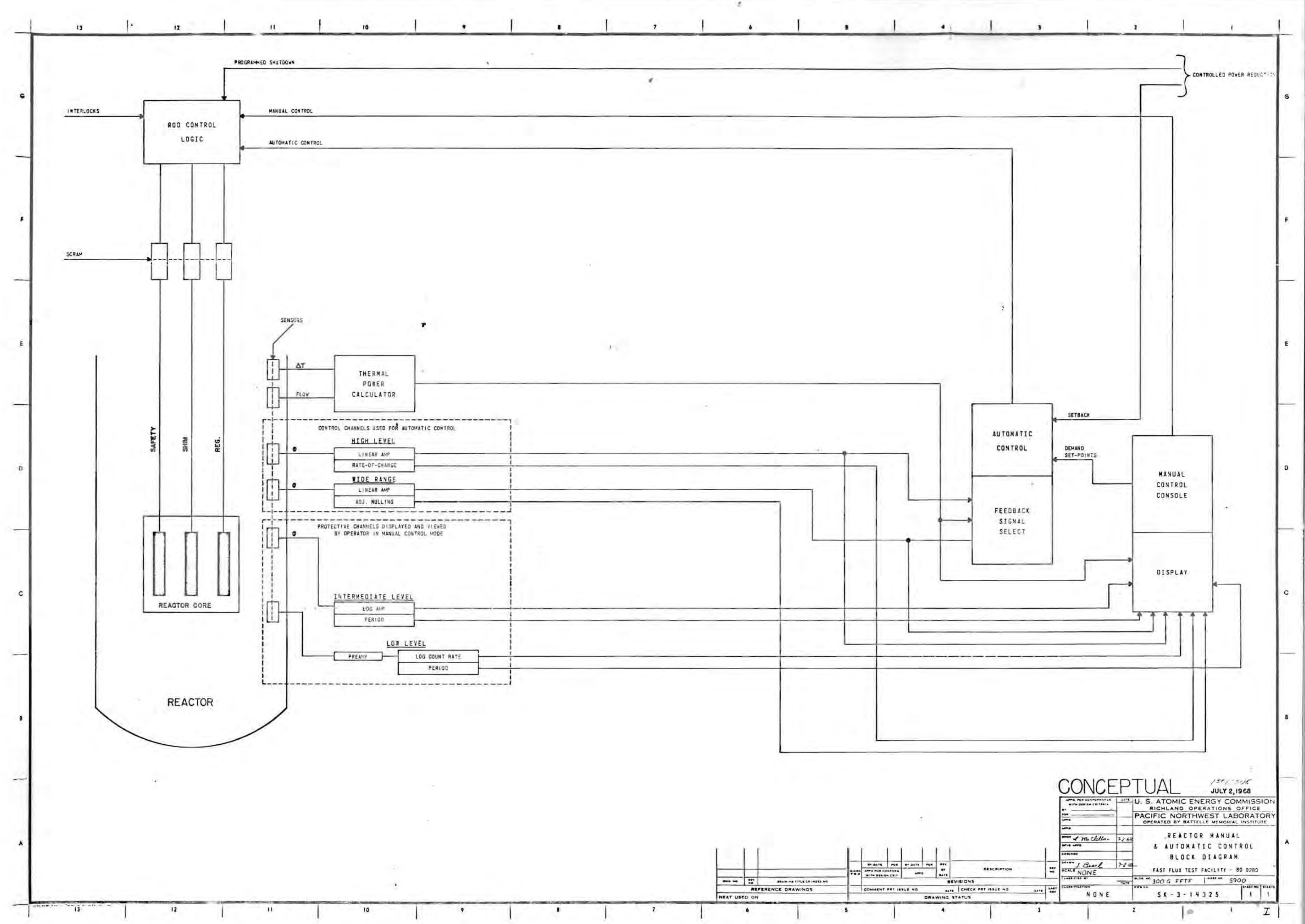




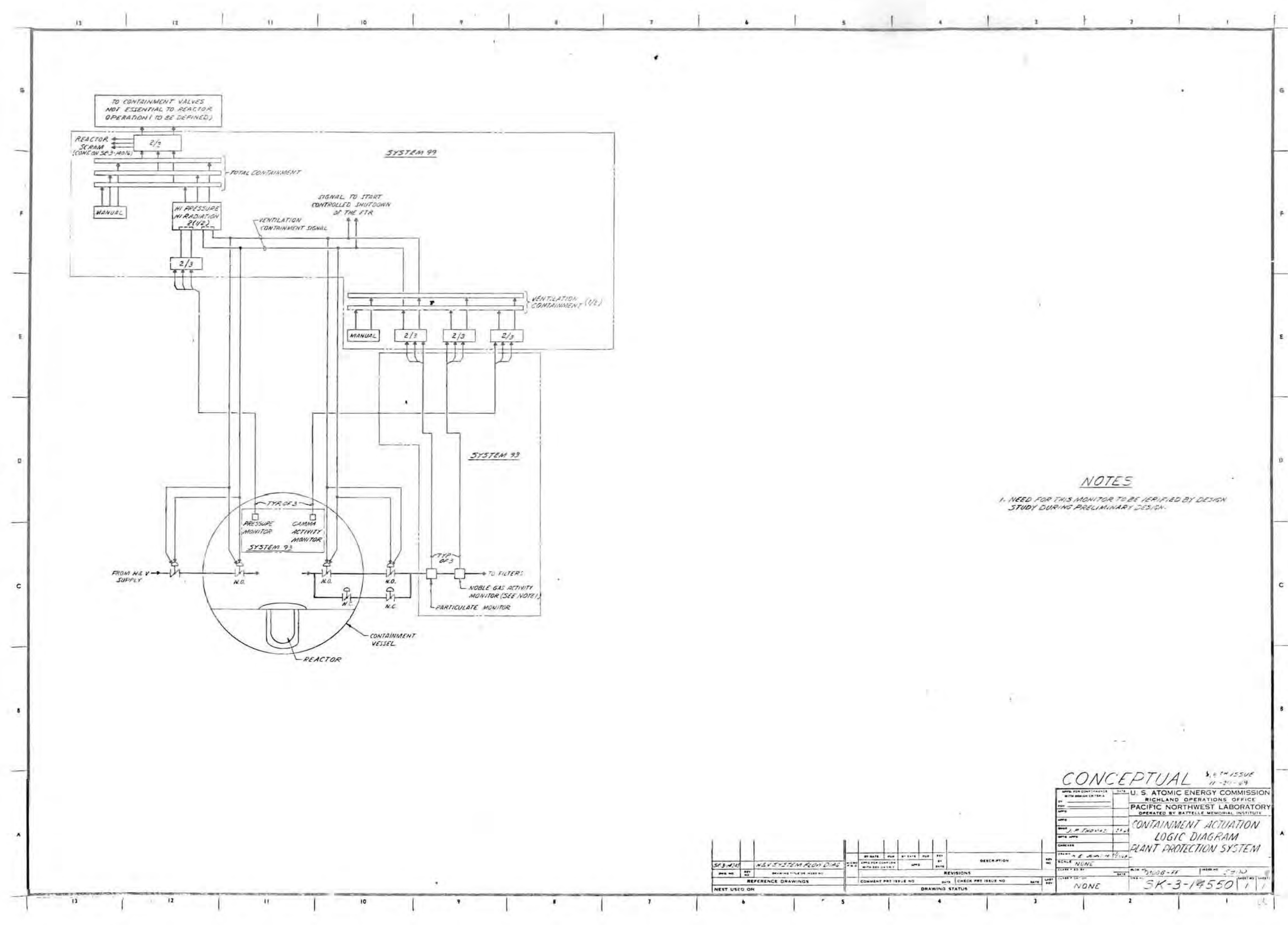




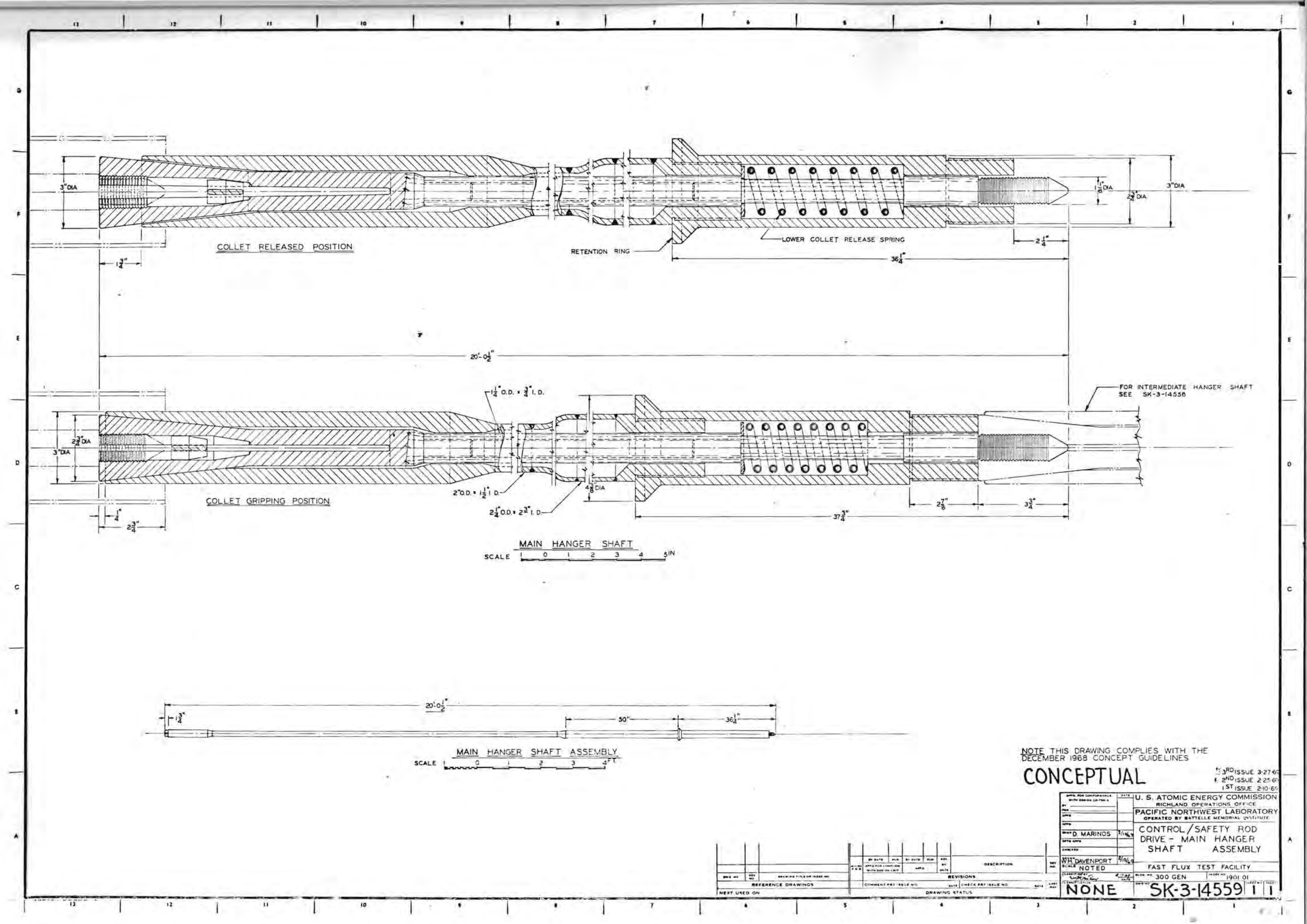




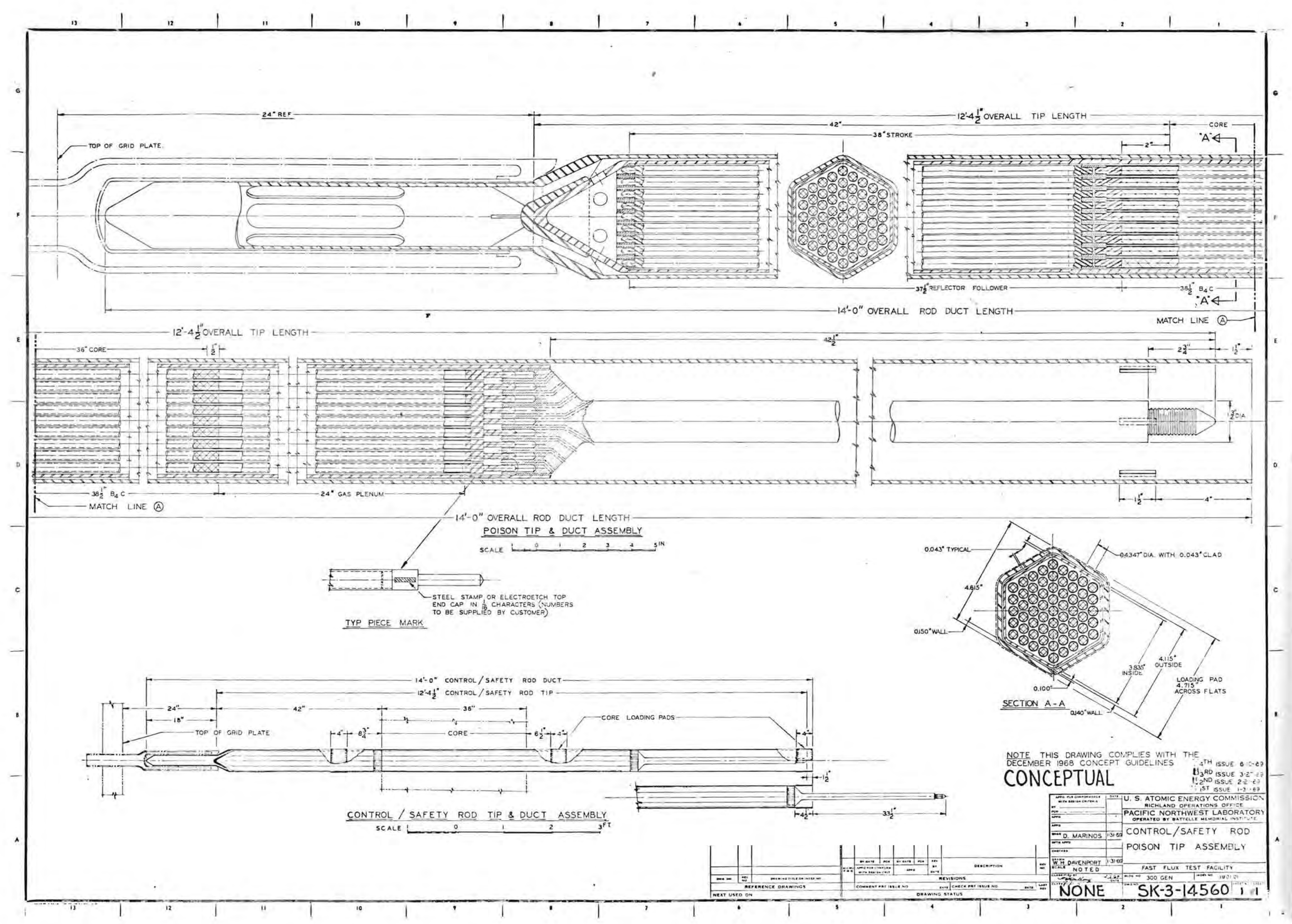




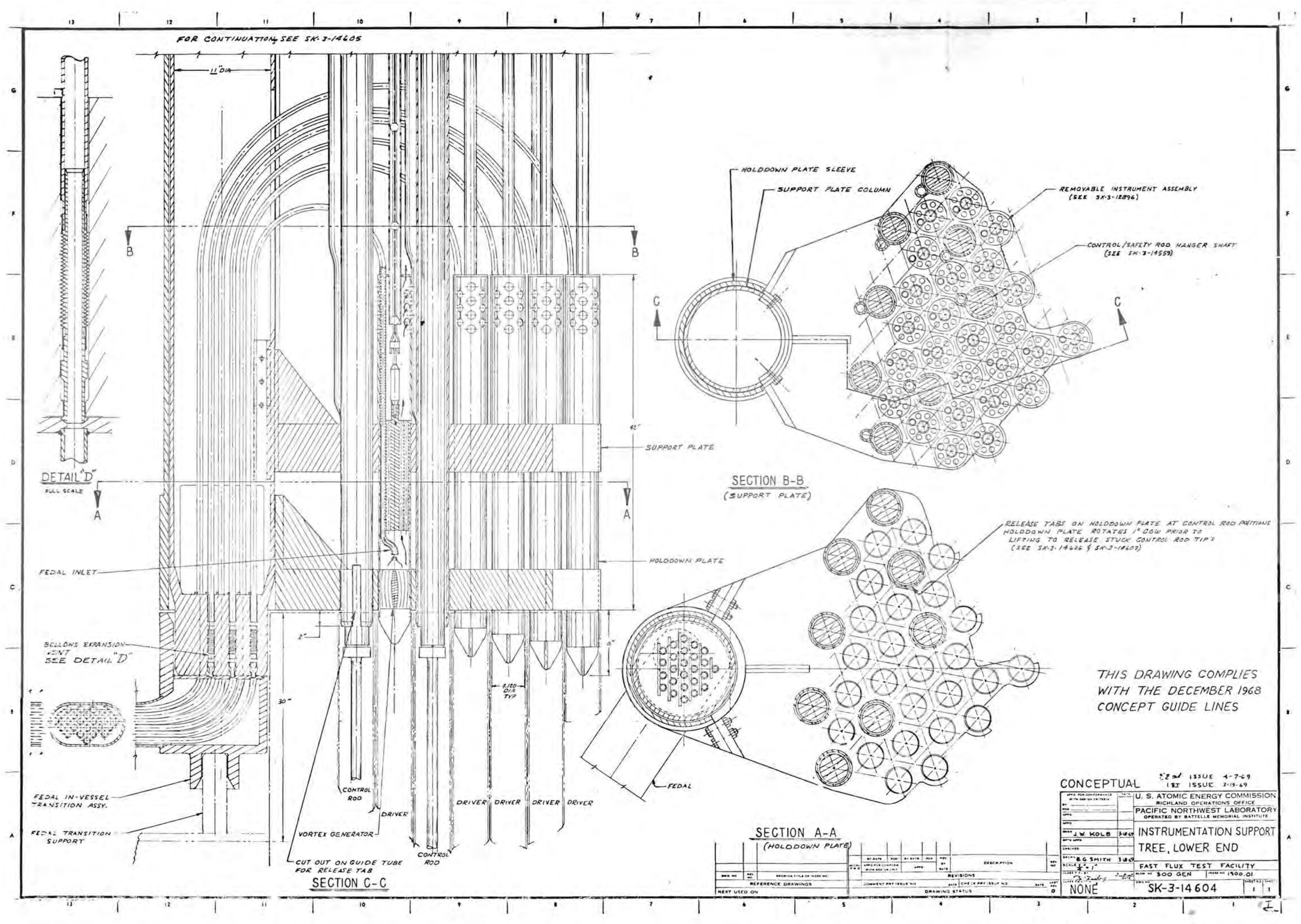




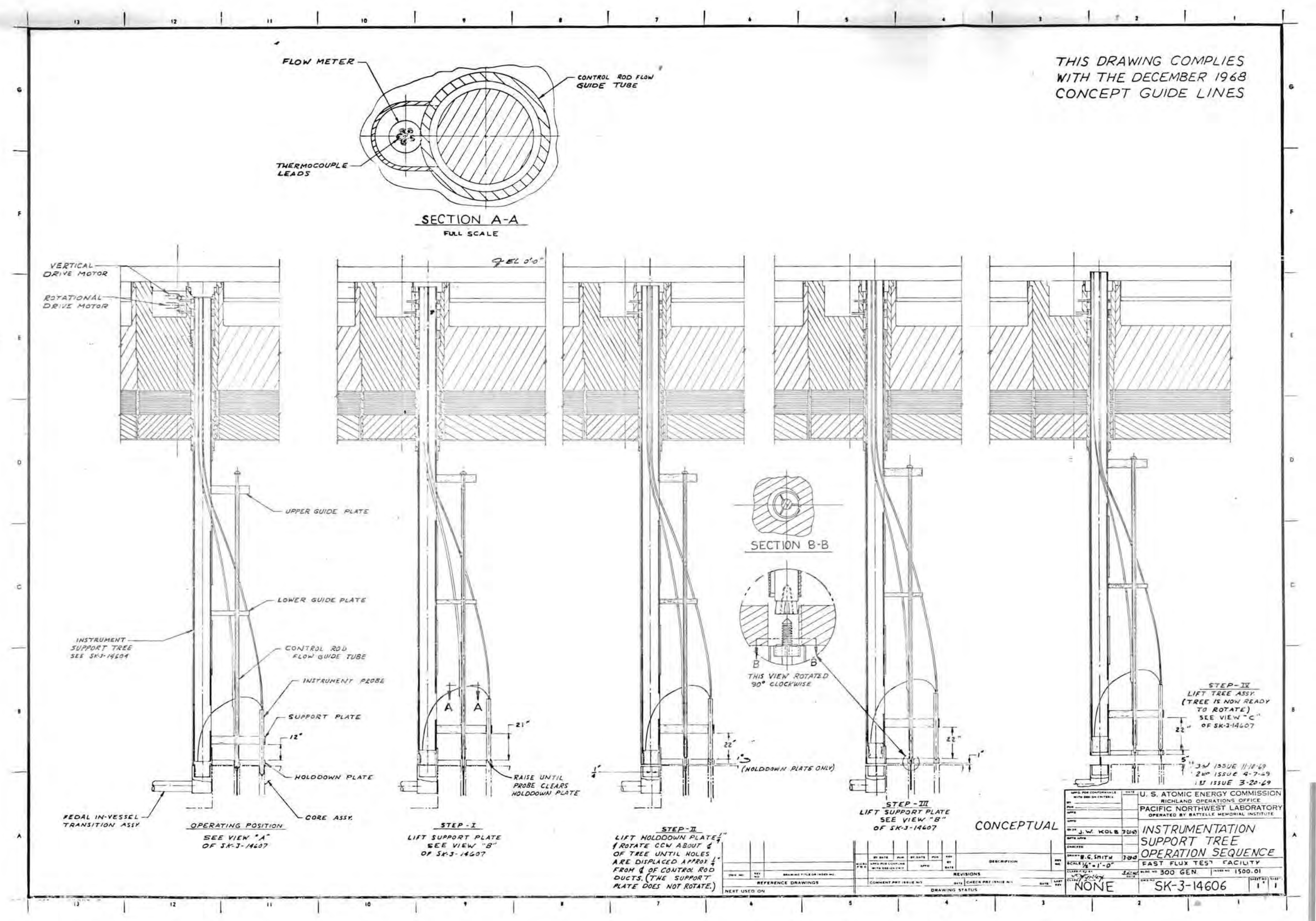


BNWL -500

Volume 33

\section{DISTRIBUTION}

No. of

Copies

4

31 U.S. Atomic Energy Commission

Division of Reactor Dev \& Tech

Washington, D.C. 20545

M Shaw, Director, RDT

Asst Dir for Nuclear Safety

Analysis \& Evaluation Br, RDT:NS

Environmental \& Sanitary Engrg

$\mathrm{Br}, \mathrm{RDT}: \mathrm{NS}$

Research \& Development Br, RDT:NS

Asst Dir for Plant Engrg, RDT

Facilities $\mathrm{Br}, \mathrm{RDT}: \mathrm{PE}$

Components $\mathrm{Br}, \mathrm{RDT}: \mathrm{PE}$

Instrumentation \& Control Br, RDT:PE

Iiquid Metal Systems Br, RDT:PE

Asst Dir for Program Analysis, RDT

Asst Dir for Project Mgmt, RDT

Liquid Metals Projects Br, RDT:PM

FFTF Project Manager, RDT:PM

Asst Dir for Reactor Engrg, RDT

Control Mechanisms Br, RDT:RE

Core Design Br, RDT:RE (2)

Fuel Engineering $B r$, RDT:RE

Fuel Handling $B r$, RDT: RE

Reactor Vessels Br, RDT:RE

Asst Dir for Reactor Tech, RDT

Coolant Chemistry $\mathrm{Br}, \mathrm{RDT}$ : RT

Fuel Recycle Br, RDT:RT

Fuels \& Materials $\mathrm{Br}$, RDT:RT

Reactor Physics Br, RDT:RT

Special Technology $B r$, RDT:RT

Asst Dir for Engrg Standards, RDT

EBR-II Project Manager, RDT:PM

AEC Chicago Patent Group

G. H. Lee, Chief

R, K. Sharp (Richland)

AEC Idaho Operations Office

Nuclear Technology Division

C. W. Bills, Director

Distr-1 
No. of

Copies

2

AEC Richland Operations Office

FFTF Program

JM Shivley

1

AEC San Francisco Operations Office

Director, Reactor Division

3

AEC Program Office - PNL

TA Nemzek

3

AEC Site Representatives Argonne National Laboratory

Atomics International

General Electric Co.

3

Argonne National Laboratory RA Jaross

LMFBR Program office

NJ Swanson

7

Atomics International FFTF Program office

Iiquid Metal Information Center AE Miller (2)

2

Babcock \& Wilcox Co. Atomic Energy Division

SH Esleeck

GB Garton

3

Battelle Memorial Institute

6

Bechtel Corporation

J. J. Teachnor, Project Administrator, FFTF

(5)

M. O. Rothwell (Richland)

1 Combustion Engineering

1000 MWe Follow-On study

WP Staker, Project Manager

$1 \quad$ Combustion Engineering

911 West Main Street

Chattanooga, Tenneessee 37401

Mrs. Nell Holder, Librarian

Distr-2 
No. of

Copies

1

4

2

1

1

1

1

16

1
Atomics Power Development Assoc. Document Librarian

General Electric Co. Advanced Products Operation Karl Cohen

Nuclear Systems Programs DH Ahmann

Gulf General Atomic Inc. General Atomic Div D Coburn

Idaho Nuclear Corporation JA Buckham

BNW Representative RM Fleischman (ZPPR)

Stanford University

Nuclear Division

Division of Mechanical Engrg R Sher

United Nuclear Corporation Research and Engineering Center RF DeAngelis

Westinghouse Electric Corp
Atomic Power Division
Advanced Reactor Systems
DC Spencer (15)
R. Strzelecki (Richland)

Oak Ridge National Lab WO Harms 
No. of

Copies

Battelle-Northwest

So Arneson

(2)

JM Batch

AI Bement, Sr.

TJ Bennett

CL Boyd

DC Boyd

JR Carrell

WL Chase

JC Cochran

DL Condotta

$\mathrm{RR}$ Cone

DR Doman

RV Dulin

TW Evans-308

IM Finch

EE Garrett

ED Grazzini

JW Hagan

JE Hanson-308

RA Harvey

RE Heineman

PI Hofmann

HE Hylbak

EM Johnston

FJ Kempf

$\mathrm{CE}$ Love

D Marinos

JS McMahon

JW Mitchell

CA Munro

JC Noakes

CN Orsborn

JA Perry

RE Peterson

OW Priebe

HCF Ripfel

DP Schivley

JM Seehuus

FH Shadel

PF Shaw

CRF Smith

RJ Squires 
No, of

Copies

DD Stepnewski

GH Strong

CD Swanson

PK Telford

JC Tobin

RC Walker

JH Westsik

JF Wett

FFTF Files (10)

Tech Publications

Tech Information

(5)

Legal-703 Bldg.

Legal-ROB

22I-A 